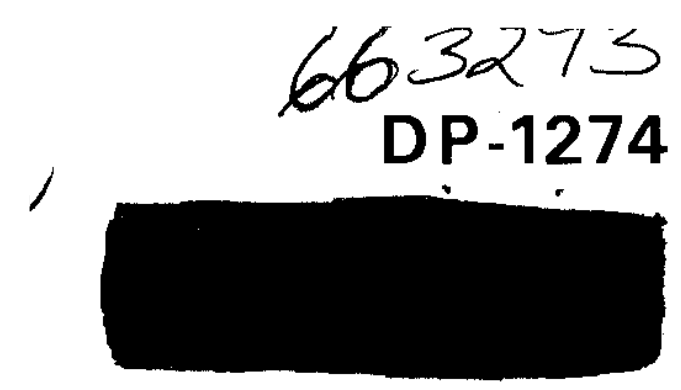

AEC RESEARCH AND DEVELOPMENT REPORT

\title{
THE DISSIPATION OF REACTOR HEAT AT THE SAVANNAH RIVER PLANT
}

\author{
J. S. NEILL \\ D. F. BABCOCK
}

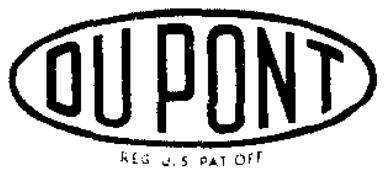

TIS FILE
RECORD COPY

ISSUED BY

Savannah River Laboratory

Aiken, South Carolina 


\section{DISTRIBUTION}

\section{Copies}

1-3. AEC, SROO

4-49. Du Pont

50-69. AEC Division of Technical Information Extension

\section{NOTICE}

This report was prepared as an alccount of work sponsored by the United States Government. Neither the United States nor the United States Atomic Energy Commission, nor any of their employees, nor any of their contractors, subcontractors, or their employees, makes any warranty, express or implied, or assumes any legal liability or responsibility for the accuracy, completeness or usefuiness of any information, apparatus, product or process disclosed. or represents that its use would not infringe privately owned rights. 


\title{
THE DISSIPATION OF REACTOR HEAT
}

AT THE SAVANNAH RIVER PLANT

\author{
by
}

J. S. Neill

D. F. Babcock

Approved by

D. F. Babcock, Section Director Nuclear Engineering Division

Classification Cancelled or Changed By Authority of

October 1971
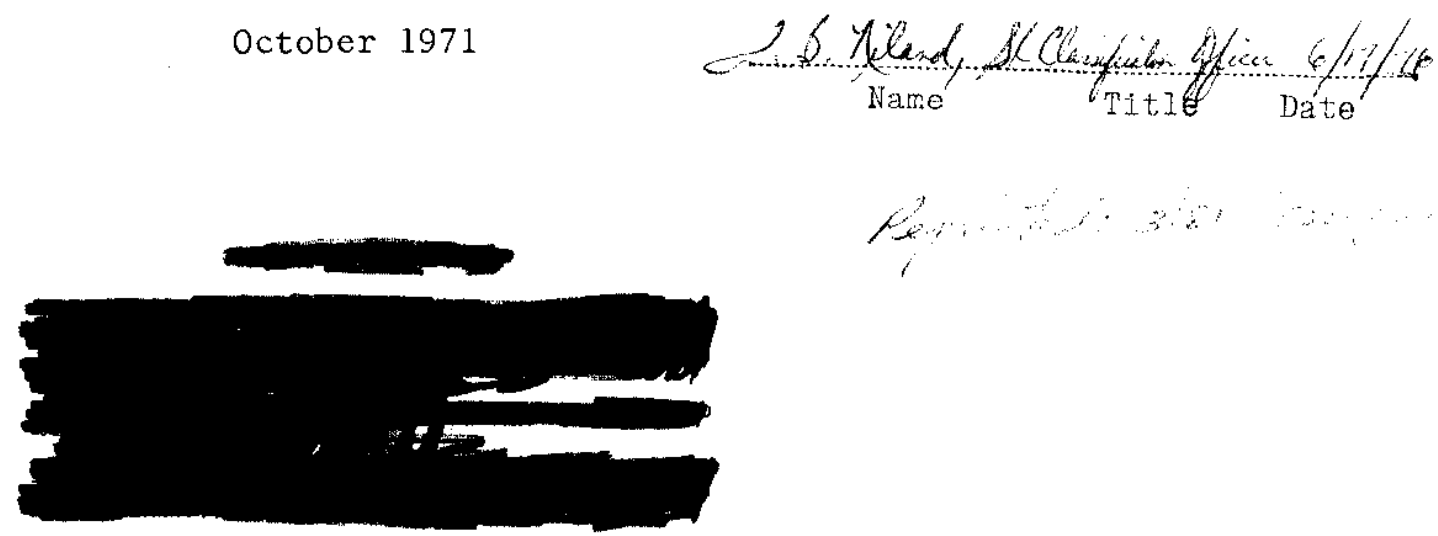

E. 1. DU PONT DE NEMOURS \& COMPANY SAVANNAH RIVER LABORATORY

AIKEN, S. C. 29801

CONTRACT AT(07.2).1 WITH THE

UNITED STATES ATOMIC ENERGY COMMISSION 


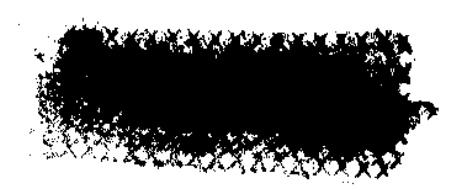

\begin{abstract}
The effluent cooling water from the heat exchangers of the Savannah River nuclear reactors is cooled by natural processes as it flows through the stream beds, canals, ponds, and swamps on the plant site. The Langhaar equation, which gives the rate of heat removal from the water surface as a function of the surface temperature, air temperature, relative humidity, and wind speed, is applied satisfactorily to calculate the cooling that occurs at all temperature levels and for all modes of water flow. The application of this equation requires an accounting of effects such as solar heating, shading, mixing, staging, stratification, underflow, rainfall, the imposed heat load, and the rate of change in heat content of the body of water.

If the water is reused for reactor cooling, its temperature is reduced to within $\pm 2^{\circ} \mathrm{C}$ of the natural equilibrium temperature by passage through a relatively deep 2500-acre pond, and is cooler in the summer than the natural equilibrium temperature. This temperature is defined as the temperature for a stagnant shallow pond at steady state. If the effluent cooling water is not reused, its temperature is reduced before discharge to the Savannah River, by passage through natural stream beds and swamps, to below $35^{\circ} \mathrm{C}$, even under the most severe summer conditions. The discharge to the river is within $3^{\circ} \mathrm{C}$ of the natural equilibrium temperature; and, because of the shade in the swamp, it may be below the natural equilibrium temperature. During the summer, however, the temperature of the Savannah River itself is as much as $8^{\circ} \mathrm{C}$ below the natural equilibrium temperature because of cold water storage in reservoirs upstream from the SRP site, so that the river is warming by natural processes as it passes the Savannah River Plant.
\end{abstract}


INTRODUCTION . . . . . . . . . . . . . . . . . . . 9

SUMMARY ........................ . . 11

DISCUSSION. . . . . . . . . . . . . . . . . . 13

HOT WATER EFFLUENT FROM THE PRODUCTION REACTORS. . . . 13

THEORY FOR THE NATURAL COOLING OF WATER. . . . . . . . 14

Energy Budget . . . . . . . . . . . . . . 14

Rate of Change in Heat Content . . . . . . . . . 15

Solar Heat Load . . . . . . . . . . . . . . 15

Heat Added by the Change in Temperature of the Flow. 16

Surface Cooling Rate . . . . . . . . . . . . 17

Equilibrium Temperature . . . . . . . . . 17

Par Pond and Lake Colorado City Experience . . . . 21

Wet-Bulb Temperature .. . . . . . . . . 22

COOLING IN THE SRP EFFLUENT CANAL SYSTEMS . . . . . 23

Description of the Effluent Canal Systems . . . . . 23

Nominal Performance of the Effluent Canal Systems. . 25

Models for the Effluent Canals and Shallow Ponds . . 25

Analysis of the Effluent Canal System Performance . 30

COOLING IN PAR POND . . . . . . . . . . . . 34

Description of Par Pond . . . . . . . . . . . . . 34

Nominal Performance of Par Pond . . . . . . . . . 36

Model of Par Pond . . . . . . . . . . . . . 37

Extension of the Theory to the Par Pond Model . . . 38

Formulation of the Par Pond Mode1. . . . . . . . . . 40

Correlation by the Par Pond Mode1. . . . . . . . . . 42

The Energy Budget for Par Pond . . . . . . . . . . 48

The Approach to Equilibrium Temperature in Par Pond. 50

Selective Withdrawal from Par Pond . . . . . . . . 51

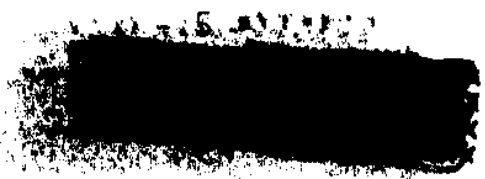


COOLING IN THE SRP STREAMS . . . . . . . . . . . 51

Description of the SRP Effluent Streams. . . . . . 51

Performance of the SRP Effluent Streams. . . . . . 53

COOLING IN THE SRP SWAMP............. 54

Description of the SRP Swamp . . . . . . . . 54

Performance of the SRP Swamp . . . . . . . . . 60

SRP DISCHARGE TO THE SAVANNAH RIVER. . . . . . . . . 61

WARMING IN THE SAVANNAH RIVER ........... 65

APPLICATIONS AT SRP . . . . . . . . . . . . 66

AREAS FOR FURTHER INVESTIGATION . . . . . . . . . 69

The Partial Differential Equation for Natural Cooling. 70

Stratification Algorithm . . . . . . . . . . 70

Solar Radiation Measurements . . . . . . . . 71

Stratified Flow . . . . . . . . . . . . . 72

Mixing of the Influent to the Pond......... 72

Wind Stress . . . . . . . . . . . . . 72

Velocity Measurements ............ 76

Swamps ................... 76

APPENDIX A - FORMULATION OF PAR POND MODEL. . . . . . 78

APPENDIX B - COMPUTER PROGRAM LIMN. . . . . . . . . . . 85

REFERENCES. . . . . . . . . . . . . . . . . . . . 105 


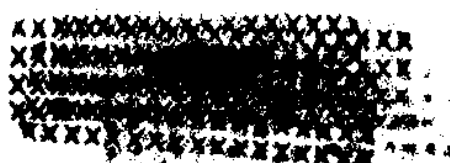

LIST OF TABLES

$\underline{\text { Table }}$

$\underline{\text { Page }}$

I Net Solar Heat Load . . . . . . . . . . . 16

II Slope of the Surface Cooling Rate Curve. . . . . . 22

II Air Wet-Bulb Temperature versus Equilibrium

Temperature . . . . . . . . . . . . . . 22

IV Par Pond Effluent Temperature Compared with the River Temperature . . . . . . . . . . . 36

$\mathrm{V}$ Analysis of Par Pond Data According to the Mode1 . . 43

VI Stratification in Par Pond . . . . . . . . . . . 45

VII Effective Area of the Effluent Streams . . . . . . . 54

VIII SRP Effluent from the Swamp Entering the Savannah River . . . . . . . . . . . . . . 62

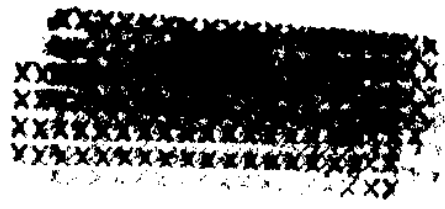


1 Surface Cooling Rate, $\mathrm{H}_{\mathrm{T}}$. . . . . . . . . . 18

2 Diagram Showing Concept of the Equilibrium Temperature .............. 20

$3 \quad R \& P$ Effluent Canals . . . . . . . . . . 23

4 Performance of the R \& P Effluent Canals . . . . 24

5 Par Pond Map . . . . . . . . . . . . . . 35

6 Mode1 for Par Pond ... . . . . . . . . . 38

7 Stratification in $\operatorname{Par}$ Pond . . . . . . . . . 44

8 Par Pond Temperature, January Through May 1964 . . 47

9 Energy Budget Diagram for Par Pond . . . . . . . . 49

10 A Variation of the Energy Budget Diagram . . . . . 50

11 Temperatures Along $\mathrm{C}, \mathrm{K}$, and L Effluent Streams to the Savannah River . . . . . . . . . . 52

12 Surface Cooling Rate, August 1966 . . . . . . . 53

13 Aerial View of Four Mile Creek Outlet into the SRP Swamp ............... 55

14 Aerial View of Pen Branch Outlet into the SRP Swamp . . . . . . . . . . . . 56

15 Aerial View of Steel Creek Outlet into the SRP Swamp ............... . 57

16 Temperatures Up Steel Creek from the Savannah River ................. 58

17 Flow of $C, K$, and $L$ Effluent Cooling Water Through the SRP Swamp ... . . . . . . . 59

18 Effective Cooling Surface and Flow Split for the $C$, K, and L Effluent Streams and SRP Swamp... 61

19 Surface Cooling Rate Under the Severe Conditions That Existed in August 1959 . . . . . . . . . 63

20 SRP Map for Computer Program LIMN . . . . . . . 67

21 Fluctuation in Pond Effluent Temperature . . . . . 73

22 Fluctuation in Wind Direction . . . . . . . . . 73

23 Fluctuation in Wind Vector and Pond Effluent Temperature . . . . . . . . . . . . . 74

24 Wind Stress and Internal Seiche . . . . . . . 75 


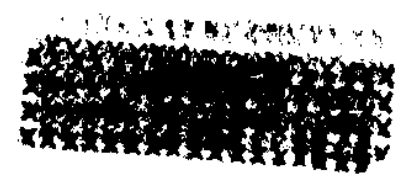

$\therefore$

\section{INTRODUCTION}

The heat from the nuclear reactors at the Savannah River Plant (SRP) of the U. S. Atomic Energy Commission is dissipated to the atmosphere during passage of the effluent cooling water through many miles of canals and hundreds of acres of cooling ponds and swamps within the SRP boundaries. This report presents a quantitative assessment of this heat dissipation.

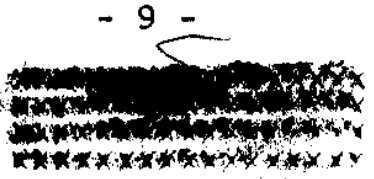



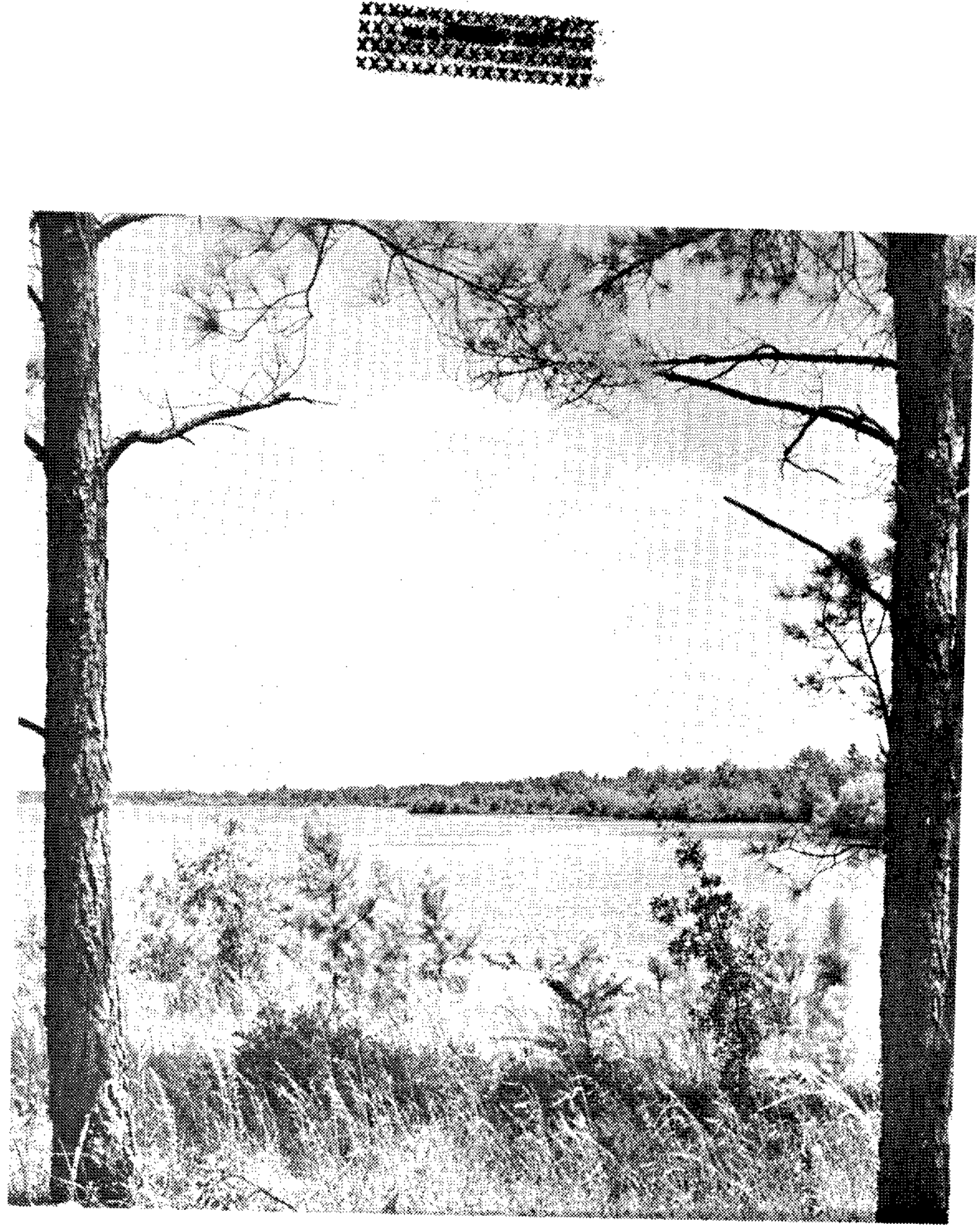

Par Pond 


\section{SUMMARY}

The decrease in the temperature of the effluent cooling watex from the sRP reactors as the water passes tirrough the effluent canals and a 2500macxe cooling pond (Par pond), ox through the stream beds and the swamp along the Savanmah River, can be accounted for by the langhaar equation for the surface cooling rate when proper consideration is given to the physical characteristics of the system, primarily the geometry of the watex body.

The langhaax equation gives the surface heat flux as a function of water surface temperature, air temperature, humidity of the aix, and wind speed. The equation has two terms. One term gives the rate at which heat is carried away from the surface by radiation ard convection. The second term gives the rate at which heat is carried from the surface by evaporation.

The physical situation determines whether the water flows by simple displacenent, i.e., slug tow, or whether there is perfect mixing, or whether water at the warmer end mixes with subsurece water that flows upstream from the coldar end of the pond. Such fow pattems are readily formulated into mathematical nodels. Using the appropriate model, the observed performance of the streams and canals is correlated by an effectiveness factor for the surface area. The observed performance of par pond is correlated by a temperature increment that varies with the season and $i s$ attributed to thermal stratification. The observed performance of the swamp is explained as the result of shading crom the solax heat, albelt with a reduction in wind speed, and an effectiveness factor for the swanp area appears reasonable as judged by aexial photographs. The concept of the equilibrium temperature is developed for the analysis.

Whe analysis of the cooling process is not completely accurate, but it is adequate. The mechanism of stratification needs to be fomulated and incorporated into the mathematical model. Stratified flow, mixing, and the effect of fluctuating wind stress need further study. Velocity measurements and a continuous record of the solar radiation intensity would be helpful. The apparent ability of a swamp to achieve lower temperatures than an open pond, by virtue of the effect of shading upon the equilibriun termerature, needs to be verified.

This report shows that the temperature of the effuent cooling water discharged at the river is within a few degrees of the vatural equilibxium temperatuxe. The natural equilibrium temp-

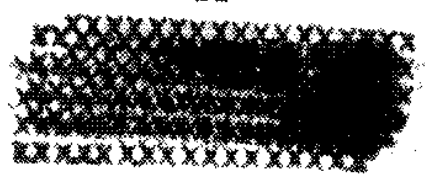


erature is derined as the temperature calculated for a stagnant shallow pond at steady state (24mourwaverage conditions). Howm ever, the temperature of the Savannah River is as much as $8^{\circ} \mathrm{C}$ below the natural equilibrium temperature in the sumertime, as a result of the coldwater storage in Clark hill Reservoir about 75 miles upstream from SRP. Thus, the temperature of the Savannah River is generally increasing naturally as it reaches the sRp site, and it continues to increase naturally as it progresses on toward the ocean. This report also shows that the temperature of the discharge from pax pond, which is recycled to the reactors, is whin $2^{\circ} \mathrm{C}$ of the natural equilibriun temperature and cooler than the natural equilibrium temperature in the summer as a result of thermal stratification effects.

Fron this analysis and the history of the river temperature and weather at SRP, the temperature of the SRP effluent cooling water reaching the Savannah River was calculated for the most severe sumer conditions. The temperature of the skp discharge from the swamp to the river (from $C, K$, and $l$ reactors) was calculated to be $35^{\circ} \mathrm{C}$. The mixed temperature in the river downstream from SRP was calculated to be $29^{\circ} \mathrm{C}$, which is in agreement with independent observations of the U. S. Geological Survey. A con puter program is given for calculating the temperature of the $S R P$ effluent cooling water at the river under other conditions. The computer program can also be used to calculate the temperature of pax pond discharge. 


\section{DISCUSSION}

\section{HOT WATER EFFLUENT FROM THE PRODUCTION REACTORS}

Whe nuclear reactors at the Savamah River Plant of the U. S. Atomic Enexgy Commission are operated for the purpose of producing rabioactive isotopes for both military and peaceful applications. Such reactors axe called production reactors. The production is accomplished by absorbing in target materials the excess neutrons from nuclear fission in the critical lattice that makes up the reactor core. The ission process generates most of the reactor heat. The rate of heat generation, or reactor power, is directly related to the production rate.

The heat that is generated in the reactor must be removed to prevent melting of the reactor components. This is done at SRE by circulating heavy water through the reactor, since heavy water is an essentich part of the reactive lattice. This heavy water then flows through the tubes of heat exchangers while ordinary water flows through the shell side, i.e., across the bank of tubes. In SRl parlance, the heavy water coolant is called "process water," and the ordinary water is called "cooling water." "we reactor heat is therby transferred in the reactor heat exw changers from the process water to the cooling water.

The production reactors are operated at a pressure not much greater than atmospheric. This requires that the bulk temperature of the process water leaving the reactor and entering the heat exchangers be less than $100^{\circ} \mathrm{C}$. The effluent cooling water in turn has to be at a lower temperature, generally less than $80^{\circ} \mathrm{C}$, since a temperature dicference of about twenty degrees between the process water and the cooling water is required in order to transfer the heat load to the cooling water.

The power of the reactor is generally limited by one or more of the temperatures that are reached at various places in the reactor system. The limiting temperature might be the effluent temperature of the process water. $0 \mathrm{r}$, it might be the naximum temperature of the fuel or fuel surface; or, the effluent temperature of the process water from a particular fuel channel. Regardw less of the tempexature limit, it is a good approximation that the reactor power is directly proportional to the difference between that limiting temperature and the temperature of the cooling water entexing the heat exchangers. For example, if the temperature limit governing reactor power is $110^{\circ} \mathrm{C}$ and if the

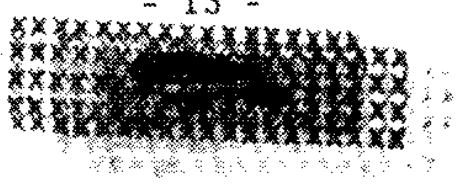


temperature of the cooling water could be lowered from 20 to $19^{\circ} \mathrm{C}$, the reactor power could be increased by $1.1 \%$. Thus, the temperature of the available cooling water is important to reactor productivity.

The cooling water for the reactors comes from either the Savannak kivex or from par pond. The effluent cooling water from the reactor heat exchangers is returned either to the rivex down stream from the river pumphouses or to par pond at a point remote from the pond pumphouse. Before reaching the river or the pond, the effluent cooling water courses natural streams or man-made canals which are several miles in length. The effluent canals leading to pax pond connect a number of artificial small ponds. The natural streams carrying effluent cooling water to the river are Four MileCreek, Pen Bxanch, and Steel Creek. These streams pass through swampy regions in the flood plain before reaching the Savannah River. Lower Three Rums Creek carries the overflow, is any, from pax pond to the river.

Studies have shown that it is not economically feasible to recover the heat in the effluent cooling water for electric power generation. Nuclear reactors for electric power generation that employ water as coolant are designed to operate at high pressure in order to achieve steam temperatures sufficiently high, not only for an acceptible thermodynamic efficiency in work recovery but also for less costly turbines. By operating at low pressure, the production reactor can employ a cladding naterial (aluminum that is less costly and less parasitic with respect to the neutrons needed to produce the desired products. Finally, the low pressure reactor is more easily charged and discharged, which is an important consideration since the fuel irradiation cycle is short compared with that for the power reactor. Because no useful work is abstracted from the effluent cooling water of the production reactor, all of the reactor heat at sRp is wasted.

\section{THEORY FOR THE NATURAL COOLING OF WATER}

\section{Energy Budget}

A mathematical analysis of the cooling process is built around four quantities that are related according to the energy budget equation

$$
H_{C}=H_{S}+H_{F}-H_{\mathrm{T}}
$$

The rate of change in the heat content of the body of water $\left(H_{C}\right)$ is equal to the rate at which heat is added by the sun $\left(H_{\mathrm{S}}\right) \mathrm{plus}$ the rate of heat addition from the change in temperature of the water that lows through the body (by) minus the rate at which heat is removed by transfer to the atmosphere $\left(\mathrm{H}_{\mathrm{T}}\right)$. Equation 1

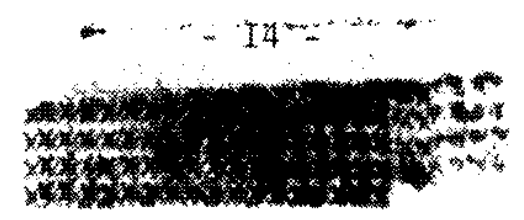


leads to a nonlinear fixst-order partial diferential equation of first degree with variable coefficients, where tine and space are the independert variables, and temperature is the dependent variable. In this report, however, the treatment of Equation 1 is simplified by variously assuming certain texms to be zero, constant, of linear, according to the situation, and by employing spot data ox timenaveraged data rather than the actual continuously varying data. The unit used in this report for each of these four quantitios is pcu/ (hrofte $\left.{ }^{2}\right)$. Each of these quantities is discussed in turn below.

Rate of Change in Heat Content, $\mathrm{H}_{\mathrm{C}}$

During the time interval do hours betweer observations at a point, a change dT $\left({ }^{\circ} \mathrm{C}\right)$ may occur in the average temperature over the depth (ft). The rate of change in stored heat is then

$$
H_{c}=62.4 h \frac{d T}{d \theta}
$$

where the volumetric leat capacity of water is $\left.62.4 \mathrm{pcu} / \mathrm{ft}^{3}{ }^{\circ} \mathrm{C}\right)$. Steady-state conditions exist when HC is zero. When either dT/de or is is sufficiently small, $H_{C}$ may be small enough in relation to the othex quantities in the energy budget equation that $\mathrm{H}_{\mathrm{C}}$ may be neglected. Thus, in the analysis of the pertomance of the canals, shallow ponds, streams, and swamp at SRP, $K_{C}$ can be set equal to zero. For the deeper $P a x$ pond at SRP, HC is an important quantity; but since it is less than 25\% of the solar heat load (as shown later), it can be considered constant for the period of the that the solar heat load is considered to be constant. Thus, for par pond, HC is seen as diminishing or augnenting the solar heat load.

\section{Solar Heat Load, HS}

The heat added to a body of water by the sun is the incident radiation minus that reflected. The incident radiation is best measured by a pymeliometer. Alternatively, it can be estimated from the latitude, altitude, month of the yeax, time of day, and clowd cover. ${ }^{2},{ }^{2}$ Tentatively, the reflected radiation is taken at

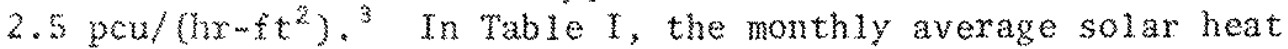
load observed by a pyrheliometex is shown to be about 70 \% of the maximun 24whour value estinated from tables. As shown in this table, the 24 mour average value for $\mathrm{Hs}$ is $19 \mathrm{pcu} /\left(\mathrm{hr}-\mathrm{ft}^{2}\right)$ in January, increasing to $44 \mathrm{pow} /\left(\mathrm{hr}-\mathrm{ft}^{2}\right)$ in May. As shown below, for par pond in way, the lyeat load imposed by the flow of reactor ef $x^{2}$ went cooling water (two reactors in operation) is only half the solax heat load. Cenerally, hs is taken as the average value during the the between observations of the temperature at a point

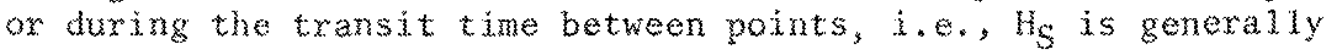
a constant in the formulations over an appreciable time interval.

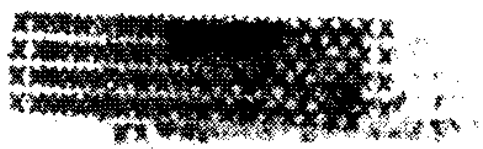




\begin{tabular}{|c|c|c|c|c|}
\hline & & $\begin{array}{r}x \times x \times x \times x \\
x \times x \times x \\
x \times x \times 1 \\
\text { TAEL }\end{array}$ & 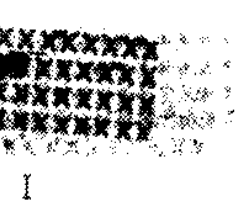 & \\
\hline & & Net Solar & eat load & \\
\hline Month & $\begin{array}{l}\text { Maximum } \\
\text { Solar } \\
\text { Heat Flax, } \\
\text { pou }\left(\mathrm{hr}-\mathrm{ft}^{2}\right)\end{array}$ & $\begin{array}{c}\text { observed } \\
\text { Solar } \\
\text { Heat Flux } \\
\text { pea/ (br-ft }\end{array}$ & $\begin{array}{l}\text { Ratio of } \\
\text { Observed to } \\
\text { Maximam } \\
\text { Heat Hux } \\
\text { perf(hr-ft") }\end{array}$ & $\begin{array}{c}H_{\mathrm{s}} \\
60.5 \% \text { of Maximum } \\
\text { Mnus } 2.5 \% \\
\mathrm{gcu} /\left(\mathrm{nr}-\mathrm{ft}^{2}\right)\end{array}$ \\
\hline$J a n$ & 31.1 & 22.3 & $0.71 \%$ & 19.1 \\
\hline Fob & 38.3 & $\therefore 1.1$ & 0.551 & 24.1 \\
\hline $\operatorname{Mar}$ & 46.7 & 34.4 & 0.737 & 30.0 \\
\hline Apr & 50.5 & 45.5 & 0.765 & 38.9 \\
\hline May & 66.7 & 47.1 & 0.705 & 43.9 \\
\hline June & 72.2 & 47.1 & 0.652 & 47.7 \\
\hline & Avg Jan-May & & 0.635 & \\
\hline
\end{tabular}

a. heference 1: clear arid conditions, 24 -hr average.

b. By pyrheliometer.

a. Alow 2.5 peu/hrift ${ }^{2}$ for retiected radiation.

Heat Added by the Change in Temperature of the Flow, HF

The heat content of the water flowing out of the body of watex is subtracted from the heat content of the water flowing into the body. This difference in heat content (in pcu/hx) is then divided by the surface area for heat transfer to the atmosphere to obtain Ha in pou/ $\left(\mathrm{hr} \cdot \mathrm{ft}^{2}\right)$. The flow is that imposed by the SRp operations plus that resulting from rainfall, which is the source of the natural stream flow. The flow from SRP operations is metered and its temperature is measured; these are generally the most signifim cant quantities. The rainfall that enters the system, which is next in importance, depends upon the drainage area and the runoff fraction; these are discussed later in connection with par pond. In diferential form, for the case where only one flow needs to be considered

$$
H_{p:}=-500 F \frac{d T}{d A}
$$

where

$$
\begin{aligned}
& F=\text { flow, gpm, } \\
& A=\text { surface area, } f t^{2} \\
& 500 \text { has the units pou }\left(\mathrm{hr}-{ }^{\circ} \mathrm{C}\right. \text { gpm) }
\end{aligned}
$$

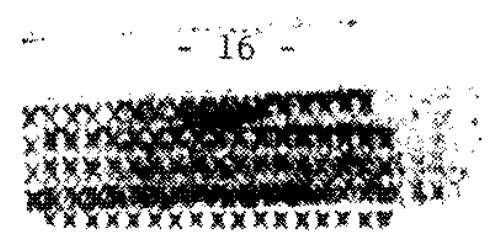


Surface Cooling Rate, HT

The rate of cooling at the surface of a body of water is predicted by the equation of $J$. W. Langhaar."s "s The equation has wo parts, one part giving the surface heat flux corresponding to the evaporation rate $\left(k_{0}\right)$ and the other part giving the surface heat flux for radiation and convection $\left(H_{x}\right)$, as follows:

$$
\begin{aligned}
& H_{\mathrm{r}}=\mathrm{H}_{\mathrm{e}}+\mathrm{H}_{\mathrm{rc}} \\
& \mathrm{H}_{\mathrm{e}}=1.63(1.0+0.1 W)\left(p-\mathrm{p}_{\mathrm{a} x}\right) \\
& \mathrm{H}_{\mathrm{rc}}=1.20(1.5+0.1 W)\left(\mathrm{p}-\mathrm{r}_{\mathrm{ar}}\right)
\end{aligned}
$$

where the atmospheric conditions are represented by the variables

$$
\begin{aligned}
& W \text { wind speed, mph "above the trees" } \\
& \mathrm{T}=\text { water surface temperature, }{ }^{\circ} \mathrm{C} \\
& T_{a i r}=a j x d y-b u l b \text { temperature, }{ }^{\circ} \mathrm{C} \\
& P \text { mapor pressure of water at } T, \mathrm{~mm} \text { kg absolute } \\
& P_{a i x}=\text { partial pressure of water vapor in air, mm Hg }
\end{aligned}
$$

The partial pressuze of water vapor in the air $\left(P_{a}+x\right)$ is the product of the vapor pressure of water at the air drymbulb tempaxature and the relative humidity. The relative humidity is a function of the air dry-bulb and wet-bulb temperatures (TWB).

For given atmospheric conditions, the surface cooling rate by the above equations is a nonlineax function of the water surace temperature. Typical curves for the surface cooling rate are given in Figure 1 . Over a short interval of temperature, for fustaxce, $10^{\circ} \mathrm{C}$, it is reasonable and convenient to approximate the fanghar curve by a straight line

$$
H_{r}=m+b
$$

\section{Equilibrium Temperature, Te}

If a stanant body of water exists initially at some arbi-w cerary temperature $\mathrm{T}{ }^{\circ} \mathrm{C}$ and $i s$ then exposed to constant atmosphexic conditions and to a given solax heat load, the temperature of the water would approach an equilibrium temperature asymptotically wh the for this case, $H_{p}=0$, and by Equations 1 and 2 we have

$$
62.4 h \frac{d r}{d \theta}=H_{S}-H_{r}
$$




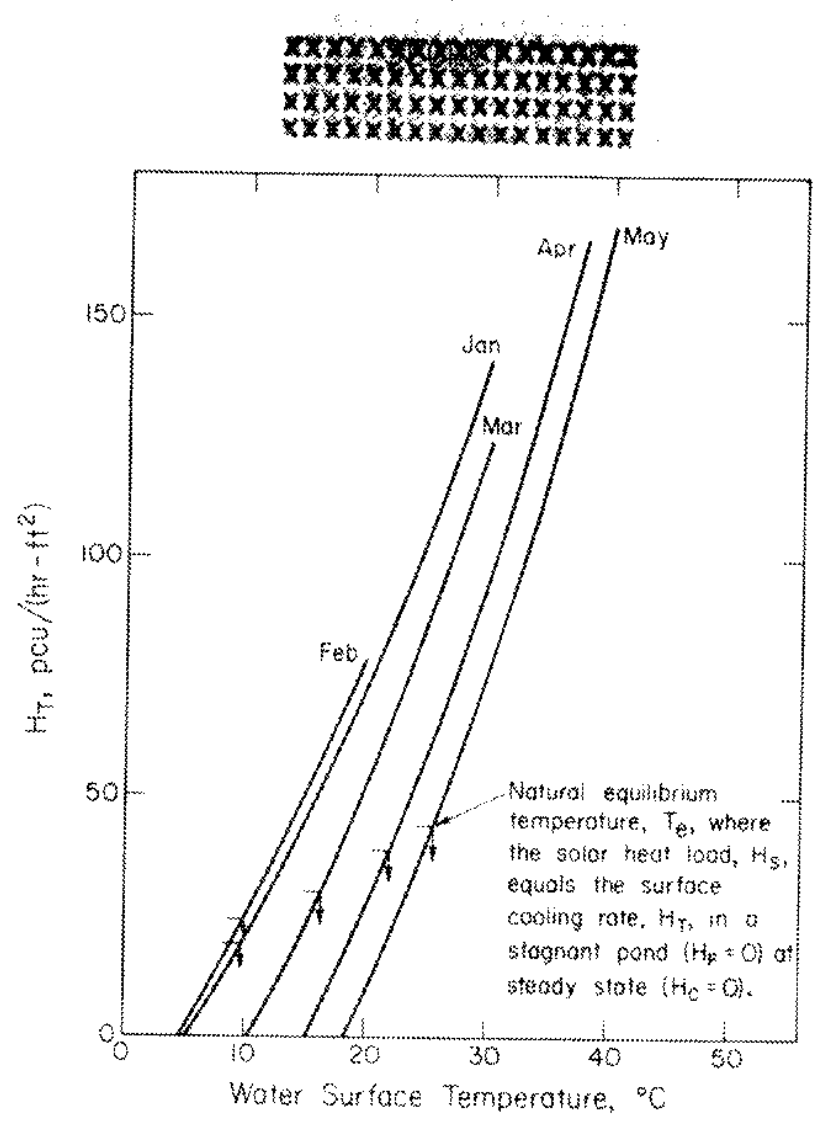

FIGURE 1. Surface Cooling Rate, HT

At the equilibrium conditions, by definition $\mathrm{dT} / \mathrm{de}=0$, so the solar heat load equals the rate of surface cooling. The watex temperature at equilibrium can be read from the appropriate surface cooling rate curve at the point where $\mathrm{H}_{\mathrm{T}}=\mathrm{H}_{\mathrm{S}}$, as shown in Figure 1. This water temperature $\left(\mathrm{T}_{\mathrm{e}}\right)$, calculated for equilibrium in a stagnant pond, is termed the natural equilibrium temperatuxe.

In the analysis of the cooling process throughout this report. however, the concept of the apparent equilibrium temperature is employed in conjunction with the straight-line approximation (Equation 7) to the Langhaar cooling rate curve between two tempcratures. This facilitates the integration with respect to time or to surface axea. Thus, taking a straight line approximation of the cooling rate curve we have, by Equations 7 and 8 , for the txansiant tempexature in a stagnant body of water

$$
\left(\frac{62.4 h}{m}\right) \frac{d T}{d \theta}=T-T_{e s}
$$

where

$$
\mathrm{T}_{e s}=\frac{w b+H_{S}}{m}
$$

Here, Tes is the apparent equilibrium temperature.

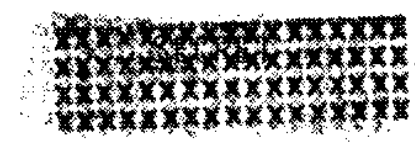


Simlarly, when water is flowing in a channel or shallow pond either under steady-state conditions where HC is zero, or where there is a long-term trend in the average temperature with the season such that ll can be considered as constant, the temperature of the water approaches an equilibrium temperature downstream at infinite distance. The temperature profile with distance is then as follows, from Equations 1 and 3

$$
-(500 \mathrm{r}) \frac{d T}{d A}=H_{T}-H_{S}+H_{C}
$$

Again, taking straight line approximation of the cooling rate curve we have, by Equations 7 and 11 , for the temperature distribution with distance

$$
\left(\frac{500 \mathrm{~F}}{\mathrm{~m}}\right) \frac{\mathrm{dT}}{\mathrm{dA}}=\mathrm{T}-\mathrm{T}
$$

where

$$
T_{e}=\frac{m b+H_{S}-H_{C}}{m}
$$

In this case, $T_{e}$ is also the apparent equilibrium temperature.

By Equations 9 and 12 the rate of change in water temperature. with time and with distance, respectively, is directly proportional to the difference between the local water temperature and the apparent equilibrium temperature for the wator as defined by Equations 10 and 13. Note that, as the straight line is fitted to the Langhaar curve at an increasingly higher temperature range, the value for the apparent equilibrium temperature increases becaluse of the increasing slope of the langhaax curve. The apparent equilibrium remperature is the temperature that the water appeass to be approaching when the cooling is viewed as the simple first-order process described by Equations 9 and 12 .

The difference betwen the apparent equilibrium temperature and the natural equilibriun temperature for pax pond is shown graphically by Figure 2; in this case, the difference is only about $0.3{ }^{\circ} \mathrm{C}$. Wowever, the diffexence beween the apparent equiifurium temperature and the natural equilibrium temperature in the effluent canals leading from the reactors, where the water is much hotter, can be as much as $20^{\circ} \mathrm{C}$ (this is shown later in conmection with pigure 4). Therefore, if the cooling extends over a long range in temperature, $s a y 10^{\circ} \mathrm{C}$ or moxe, the surface cooling rate curve should be approximated by several straight-line sections. Each section then has its ow apparent equilibrium temperature. Equation 9 and 12 is integrated for each section, and the time increments or the area increments for the sections are then summed. 


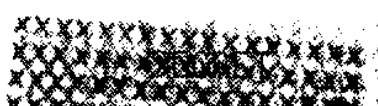

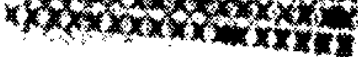

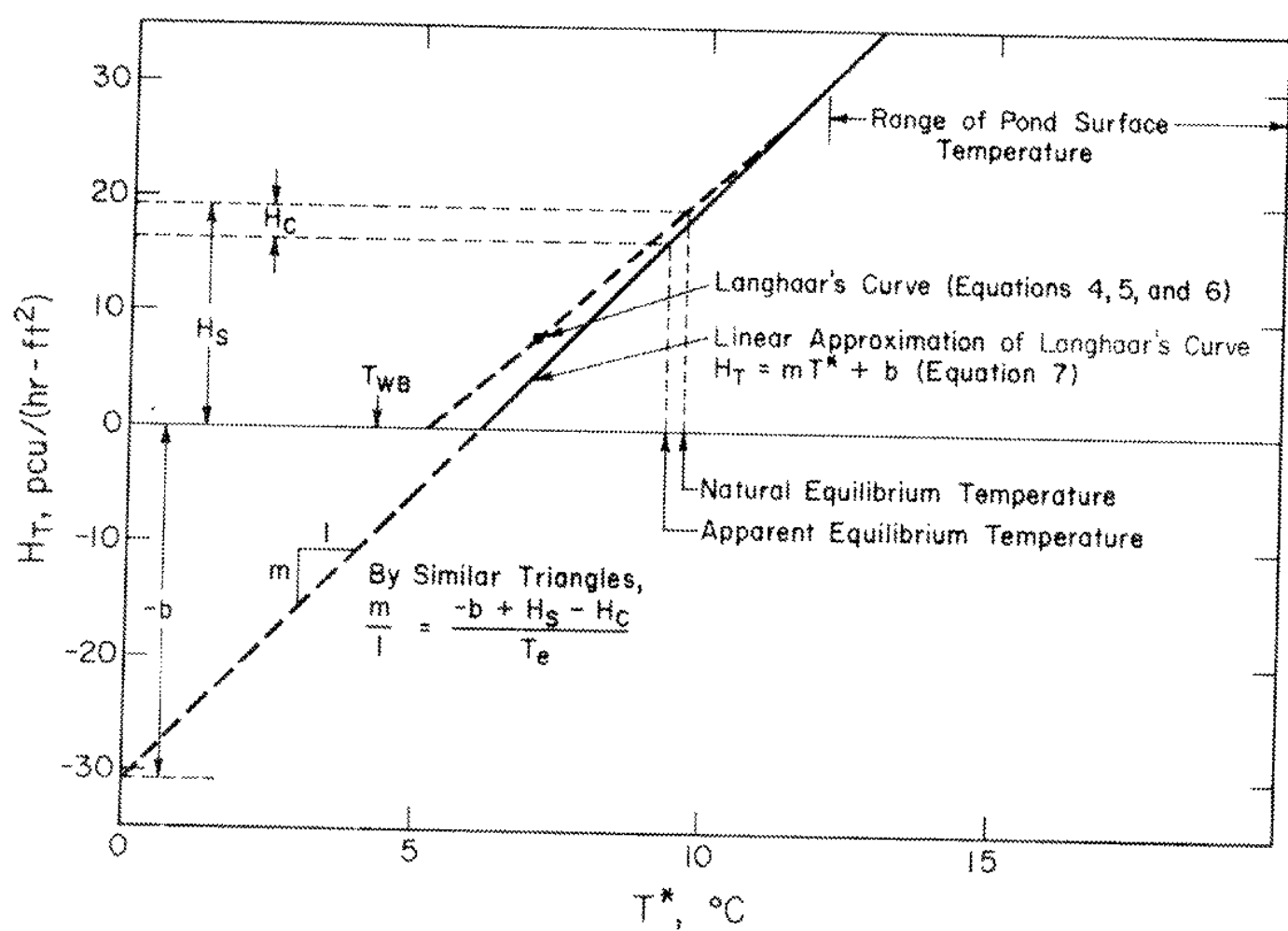

FuURE 2. Diagram Showing Concept of the Equilibrium Temperature January 1964 Conditions (See Table VI) (The asterisk (*) on $T$ indicates it is specifically the temperature at the surface, not the bulk temperature of the water.) 


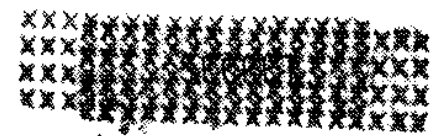

$T_{e s}$ by Equation 10 is the natural equilibrium temperature, as defined above, only when $m$ and $b$ correspond to the targent to the langhaar curve at that particular temperature. Tes deviates from the natural equilibrium temperature to the extent that the straightine fit deviates from the Langhar curve at the point where $\mathrm{H}_{\mathrm{T}}$ is equated to $\mathrm{H}_{\mathrm{S}}$.

The apparent equilibriun terpexature $T_{e}$ by Equation 13 is less than the apparent equlibrim temperature $\mathrm{T}_{\mathrm{es}}$ when $\mathrm{H}_{\mathrm{C}}$ is positive. $H_{C}$ is positive when the average temperature of the pond is greater at the end of the time increment than at the beginning, i.e., when dT/de in Equation 2 is positive. With positive $H_{C}$, more of the heat from the sun and from the imposed flow goes to another sink (the pond contexts) than to the atmosphere. Hence, in approaching equilibrium at the discharge end of a deep pond having positive $\mathrm{K}_{\mathrm{C}}$, the surface temperature need not be so high as the natural equilibrium temperature in a shallow stagnant pond where all the solar heat must be transferred to the atmosphere. Similary, when $\mathrm{H}_{\mathrm{C}}$ is negative, some of the heat to be transferred to the atmosphere stems from a source (namely, the pond contents) other than the sun and the imposed flow, so that the apparent equilibrin temperature is greater than the natural equilibrium cemperature. It follows that, given sufficient surface area, the surface temperature at the discharge end of a deep cooling pond during the period of positive $H_{C}$ can be lower than the natural equilibriun temperature. This effect of $\mathrm{k} c$ on the apparent equilibrin temperature and, accordingly, on the cooling rate and the surface temperatuxe is expounded furthe in comection wh the twomregion model for Par Pond.

\section{Par pond and lake Colorado city Experience}

If the tangent to the surface cooling wate curve is drawn at the point where the equilibrim temperature occurs, the slope n is the increment in surface heat flux corresponding to the imposed heat load (i.e., from $\mathrm{H}_{\mathrm{F}}$ ) per ${ }^{\circ} \mathrm{C}$ difference between the actual temperature and the equilibrim temperature. Although the slope whas the units of a heat txansfer coefficient, pcu/(hr-fet ${ }^{2}{ }^{\circ} \mathrm{C}$ ), it should be noted that for a heat transfex coefficient the total heat flux is divided by the temperature difference in the direction of heat flow. Typual values of the slope mor far pond are given in Table II. The value ranges from 5.1 in January to 7.3 in May. Simlar values have been reported for Lake colorado city, Texas, where it is stated that ".. the anount of heat disposed of in lake Colorado City range from winter to sumer between approximately 4 and 8 pou per sq ft per hr per degree (Centigrade) differm ence in water-surface temperature. The average for the year was 6.7 pcu per $5 q$ ft per hx per degree temperature difference. The temperature difference is the rise in watex-surface temperature, not the ainwater temperature difference." 


\section{TABLE II}

Slope of the Surface Cooling Rate Curve ${ }^{\alpha}$

\begin{tabular}{|c|c|c|c|c|c|c|}
\hline Month & Jan & feb & Max & Apr & May & 3 -Month Average \\
\hline $\begin{array}{l}\text { Slope, m } \\
\left.\text { pcu/(hr- } \mathrm{tt}^{2}-\mathrm{C}\right)\end{array}$ & 5.1 & 5.5 & 6.2 & 6.8 & 7.3 & 6.2 \\
\hline
\end{tabular}

\section{Wet-Bulb Temperature}

A stagnant body of water at equilibxium with the atmosphere, but protected from solar radiation, is analogous to a hygrometer. Hoy bquation 1 is then zero; hence, by Equations 4,5 , and 6 , $\mathrm{H}_{\mathrm{e}}$ and $\mathrm{H}_{\mathrm{xc}}$ are equal in magnitude but opposite in sign. The heat for evaporation is supplied by radiation and convection from the atmosphere. Thus, the temperature at the intercept of the surface cooling rate curve at $\mathrm{HT}=0$ is analogous to the air wet-bulb temperature that is obtained by the hygrometer. However, as shown in Table III and in Figure 2, the intercept temperature is higher by about $1^{\circ} \mathrm{C}$ than the air wetmbulb temperature. It is also shown in Table III and in Figure 2 that the apparent equilibrium temperature of par Pond, which has not only the solar heat load but also an imposed heat load, is 5 to $7^{\circ} \mathrm{C}$ higher than the air wet-bulb temperature during the period January through May.

\section{TABLE III}

Air Wet-Bulb Temperature Versus Equilibriun Temperature

Wonth

Aix wet-bulb temperature $T \mathrm{BB},{ }^{\circ} \mathrm{C}$

Intercort temperature, $b$ "

Natural equilibrium temperature, $\mathrm{oc}$

Apparent equlibrum temperature $\mathrm{T}_{e}, \mathrm{~d}^{\circ} \mathrm{C}$

$\mathrm{T}_{\mathrm{B}}-\mathrm{r}_{\mathrm{W}},{ }^{\circ} \mathrm{C}$

2. Monthly average

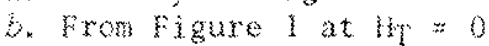

* From Figure 1 at Ho $=M$

d. From Equation 13 and Table vell

$$
\begin{array}{rrrrr}
3 a n & \text { gab } & \text { Mar } & \text { Apr } & \text { May } \\
\hline 4.3 & 3.8 & 9.4 & 14.2 & 17.2 \\
5.2 & 4.7 & 10.5 & 15.2 & 18.4 \\
9.6 & 10.0 & 16.2 & 22.0 & 25.6 \\
9.3 & 10.1 & 15.2 & 20.9 & 24.5 \\
5.0 & 0.3 & 5.8 & 6.7 & 7.3
\end{array}
$$


COOLING IN THE SRP EFFLUENT CANAL SYSTEMS

Description of the Effluent Canal Systems

The canal systems for conducting the effluent cooling water from $p$ reactor and from $R$ reactor to par pond are shown in Figure 3. The reactor effluent is conducted to the midle (ow north) arm of Pax Pond; the $R$ reactor effluent, to the upper (or east) arm. The elevation drops from about $300 \mathrm{ft}$ ms 1 at the reactors to 200 ft ms 1 at the par Pond surface. From p reactor there are 4 triles of canals and five ponds, the largest being 36 acres, plus a 140-acre impoundment of the middle arm of par Pond upstream from the by-pass road embankment, which is called the "precooler"; the total surface area is 227 acres. From $\mathrm{R}$ reactor there are 3 z miles of canals and two ponds, 7.4 and 260 acres in size; the total surface area is 285 acres.

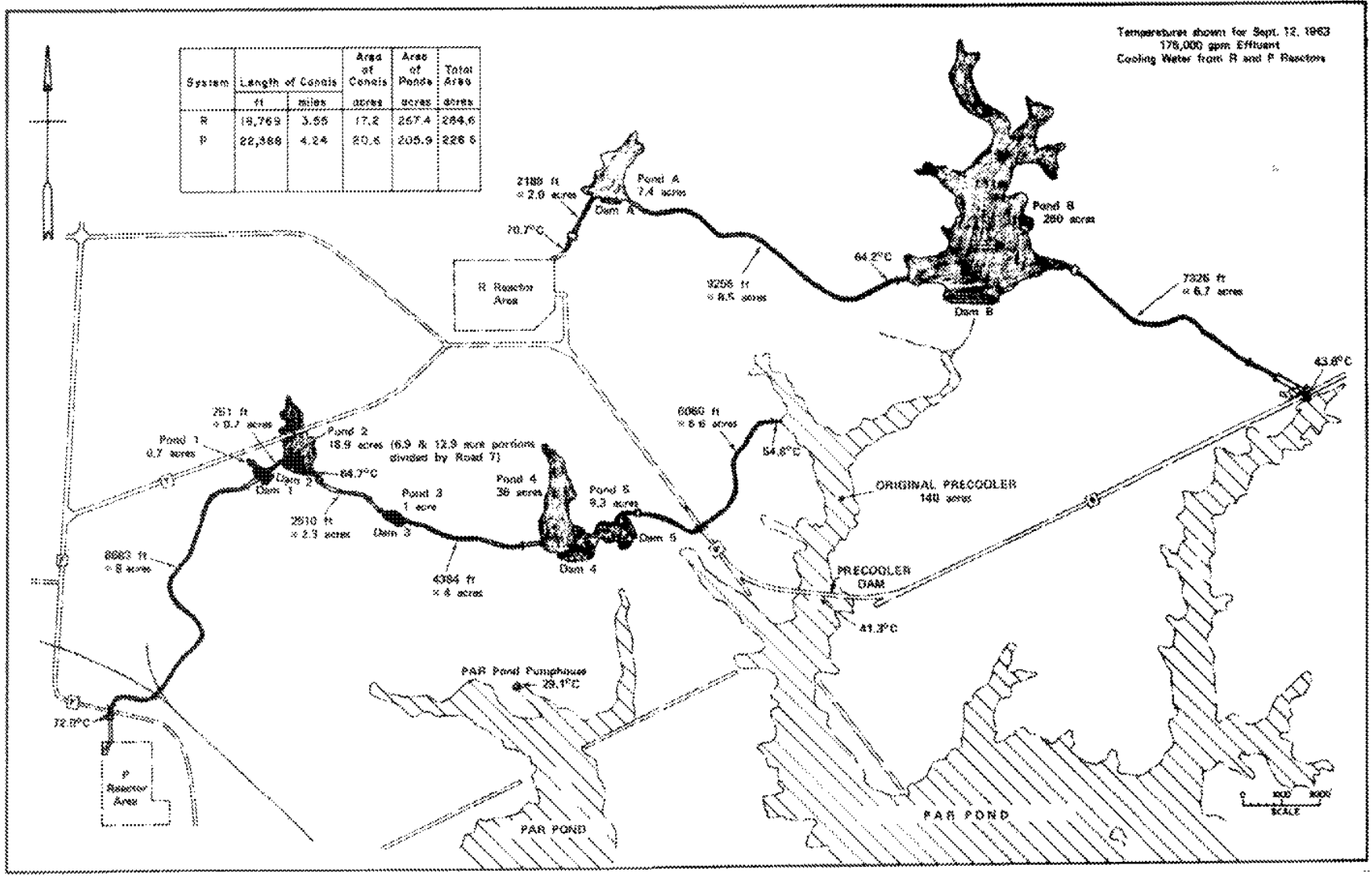

mlauRE 3. R P Effluent Canals 


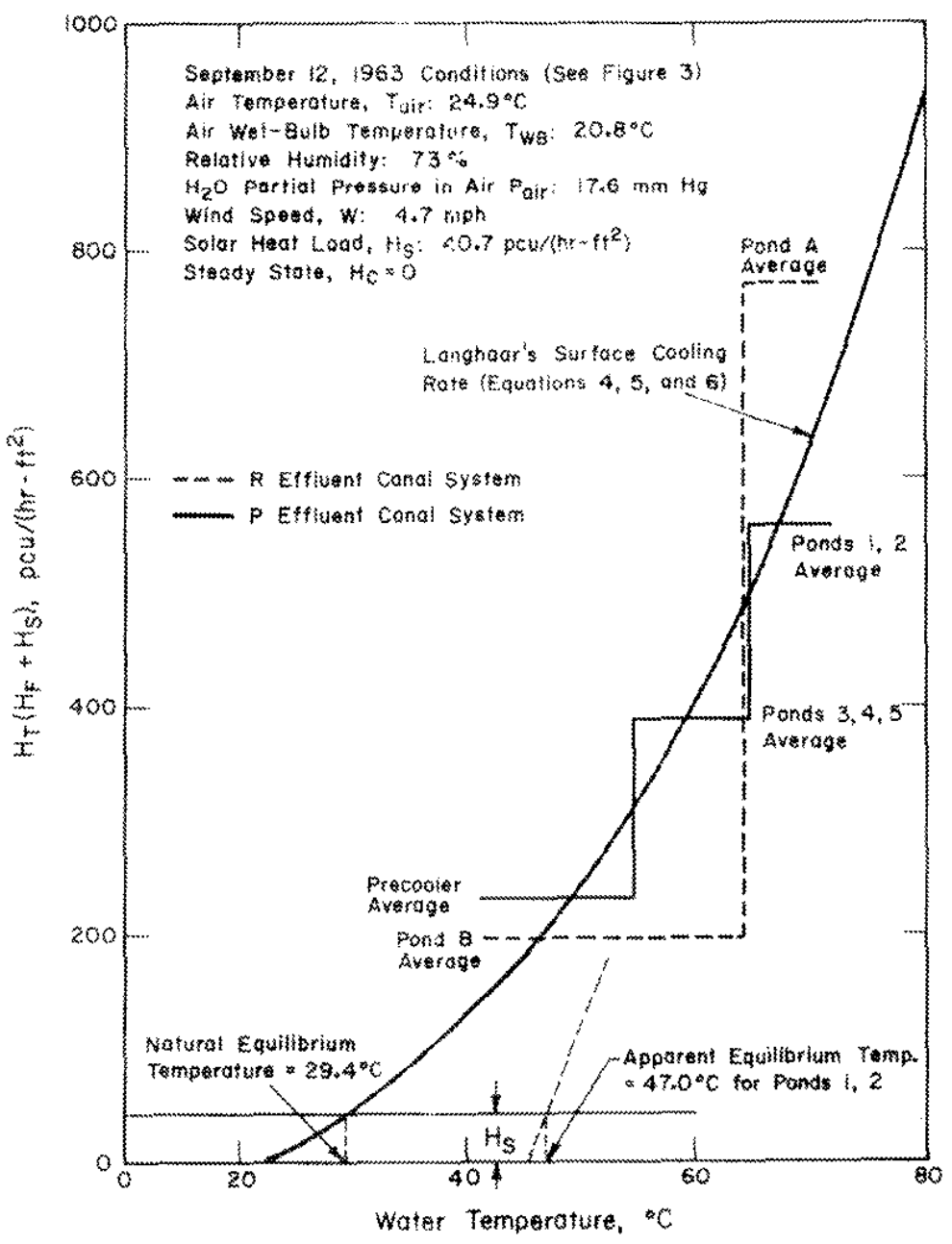

FIGURE 4. Performance of the $R$ \& Effluent Canals 
Typical temperatures axe also shown in Figure 3 at various locations along the efluent canals for a day in Septenber 1963. Both canal systems are seen to produce about the same reduction in temperature before reaching Par Pond. In fact, the effluent canal systems dissipate about $70 \%$ of the heat generated in the reactors. The reactor effluent temperature of $77^{\circ} \mathrm{C}$ was reduced to $42^{\circ} \mathrm{C}$ at the inlet to par pond; the effluent from par pond was $29^{\circ} \mathrm{C}$.

\section{Models for the Effluent Canals and Shallow Ponds}

Several models for the canals, streams, and shallow ponds at SRP have been formulated: 1) single stage, 2) r equalmsize stages in series, 3) n unequal size stages in series, and 4) infinite muber of stages in series. Each stage is considered to be perfect ly mixed such that the surface temperature is the sane at all points and is equal to the effluent temperature from that stage. An infinite number of stages in series is also known as the slugm llow nodel. For slug flow, integration of Equation 12 gives the effluent temperature Tout as a function of the inlet temperature in for a given surface area $A$ at given cooling conditions $\left(m, b\right.$, and $u_{S}$, as follows:

ar,

$$
\begin{gathered}
\int_{T_{i n}}^{T_{\text {out }}} \frac{d T}{T-T_{e}}=-\frac{m}{500 F} \int_{0}^{A} d A \\
\ln \left(\frac{T_{o u t}-T_{e}}{T_{i n}-T_{e}}\right)=-\frac{n A}{500 F} \\
T_{\text {out }}=T_{e}+\left(T_{i n}-T_{e}\right) e^{-\alpha}
\end{gathered}
$$

where

whe quantity 500\%/m is the "attenuation area"; $\dot{x}$..., the surface area recuired to reduce the temperature in excess of the apparent equilibrium tempexature by a factor of e $=2.718$. The models (show on the following pages) employ a linear fit to the langhat equation over the temperature range that exists in the canals, or in portions of them. The models also employ the concept of an apparane equilibxim cempexature. Use of the hanghar relation itself rather than a linear fit would be better, but more tedious; this does not seem to be justified. 


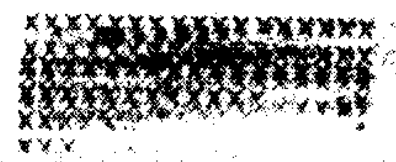

MOOELS FOR THE EFELUENT CANALS

WODEL: SINGLE STAGE

Assuas perfect mixing in the region corresponding to surface area $A t^{2}$. Then the surface temperature overywhere is equat to the ascharge temperature rout

Let $\hat{f}_{\mathrm{A}}=$ ertectiveness factor on $\mathrm{A}$

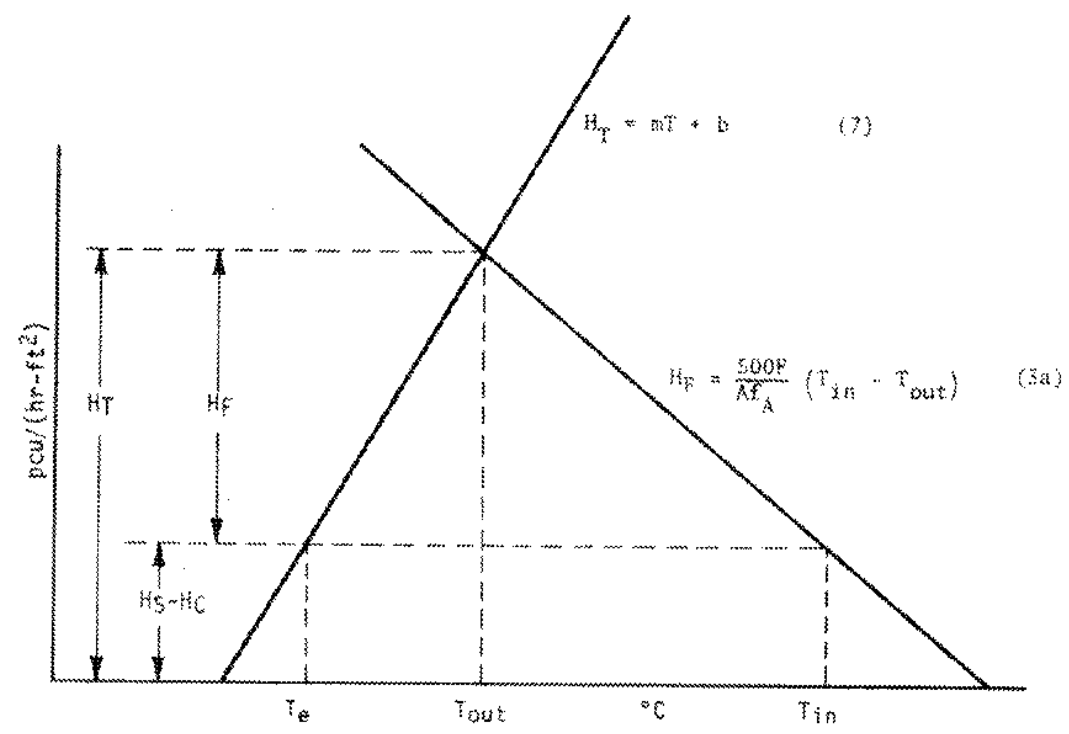

$$
\begin{aligned}
& \text { As } h_{W}=0 \\
& \text { we have from (1) and (7) } \\
& 0=m+b-h_{S}+b_{C} \\
& \text { ors } \\
& T_{k}=\frac{-b+H_{s}-b_{C}}{m}
\end{aligned}
$$

$$
\begin{aligned}
& \text { At } H_{\mathrm{f}}=\mathrm{H}_{\mathrm{Y}}-\mathrm{H}_{\mathrm{S}}+\mathrm{H}_{\mathrm{C}} \\
& \text { we have from (2) and (7) }
\end{aligned}
$$

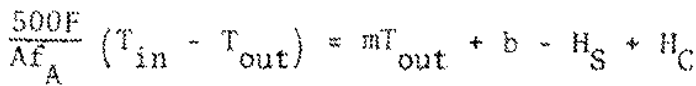

$$
\begin{aligned}
& \text { ors. } \\
& \frac{T_{\alpha u t}-T_{g}}{T_{n}-T_{g}}=\frac{1}{I+\alpha t}
\end{aligned}
$$

where

$s=\frac{m x}{500 \mathrm{f}}$ 
MODE: $A$ EOURLSTZE STAGES

Replace the effectrones factor $\left(f_{\mathrm{f}}\right)$ used in the single stage Model with the apparent number of stages (n). The following equation is dexived drectly from tquation 17:

$$
\frac{\text { out }-\mathrm{e}}{\mathrm{T}_{\mathrm{n}}-\mathrm{r}}=\left(\frac{1}{1+\frac{\alpha}{n}}\right)^{\mathrm{n}}
$$

MODEL: UNEQUAL-SIZE STAGES

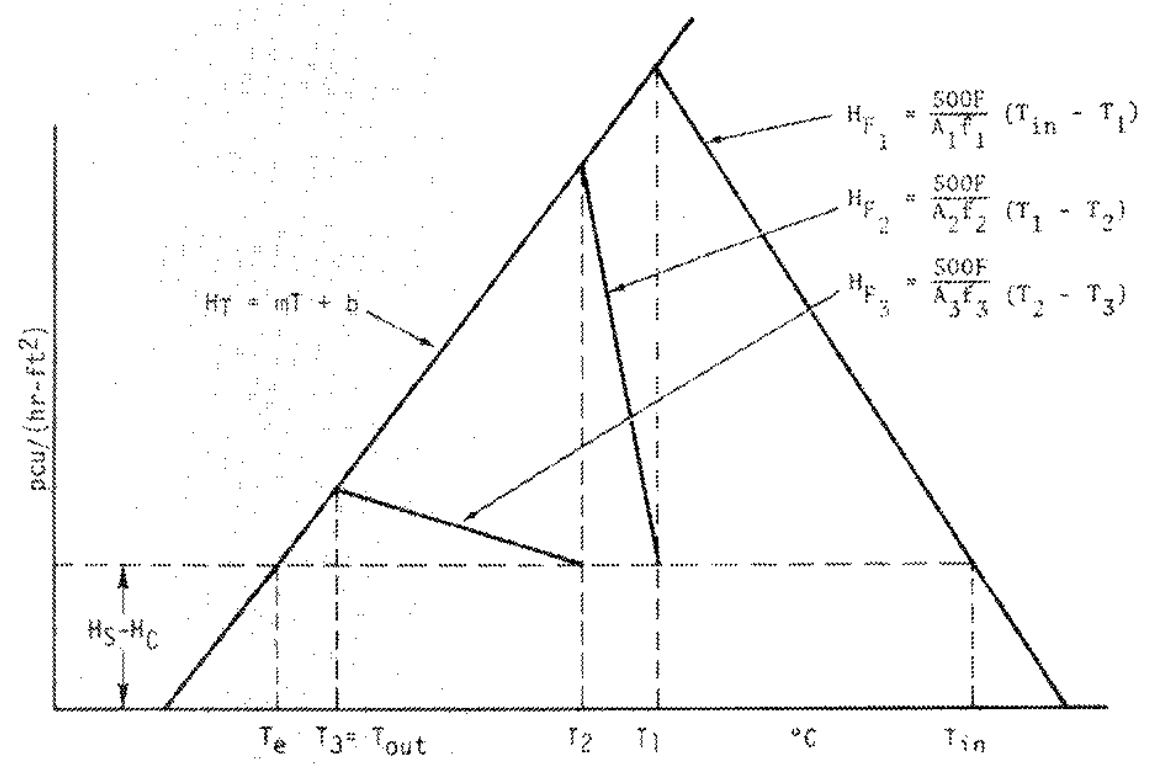

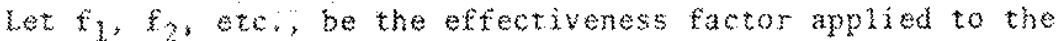

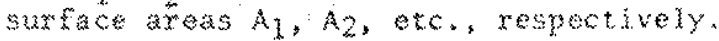

Kssume perfoct mixing in each stage.

whe first stage overflows to the second stage, eto.

$A_{1}+A_{2}+$ etco $=A$, the total surtace axea. 


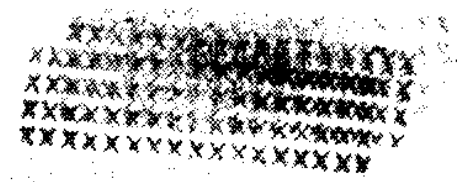

Assume same lineax fit to langhax" cooling rate curve (Equations 4. 5,6$)$; .0. , same Equation 7 . Then,

$$
\begin{aligned}
& \alpha_{1}=\frac{m A_{1}}{500 F}=\alpha A_{1} / A ; \alpha_{2}=\frac{m_{2}}{S 00 \%}=\alpha A_{2} / A ; \text { atc. } \\
& \alpha_{1}+\alpha_{2}+e t c=\alpha=\frac{m A}{500 \mathrm{~F}}
\end{aligned}
$$

Two lnequa $1-S$ zize stages:

$$
T_{\text {out }}\left(1+\alpha_{1} f_{1}\right)\left(1+\alpha_{2} f_{2}\right)=T_{3 n}+T_{e}\left(\alpha_{1} f_{1}+\alpha_{2} f_{2}+\left(\alpha_{1} f_{1}\right)\left(\alpha_{2} f_{2}\right)\right\}
$$

Three Unequal-size Stages:

$$
\begin{aligned}
& T_{\text {out }}\left(1+\alpha_{1} f_{1}\right)\left(1+\alpha_{2} f_{2}\right)\left(1+\alpha_{3} f_{3}\right)=T_{\text {in }}+
\end{aligned}
$$

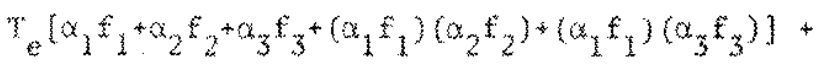

$$
\begin{aligned}
& \mathrm{T}_{\mathrm{e}}\left(\left(\alpha_{2} f_{2}\right)\left(\alpha_{3} \hat{f}_{3}\right)+\left(\alpha_{1} f_{1}\right)\left(\alpha_{2} f_{2}\right)\left(\alpha_{3} \hat{x}_{3}\right)\right]
\end{aligned}
$$

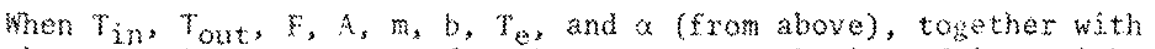

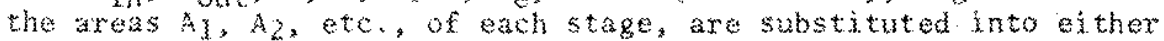
Equation 19 or Equation 20 , an equation 3 in $f_{1}, f_{2}$, te. is ob taned. If similar data were available for other days, particu lar $3 y$ over a diferent range of temperature andor flow, it shoud be possbe to tind "best fit" values for $f_{1}, f$, etc., which also fet the data beter than some other nodel. Here, however assume

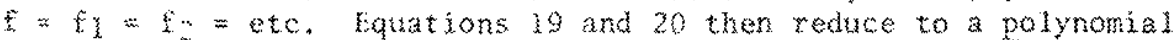

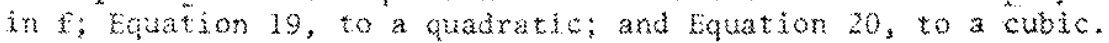

\section{WODE: WWTHTE NUMBR OF STACSS}

Mris is the "slugmow" mode?.

l.et $\tilde{E}_{\mathrm{f}}=$ effectiveness factor on the surface area $\mathrm{A}$. 
Integrate Euarion 12:

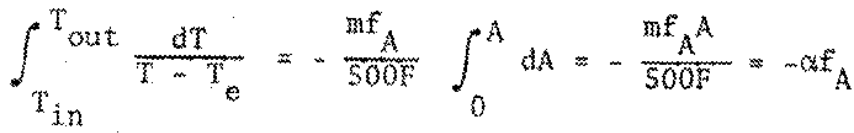

$$
\begin{aligned}
& \ln \left(\frac{T_{\text {out }}-T_{\mathrm{T}}}{\mathrm{T}_{\mathrm{in}}-\mathrm{T}_{\mathrm{T}}}\right)=-\alpha f_{\mathrm{A}} \\
& \frac{T_{\text {out }}{ }^{-T}}{T_{\text {in }}-T_{e}}=e^{-a f_{A}}
\end{aligned}
$$

Note: Commarison of Equation 35 with Equation 18 obtained for the model of mequal-size stages gives the identity:

$$
\frac{1}{e^{a f_{A}}}=\operatorname{limit}_{n \rightarrow \infty}\left(\frac{3}{l+\frac{a f_{A}}{n}}\right)^{n}
$$

Note: In tems of the logarithic mean temperature difference above re, Equation $15 b$ reduces to

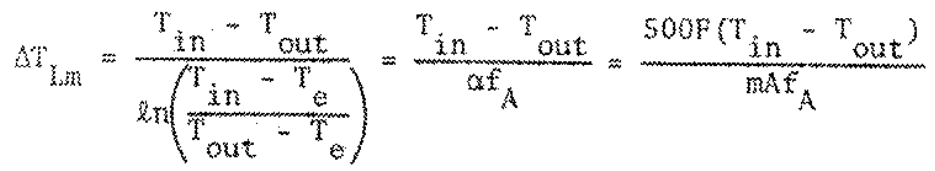

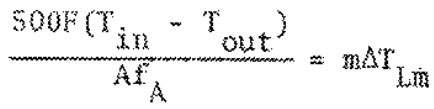

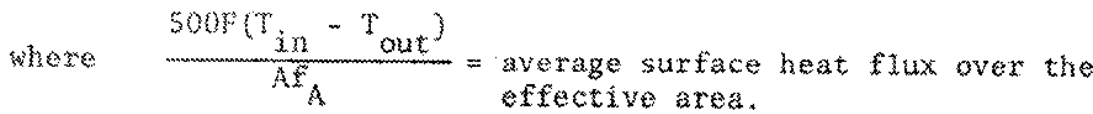

For an explanation of why is is not a heat transfer coefticitent in the usual sense see parge 22 . 
Aralysis of the Effluent Canal System Performance

The average heat load over stretches of the effluent canals and ponds between the points where temperatures were measured (Figure 3) is plotted in rigure a versus the corresponding range in the water temperature. The average heat load is the sim of heat load imposed by the flow of hot watex (H) and the sun (Ms). As shown, the $R$ effluent canal system is divided into two steps (ashed lines); the $\mathrm{g}$ effluent canal system, into three steps (solid lines). On the same figure is plotted the curve for the surface cooling rate (HT) corresponding to the weather conditions for that day, by langhaar's Equations 4,5 , and 6 . The system is regarded as steady state, so $\mathrm{H}_{\mathrm{C}}=0$. Now, if 1 lug flow existed in the region between temperature measurements, the flats of the steps, which are the average heat load over that particular temperature range, would straddle, i.e., be bisected by, the cooling rate curve. If there were perfect ming in that particular region, the tip of the step would just touch the cooling rate curve, i.e., the steps would touch the curve from the right side. Fond $A$ in the $R$ effluent canal system as show in igure 3 is cooling bettex than can be predicted. Also, the precooler in the $P$ effluent canal system is shown to be somewhat better than the infinite-stage model (the better performance might be interpreted as the surface temperature being about $1.4^{\circ} \mathrm{C}$ higher than the average in the cross section nomal to the direction of flow everywhere in the precooler pond. The rest of the effuent canal systen shows performance lying between the single-stage and the infinitemstage model.

The data of figures 3 and 4 are analyzed two ways, as shown on the following pages. First, a superyotal watysis is made based only on the effluent cooling water temperatures measured leaving the reactor area and entering par ponx. The values for fa on $n$ can be used in the corresponding equation shown to predict the effect of different flows, temperatures, and weather conditions. Both systems axe shown as performing better than the singlemstage model, since in 3 greater than for the latter. model. The $P$ effluent canal system performs better than the $R$ offluent canal system.

whe moremetatled aralysis of the data in figures 3 and 4 is preferred for making predictions. In this analysis, slug flow is assumed in the carals and in the ponds of one acre or less. The temperature of the water entering and leaving each of the larger ponds can then be calculated where they are not already available from the data. Each pond is then evaluated according to the alternative models. From the results, the slug flow model is recomended for all of these ponds using the following factors fox the effectumess of the pond surface area: pond $A_{2} f_{A}=1.98$; Pond $B, f_{A}=0.61 ;$ Pond $2, f_{A}=0.93 ;$ Ponds 4 and $5 . f_{A}=0.99$; and precooker, $f_{\mathrm{A}}=1.13$. Using the slug flow model (Equations 15 and 16), the total effective area in the refluent canal system is $8.30 \times 10^{6} \mathrm{t}^{2}$; in the $\mathrm{P}$ effuent canal system, it is $10.58 \times 10^{6}+2^{2}$. 


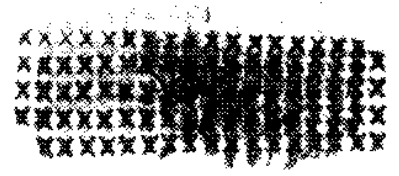

\section{AWALYSIS OF DATA ON THE EFLUEN CANAL SYSTEMS}

\section{SUPERFICLAL ANALYSIS}

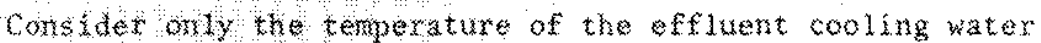
antexing the chal systen the reactor area (Tin) and leaving

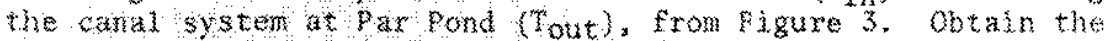

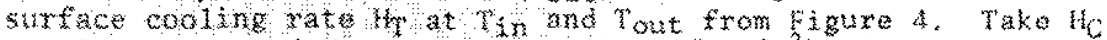

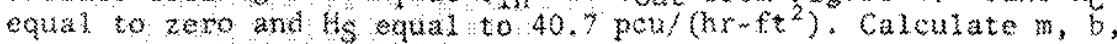
Te, and W. Then calculate... For n for the alternative models.

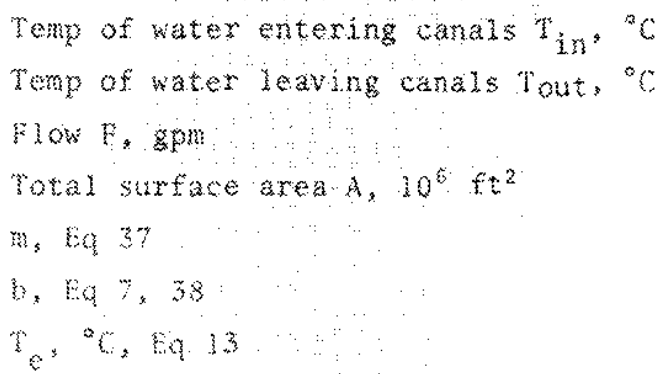

\begin{tabular}{|c|c|}
\hline$R$ & $P$ \\
\hline 70.7 & 72.0 \\
\hline 43.6 & 43.3 \\
\hline 175,000 & 175,000 \\
\hline 12.40 & 9.86 \\
\hline 17.85 & 17.71 \\
\hline .615 .0 & -593.0 \\
\hline 36.8 & 35.8 \\
\hline 2.53 & 2.00 \\
\hline $1.5 \%$ & 2.79 \\
\hline 1.90 & 36.5 \\
\hline 1.32 & - \\
\hline n & 1.45 \\
\hline 0.634 & 0.943 \\
\hline
\end{tabular}

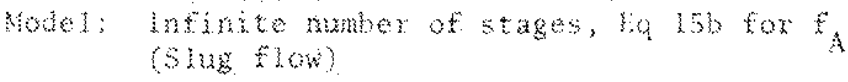

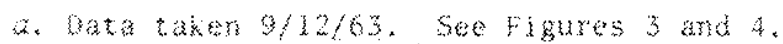




\section{MORE-DETALED ANALYSIS}

Assume slug flow (fquation 15b) in the canal sections and ponds of one acre or less in oxder to calculate lin and 'tout for the larger ponds where these temeratures are not given in

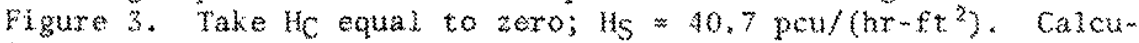
late $m$, $b$, and $T_{e}$ for a straight line fit to bara 4 between the temperatures given in Figuxe 3 . Then calculate fid ox n according to the alterrative models for the larger ponds in the effluent canal system

\section{Reffinent Canal System}
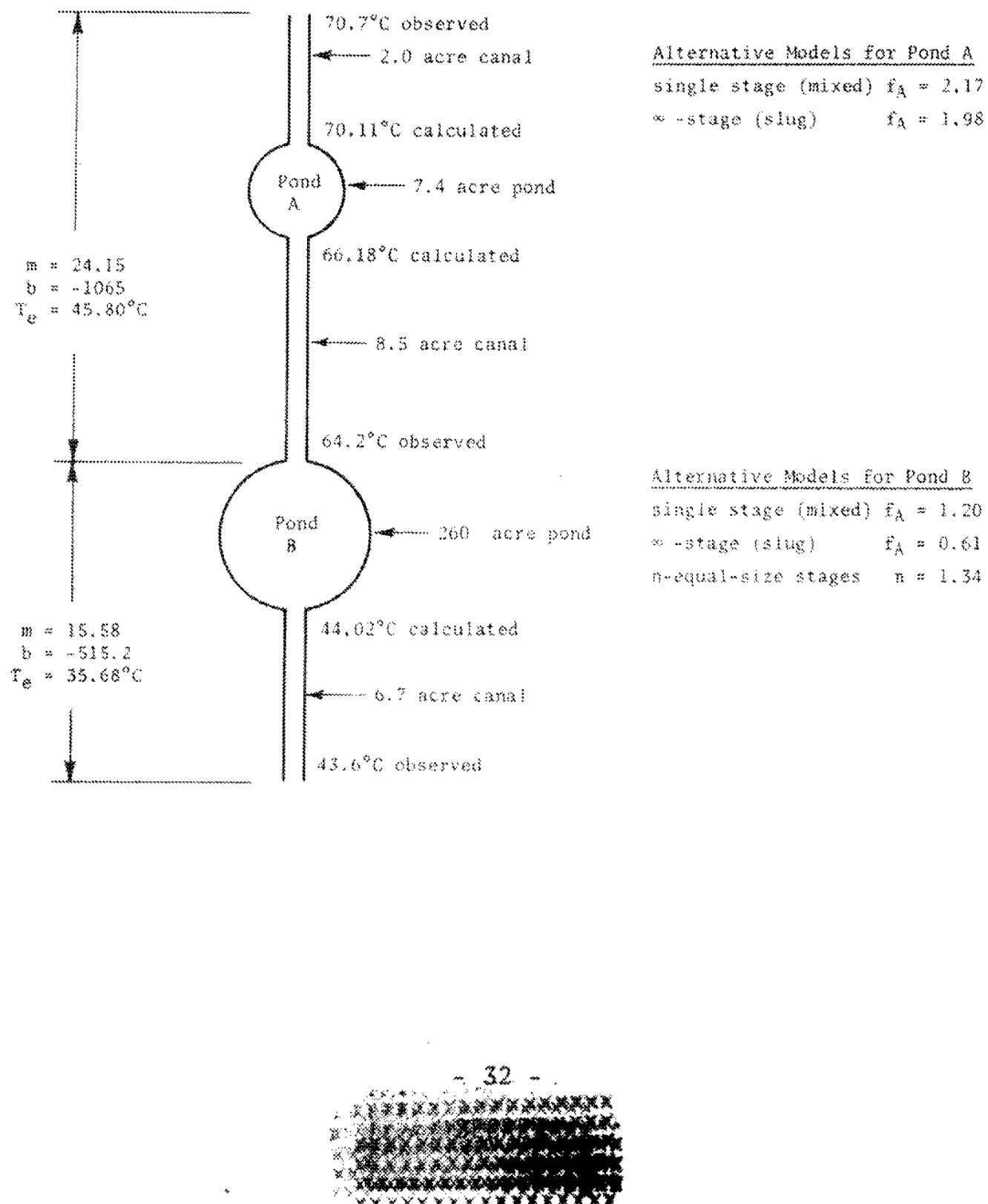


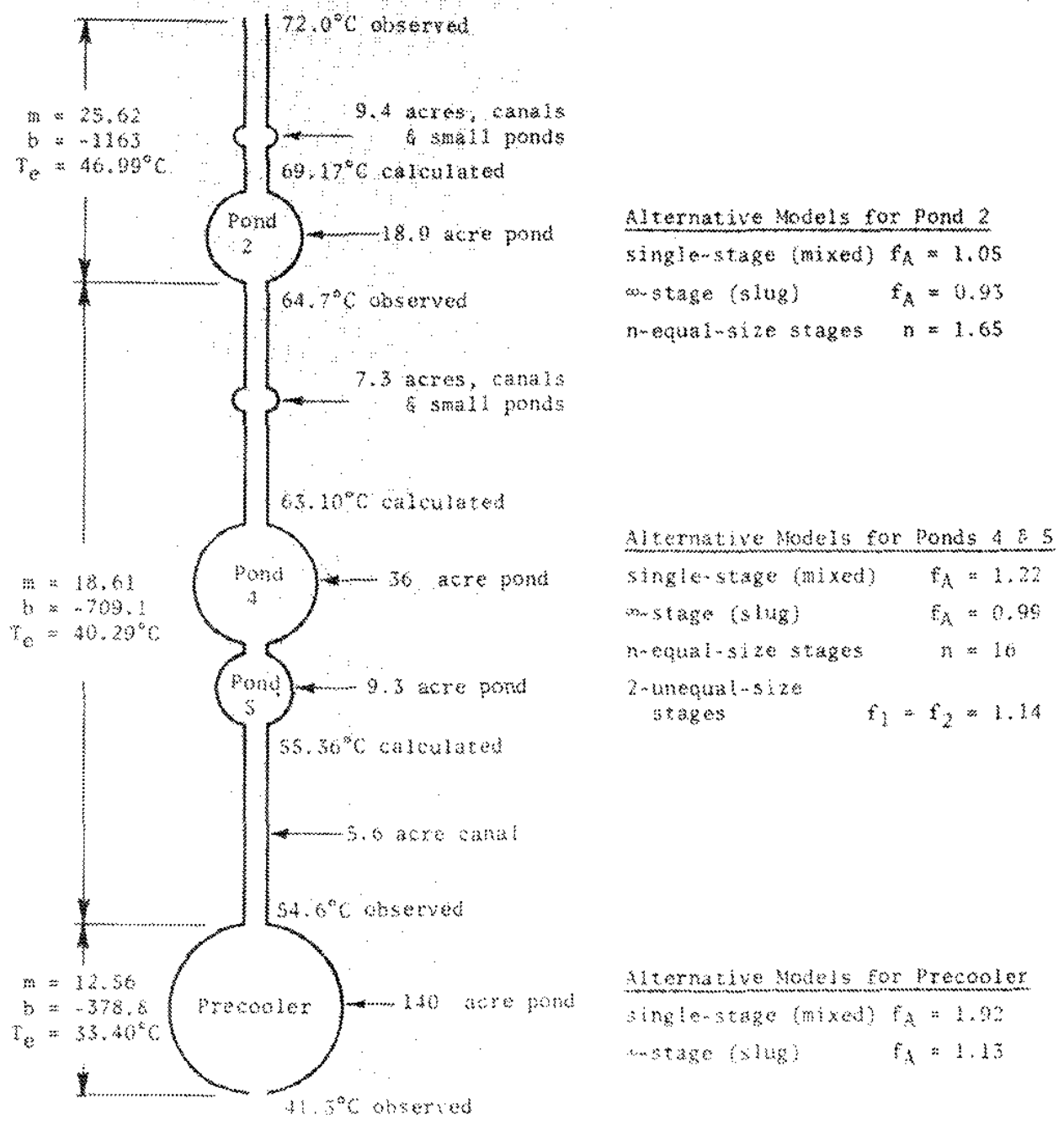

Arerrative rode 15 gor ponds 45

\begin{tabular}{|c|c|}
\hline nglestage haxed & $f_{1}=1.22$ \\
\hline 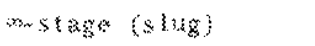 & $f x=0.96$ \\
\hline 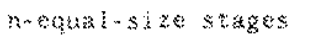 & $n=16$ \\
\hline $\begin{array}{l}\text { whegura l-s } \\
\text {; :agos }\end{array}$ & $\approx 1.1 .4$ \\
\hline
\end{tabular}

Harnative Sodeds for procooles

singlonstage (mixed)

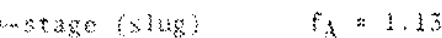

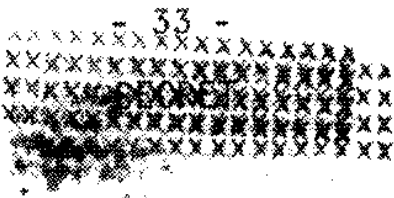


COOLING IN PAR PONO

Description of par pond

Par Pond covers 2640 acxes to an average depth of $20.4 \mathrm{ft}$. A 140-acre portion is separated trom the main body of par pond by the bypass road embankment to form the "precooler" which is considered to be a part of the p effluent canal system. The surface area of the main pond is therefore 2500 acres, or 109 million $\mathrm{ft}^{2}$. The par watershed is $36 \mathrm{mi}^{2}$. The greatest depth in pax Pond is about 55 fr neax the dam.

The plan for par Pond is shown in Figure 5. There are three major axms. The effluent canal from $\mathrm{R}$ reactor terminates at the shallow end of the east arm; the effluent canal from $p$ reactor, at the shallow end of the north or midle arm. The pump house is located at the shallow end of the west arm. The main dam is to the south across Lower Three Runs creek. The intake slot at the pump house, which is located along the bank, is $100 \mathrm{ft}$ wide with the ppening at a depth extending from 17 to 20 ft. During construetion, the pond bottom was bulldozed as necessary to provide a $20 \mathrm{~m}$ f deep chamel 300 ft wide leading to the pump house intake from a distance of 2000 it out, where the natural -20 ft contoux was intercepted.

The rated capacity of the par pump house is $275,000 \mathrm{gpm}$. which is about $30 \%$ of the total sRp capacity for pumping cooling water to the reactors. This flow is divided between $R$ and $P$ reactors ( $R$ reactor was shut down in mid-1964). With both $R$ and $p$ reactors in operation and with each reactor requiring about $180,000 \mathrm{gmm}$, additional cooling water was dxawn from the river system. The effluent cooling water fron both reactors was discharged to par pond through the effuent canal system. The excess cooling water then overiowed at the dam and traveled to the Savamak River via Lower Three Runs. Because the cempexature of the overflow at the dam was only slightly above the equilibrium temp arature, and the water was further cooled during its 18 mile flow path to the Savannah River, there was no thermal impact on the river because of the operation of $R$ and $P$ ractors. At the present time, with par pond serving only reactor, there need be no

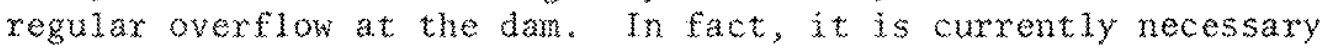
to add about 7500 gpm of water from the river system to maintain constant level in the pont.

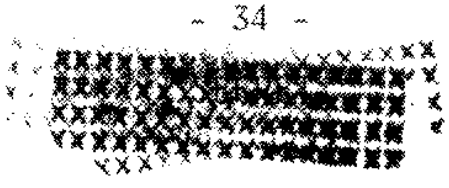




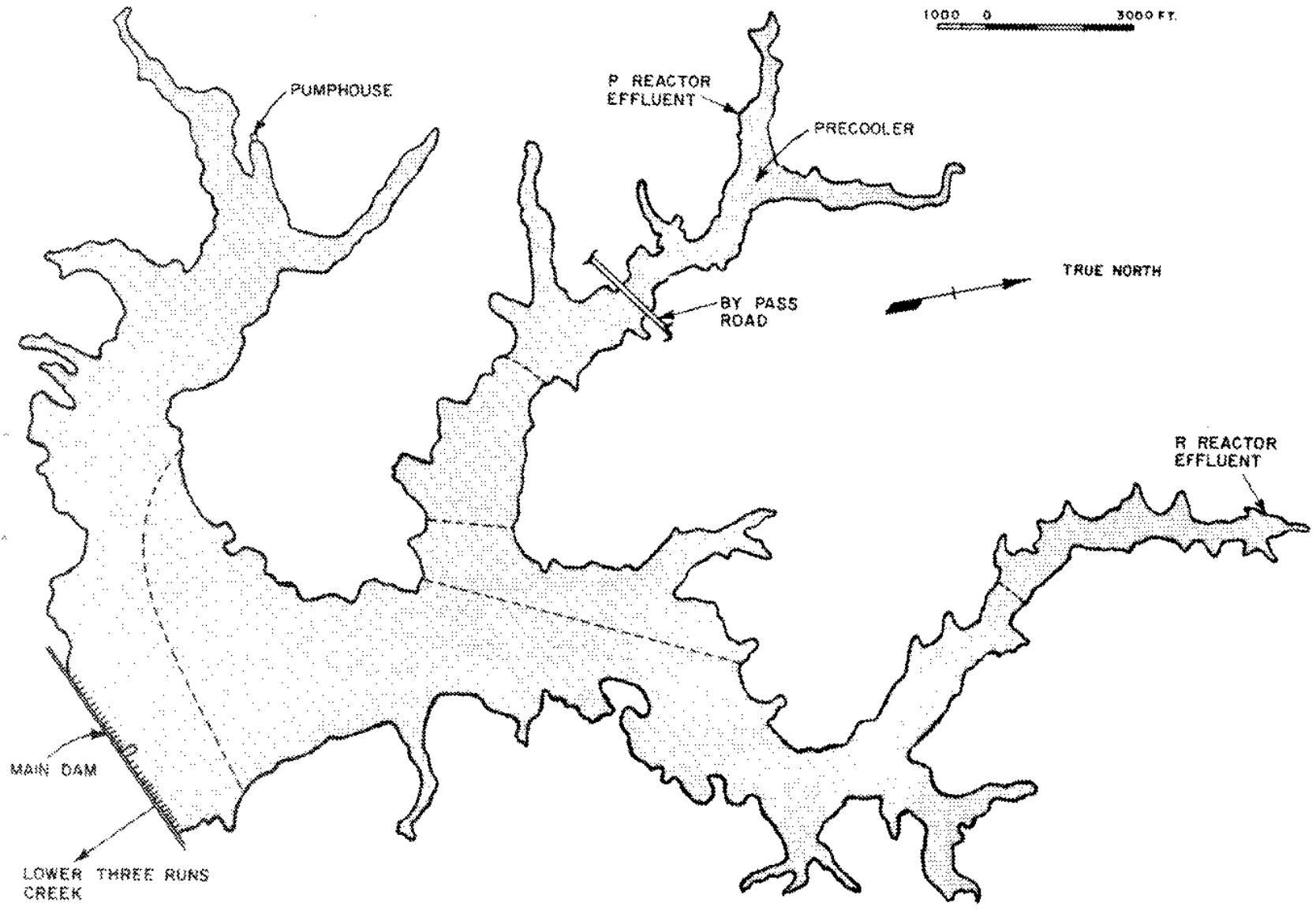

FIGURE 5. Par Pond Map 


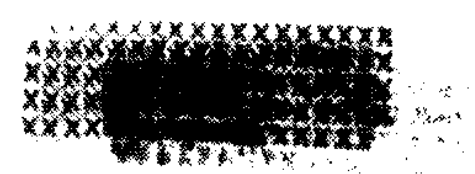

par pond contains about 18 billion gallons of water. At the rated capacity of the pump house this quantity corresponds to 45 days fox displacement; at $180,000 \mathrm{pgm}$ for P reactor only, it corresponds to 68 days.

\section{Nominal Performance of Par Pond}

The concern with pax pond is the extent to which the tempexature of the water is cooled before being pumped back to the reactor heat exchangers. Thus, over the years the effluent temperature from par pond has been compared with that of the Savanal kiver at SRP. As shown in Table IV, the effluent temperature from par pond has averaged about $3^{\circ} \mathrm{C}$ higher than the temperature of water from the river but at times it nay be as much as $7^{\circ} \mathrm{C}$ higher than the river. The study of Par pond has shown that the effluent temperature is within $\pm 2^{\circ} \mathrm{C}$ of the natural equilibrim temperature, and the water punped from par pond at a depth of $-20 \mathrm{ft}$ may be less tham the apparent equilibrium temperature because of stratification.

TABLE IV

Par Pond Effluent Temperature Compared with the River Temperature

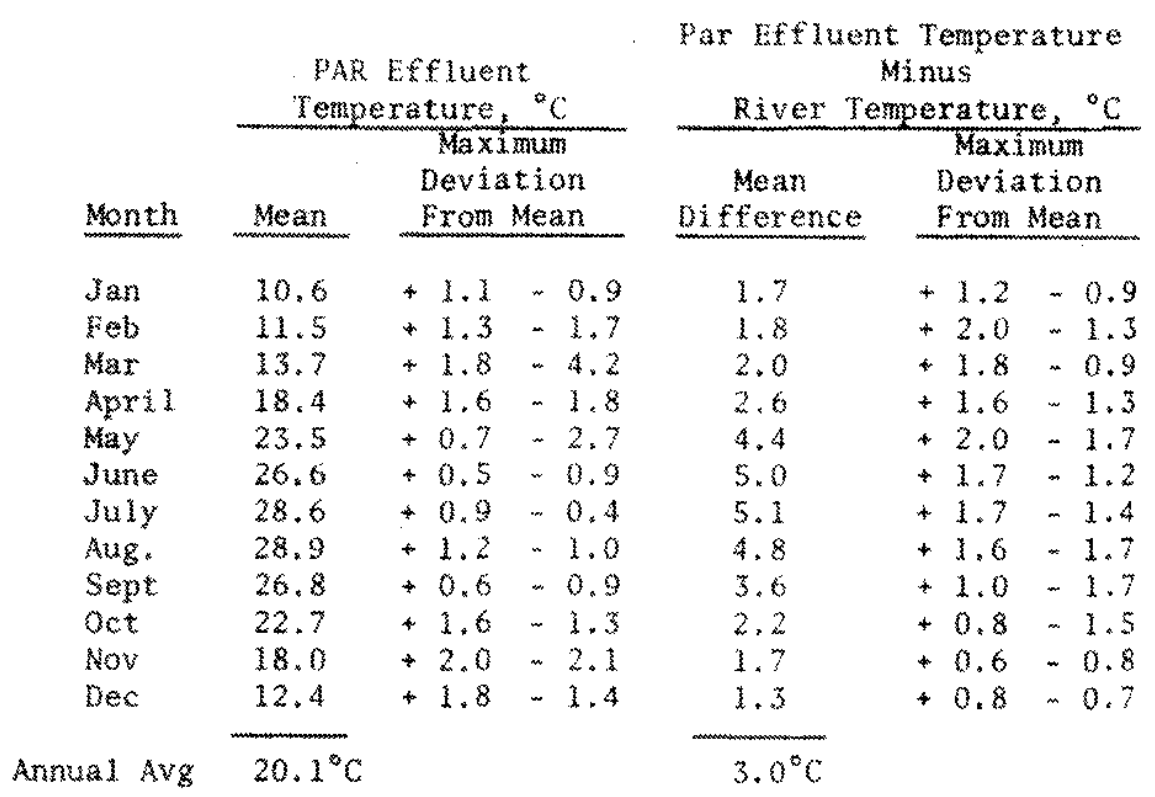

a. Monthly average values 1959 through 1965

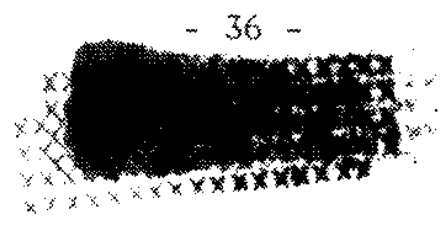




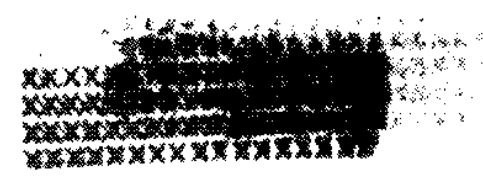

"We principal reason for the difference between par pond extuent temperature and the river temperature arises from the fact that the river is not at its natural temperature because of the Clark Hill Reservoin. The seven year average temperature of par Pond effluent, which is shown in Table IV to be $20.1^{\circ} \mathrm{C}$, is only $0.4^{\circ} \mathrm{C}$ higher than the average temperature of the Savamah kiver before construction of Clark Hill dan, i.e., from 1935 through 1950. The effect of Clark Hill Reservoix on the temperature of the Savannain River is discussed at more length later. Par pond is not sufficiently large and not sufficiently deep, particularly at the pump house intake slot, fox its performance to benefit greatiy from themal stratitication.

\section{Model of Par pond}

Observations at par pond, primarily by temperature traverses, have led to a model for a relatively deep cooling pond (figure 6). The pond is conceived as a rectangular channel having two regions of thow, namely, an upper flow region, which moves in the direction of the pump house from the inflow point, and a countexcurrent underHow. Wam water crom the canals at temperature $T_{i}$ enters the pond and inmediately mixes with a parts of undexflow at temperature Tp to give the temperature Tiu, which is the average temperature of the upperflow at the warm end of the pond. The underflow at Ty has travelad upstream from the cool end of the pond and is at the same temperature as the watex discharged from the pond through the pump house intake slot. The excess of the inflow over that whthdraw at the pump house overflows at the cool end of the pond as a temperature $r_{0}{ }^{*}$. The asterisk on the temperature symbol indicates that it is a surface temperature; the average temperature of the upperflow at the cool end of the pond is $\mathrm{T}_{0}$. Simim $\operatorname{lar} l y$, at the waxn end the surface temperature is Tu. The flow of vapot from the pond is considered as part of the overflow. The pond receives heat from the sun at the rate $\mathrm{H}_{\mathrm{S}}$ and experiences a gradual change in stored heat at the rate $\mathrm{K}_{\mathrm{C}}$; the quantity $\mathrm{H}_{\mathrm{S}}-\mathrm{H}_{\mathrm{C}}$ is uniformly distributed over the surface of the pond. HC is based on the average depth of the pond $(h=20.4 \mathrm{ft})$, not on the depth of the umperflow region, which is not specified. Because the depth of the wperflow region may be only a few feet, and because of the hich internal circulation (the u effect), the transit time from the warm and to the cool and of the pond may be about a day. As the upperflow traves from the warm end to the cool end of the pond, heat is dissipated to the atmosphere at the rate H, decreasm ing as the surface temperature decreases from $\mathrm{T}_{\mathrm{i}}{ }^{*}$ and $\mathrm{T}_{\mathrm{O}}$ * according to the sug flow model discussed in the next section. The difference beweer the surface temperature T* and the average temperature $T$ of the upperflow in a section normal to the upperflow is conm sidered to be constant everywhere in the pond; this difference has the symbol $\mathrm{Ar} G$. It is expected that this excess temperature at the

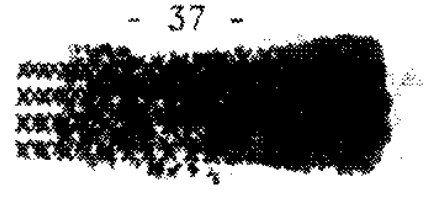


surface varies whth the season depending on the extent of themal stratification. As show in Figuxe 6, part of the runoff from rainfall (which is also the source of natural stream flow into the pond) mixes with the water in the canal system, while the balance enters the pond by other routes; the runoff is at the air wetwbulb tempexature, TWB.

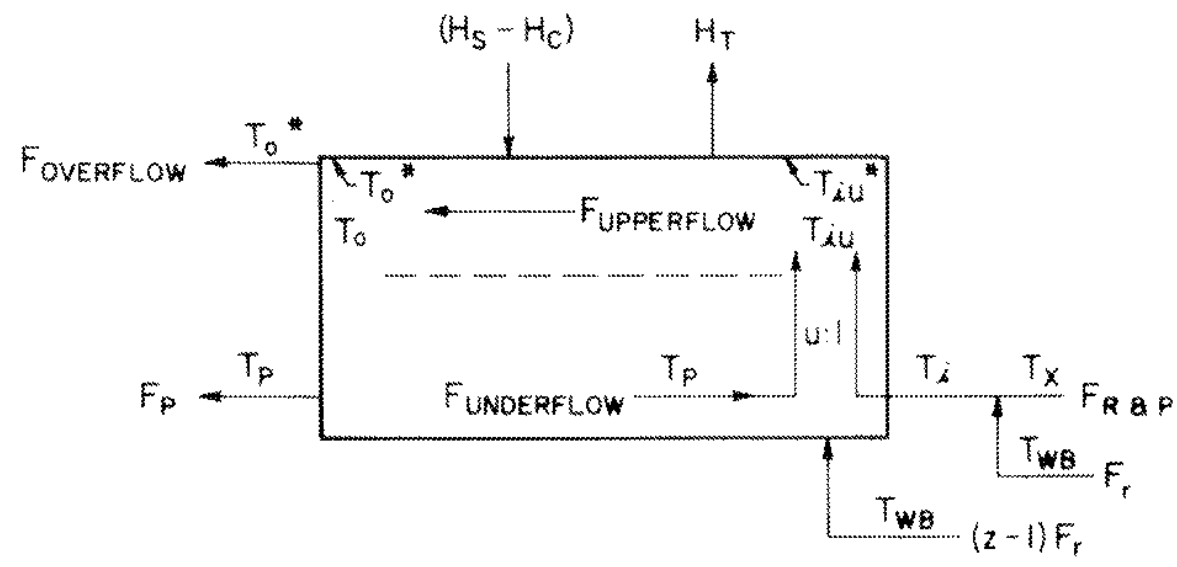

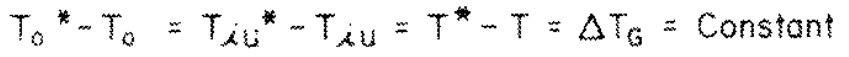

FIGURE 6. Model for par Pond

\section{Extension of the Theory to the Par Pond Model}

Consider the energy budget equation not only for the region of the upperflow but also for the region of the underflow. Only part of the solar heat load $H_{S}$ (say, the fraction $x$ ) and only part of the heat content rate-of-change $H_{C}$ (say, the fraction $y$ ) are assigned to the uppex region. For the underflow there is no surface heat transfer, $50100 \%$ of $\mathrm{HT}$ is assigned to the upperflow. Also, there is no change in temperature of the underflow as it moves from the discharge point (the pump house) to the inflow point at the warn end of the pond. Thus, there is an HF term only for the upper. flow. Whe two energy budget equations are consequently as follows:

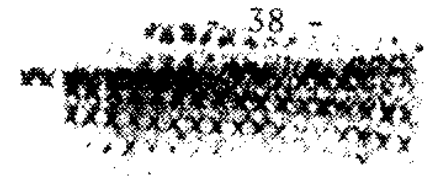


Upper hayer

$$
62.4 \text { yh } \frac{\partial \mathrm{T}}{\partial \theta^{2}}=\mathrm{XH} \mathrm{S}-500 \mathrm{~F} \text { upperflow } \frac{\partial \mathrm{T}}{\partial \mathrm{A}}-\mathrm{H}_{\mathrm{T}}
$$

Lower layex

$$
62.4(1-y) h \frac{\partial \mathrm{T}_{\mathrm{b}}}{\partial \theta}=(1-\mathrm{x}) \mathrm{h} \mathrm{s}
$$

Adding these equations gives the combined energy budget equation

$$
62 \cdot 4 h\left[y \frac{\partial T_{a}}{\partial \theta}+(1-y) \frac{\partial T_{b}}{\partial \theta}\right]=h_{S}-500 f_{\text {uppertow }} \frac{\partial T_{a}}{\partial A}-H_{T}
$$

The lefturand side of the combined equation is $h_{C}$ for the pond.

The quantity (l-y) aTb/a6 is generally more significant than the quantity y ara $/ 20$. Conseguently, since the discharge temperature Ty is also the temperature th of the lower layer, in the model for par pond, it is reasonable to measure the time rate of change in pond heat content by the time rate of change in the discharge temperature. Note that the fraction $x$ (ot the solax radiation that is absorbed in the upper layer) has dropped out of the comm bined exergy buget equation. Thus, whth the substitution of $\mathrm{HC}_{\mathrm{C}}$ for the left-hand side of Equation 24 , the energy budget equation for the par pond model appears the same as that presented above under Theory, where only a single region was considered. All of the solar energy and all of the pond heat content is considered to be in the upper layer.

Actually, the time rate of change in the temperature of the underayer is not determined just by the attenuation of the solar energy that occurs in that region. The quantity $\mathrm{XHg}$ Hr in the enersy budget equation for the upper layer varies greatly between night and day, being much more negative at night. (In this report, the $24-h x$ average has been used for $\mathrm{H}_{S}$ and $\mathrm{W}$ ). The colder water produced at the surface during the night is transported to lower levels by convaction in seeking stable stratification (see page 70 ). In effect, the solax heat that is absorbed in the lower layer is convensated by the downward transport of colder water to this region. To the extent that the solar heating in the lower layer is more than compensated by the diumal convection, $3 \mathrm{p}_{\mathrm{b}} / 3 \mathrm{~g}$ may be negative, as in the fall. The downard transport of colder water to the lower layer is accompanied by the upward transport of

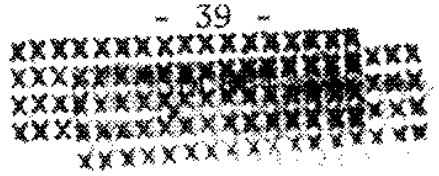


warmer water to the upper layer, in effect increasing the apparent solar heating in the upper layer. The combined energy budget equation above renains unchanged by this diurnal convection since the quantities xHs and (1-x)HS in the separate energy budget equations were the apparent solar heat loads, by whatever mechanism; and, in the combined equation, the value of the split assigned to the two regions for the solar heating contribution is unimportant. When diurnal convection is sufficient for the average $\partial T_{b} / \partial \theta$ to become negative, the average $\partial \mathrm{T}_{\mathrm{a}} / \partial \mathrm{O}$ is a lso expected to become "egative. In fact, at the "turnover" in the early fall, Ta has managed to drop below $T_{b}$ by virtue of ata/20 being more negative than atb/oe. The heat content rate-of-change $H_{C}$ for the pond is negative following the fall "turnover" as the pond temperatures decrease.

At the time of the fall "tumover," the pond contents undergo extensive mixing whereby the themal stratification that developed in the spring is largely, but not completely, destroyed. Asso, a temperature gradient must still exist from the inflow point to the pump house. The Par Pond model described above should apply just as well with negative $H_{C}$ as with positive $H_{C}$.

\section{Formulation of the Par Pond Model}

The total heat load per square foot of effective surface area that is imposed on the pond by the change in temperature of the flow through the pond, Ha, is derived by two independent methods (shown in Appendix A). First, $h_{F}$ is obtained by difference from consideration of the energy budget equation with $\mathrm{HS}_{\mathrm{S}}$ and $\mathrm{K}_{\mathrm{C}}$ constant and with Langhar's surface cooling rate averaged over the pond (Equation A-5). Second, HF is formulated directly from its definition (Equation $A-6$ ). Hy is then eliminated between Equation $A-5$ and $A-6$ to give Equation $A m 7$. Some of the variables in Equation Am?, however, are not directly measured; but they are readily derived by material and heat balances, from consideration of the model (Figure 6), in terms of other variables that are usually measured (except the quantity $\Delta \mathrm{T}_{\mathrm{G}}$ ). Thus, Equation $\mathrm{A}$. 13 a is obtained wich gives $\Delta T_{G}$ explicitly in tems of the average discharge temperature $T_{p}$ at the pump house during the time interval of d days, the average temperature $r_{1}$ of the water extering the pond from the canal systems, the average air wet. bulb temperature TWB, and the apparent equilibxium temperature $\mathrm{T}_{e}$, whoch is calculated by Equation 13 . The coefficients $\mathrm{K}_{0}, \mathrm{~K}_{2}, \mathrm{~K}_{3}$, $K_{4}$, and $K_{5}$ in Equation $A-13$ a are weighting factors applied to the five temperatures. These coefficients are functions of the average flow from $R$ and $P$ reactors ( $F_{R} p, g p m$ ), the average pump house flow (Fp, gpm), the rainfall ( $x$ inches during d days), the

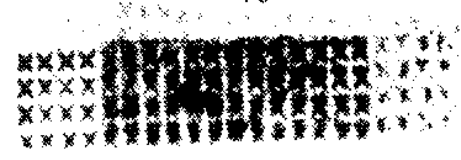


average weather conditions expressed in terms of the slope mand intercept $b$ (Equation 7 ), the solax heat load $\left(H_{S}\right)$, the pond atrenuation coefficient $(\alpha)$, and the mixing ratio at the warm and of the pond (u). Other factors are the ratio of total runoff to the runofinto the canal systems (2), the runoff fraction $\left(f_{x}\right.$ ), the pond area effectiveness factor $\left(f_{A}\right)$, and the pond heat content factor $\left(f_{C}\right)$.

In order to calculate the values for some of the coefficients in Equation $A-13$ and for the apparme equilibriun temperature te by Equation 13, it is necessary first to obtain the slope mand intercept b of the straight-line approximation to Langhaax's curve for the surrace cooling rate (Equations 4, 5, and 6). The line is fitted between the extremes in surface temperature in the pond, $T_{i u}{ }^{*}$ at the warm end and $T_{0}{ }^{*}$ at the cool end using Equations A-15 and $A-16$. The temperatures $T_{i} u^{*}$ and $T_{O}^{*}$ are calculated by Equations $A-1$ and $A-12$, which use $\triangle T G$; hence, a trialmand-error solution for the value of $\Delta T_{G}$ during the period of d days is required in order to place the straight line properly on the surface-coolingrate curve.

The rate of change in stored heat $H_{C}$ is also required in calculating the apparent equilibrium temperature $\mathrm{T}_{\mathrm{e}}$ by Eqation 13. The data on par pond performance did not include temperature traverses of the pond such as would be needed to estimate the heat content of the pond at the begiming and at the end of the interval of d days. It is therefore assumed that the change in the discharge temperature over the d days is a measure of the change in the average pond temperature, with the factor fo included for purposes of obtaning a bettex correlation if desired, Thus Ho is estimated by Equations 2 a and $A-14$.

The atcenuation coeficient $\alpha$, used in the coefricients of Equation A-13a, is calculated by Equation 16 a in terms of the slope m and the upperflow, which is calculated by Equation A-9.

The flow $F$ contributed to the discharge from the canal systems by mofef from rainfall is also needed to calculated the coescicients in Equation Am. 3 a and the upperfow. It is calculated by Equation A-17.

Thus, fata on par pond perfomance are evaluated so as to obtain a set os ATG values, say, according to the month of the year, using the correlating Equation A-13a. The data requixed are the weather conditions, the solar heating rate, the rainfall, the thow of effluent cooling water to the ponts, the average temperature of the water discharging fxom the canals into the warm end of the pond, the discharge flow at the pump house, and the average discharge temperature at the pump house. Also, importantly for $\mathrm{H}_{\mathrm{C}}$, the data inciude the discharge temperature $\mathrm{T}_{1}$ at the start of the interval of d days and the discharge cemperature $\mathrm{T}$ at the end of the interval. 


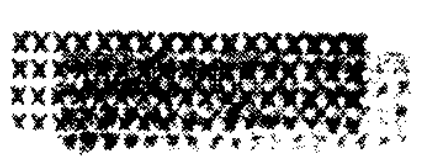

Having determined the set of $\Delta T_{G}$ values from the analysis of Par pond perfomance, it is then desired to axrange the correlating Equation A-13a so as to give the average discharge temperature $\mathrm{Tp}$ explicitly; then Tp can be calculated for other conditions of the weather, flows, and temperatures. Now, the temperature $\mathrm{T}_{1}$ at the start of the time interval will be known, but not the cemperature $T_{d}$ at the end of the interval. However, for a short enough interval of time, the average discharge cemperature Tp can be assuned to be equal to the average of $\mathrm{T}_{1}$ and $\mathrm{T} d$ (equation $\mathrm{A}-18$ ). Thus, Tp is given explicitly by Equation A-2l in terms of $T_{1}, T_{i}$, TWB, Tes, and $\Delta T_{G}$. Here, the equilibrium temperature res is approximately that for a stagnant shallow pond at steady state, calculated by Equation 10 using $m$ and $b$ values from the straight-line fit to Langhaar's curve at T $\mathrm{T}^{*} \mathrm{u}^{*}$ and $\mathrm{T}_{\mathrm{O}}$.

The arguments in favor of such a complex-appearing function as Equation $\mathrm{A}-13 \mathrm{a}$, togethex with its satellite equations for the $\mathrm{K}$ coefficients, for correlating the pond perfomarce, or Equation $A-21$ for predicting the pond performance, axe as follows: The numerous parameters must be considered if they are thought to have an appreciable effect on the pond effluent temperature. The equations that involve these parameters are the equations that express the physical phenomena according to the model envisioned in Figure 6; they are not mere empirical equations. The factors $u, f_{x}, z_{,} f_{A}$, and $f_{C}$ might be varied to obtain a bettex correlation, but the values of these factors must be reasonable; otherwise, a bettex model should be sought. These factors are not intended to be mere correlating constants. Moreover, the coefficients in the langharax Equations 5 and 6 are not legitimate areas for tamering merely co force a better fit to the data on pond perfomance. These equations give the heat and mass transfer rates to the atmosphere; the coefficients are determined only by consideration of these effects. Although the $\Delta T_{G}$ value may be regarded as merely a shift (to the left) of the Langhar cooling curve, it is tentatively believed that $\Delta \mathrm{T}_{\mathrm{G}}$ is related to thermal stratification and is not a correction to the surface cooling rate, In sum, the complex-appearing Equations Aw13a and A-21. for Par pond performance are a composite of the elementary considerations, such as, the rates of heat and mass transter, enexgy and material balance, mixing, staging, stratification, underflow, overflow, rainfall, and heat content, and are devoid of purely empirical factors and coefficients.

\section{Correlation by the Par Pond Model}

Data on par pond performance were avalable for the period January through May in 1964 in sufficient detall for evaluation by Equation $A-13 a$. These data and detalls of the analysis are presented in Table $V$. The ATG values by months were found to be as follows:

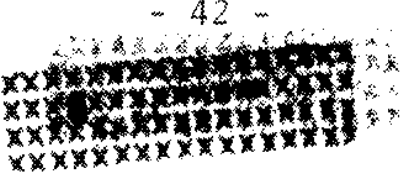




$\begin{array}{rrrrrr} & \text { Jan } & \text { Feb } & \text { Mar } & \text { Apr } & \text { May } \\ \mathrm{AT}_{\mathrm{G}}{ }^{\circ} \mathrm{C} & 1.2 & 1.1 & 1.7 & 2.6 & 1.9\end{array}$

where $\Delta T_{G}$ is the difference between the surface temperature and the average temperature of the upperflow. The trend is towaxd increasing $\mathrm{AT}_{\mathrm{G}}$ as summex is approached, as expected.

TMg.

Analysis of Par Pond nata According to the Moder

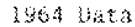

\begin{tabular}{|c|c|c|c|c|c|}
\hline Nomets & January & somary & March & Apsin & May \\
\hline$\{$ mo $\{a t \cos a\}$ b, days & 33 & 29 & 3 & 30 & $\vdots$ \\
\hline \multicolumn{6}{|l|}{ Menthis Average conditions } \\
\hline 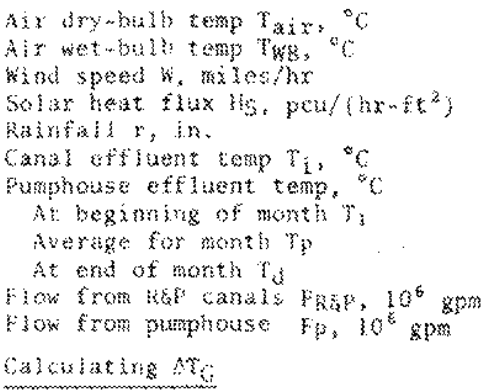 & $\begin{array}{l}10.06 \\
10.67 \\
11.0 \% \\
33.3182 \\
0.1847\end{array}$ & 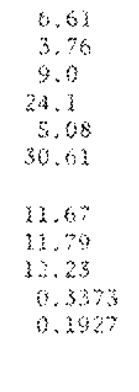 & $\begin{array}{l}32.23 \\
35.48 \\
36.43 \\
0.334 \\
0.5398\end{array}$ & $\begin{array}{c}18.04 \\
14.15 \\
7.3 \\
38.9 \\
3.24 \\
35.16\end{array}$ & $\begin{array}{c}23.22 \\
17.27 \\
7.3 \\
43.9 \\
4.20 \\
58.43\end{array}$ \\
\hline 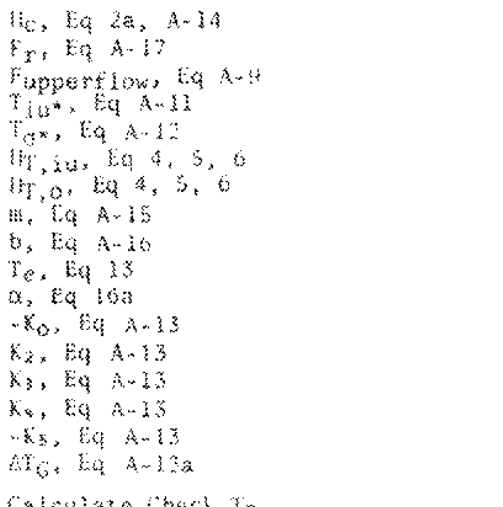 & $\begin{array}{l}2.75 \\
0.0097 \\
1.099 \\
10.00 \\
12.06 \\
54.22 \\
30.22 \\
5.06 \\
-30.7 \\
9.32 \\
1.002 \\
2.500 \\
0.30 ? \\
0.019 \\
2.123 \\
2.003 \\
1.19\end{array}$ & 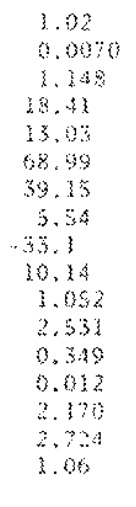 & $\begin{array}{l}9.19 \\
0.0082 \\
1.145 \\
2.32 \\
17.42 \\
60.72 \\
36.20 \\
6.19 \\
71.0 \\
35.21 \\
1.174 \\
2.630 \\
0.309 \\
0.013 \\
2.306 \\
2.838 \\
1.07\end{array}$ & $\begin{array}{c}8.37 \\
0.0070 \\
1.313 \\
26.64 \\
22.40 \\
69.84 \\
43.25 \\
6.75 \\
110.2 \\
20.86 \\
1.321 \\
2 . .22 \\
0.259 \\
0.010 \\
2.445 \\
3.020 \\
2.01\end{array}$ & $\begin{array}{c}3.26 \\
0.0058 \\
1.130 \\
29.94 \\
25.83 \\
73.35 \\
45.16 \\
7.31 \\
.143 .4 \\
24.50 \\
3.409 \\
2.765 \\
0.244 \\
0.007 \\
2.514 \\
3.007 \\
3.94\end{array}$ \\
\hline \multicolumn{6}{|l|}{ 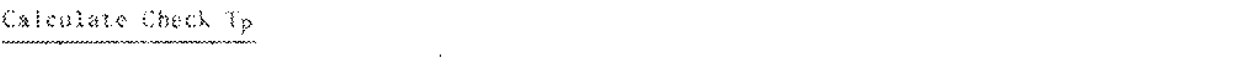 } \\
\hline 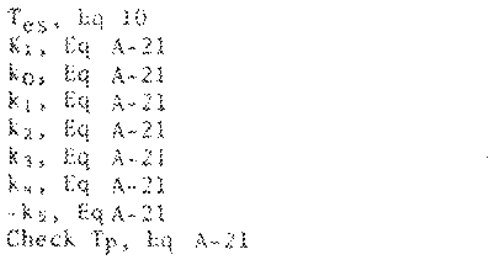 & $\begin{array}{l}9.85 \\
1.435 \\
3.348 \\
0.383 \\
0.093 \\
0.005 \\
0.538 \\
0.683 \\
10.24\end{array}$ & $\begin{array}{l}10.38 \\
3.43 \\
3.363 \\
0.308 \\
0.080 \\
0.003 \\
0.548 \\
0.687 \\
11.95\end{array}$ & $\begin{array}{l}3.36 \\
1.280 \\
3.310 \\
0.32 \% \\
3.079 \\
0.065 \\
0.560 \\
0.326 \\
15.10\end{array}$ & $\begin{array}{l}22.0 \% \\
1.283 \\
3.003 \\
0.320 \\
0.067 \\
0.002 \\
0.611 \\
1.254 \\
29.19\end{array}$ & $\begin{array}{l}25.63 \\
3.17 \% \\
3.942 \\
0.299 \\
0.062 \\
0.002 \\
0.638 \\
0.763 \\
23.56\end{array}$ \\
\hline 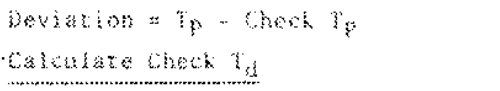 & $-0.0 \%$ & -0.06 & +0.38 & +3.30 & +0.04 \\
\hline 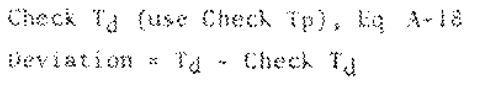 & $\begin{array}{l}11.23 \\
+0.25\end{array}$ & $\begin{array}{l}12.03 \\
+0.20\end{array}$ & $\begin{array}{l}\{7.9 \% \\
1.54\end{array}$ & $\begin{array}{l}21.8 \% \\
-0.82\end{array}$ & $\begin{array}{l}20.07 \\
0.3 \%\end{array}$ \\
\hline
\end{tabular}




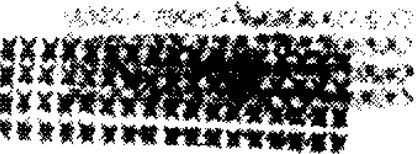

For the analysis in table $V$ the following parameters were specified as being reasonable values: the runoff factor, $f_{x}=$ 0.25 ; the ratio of the total wunof to the runoff into the canals, $z=2.71$; the pond area effectiveness factor, $f_{A}=1.0$; and the pond heat content factor, $f_{C}=1.0$. The mixing ratio $u$ at the warm end of the pond was taken to be 2.3 , which is the average of 13 values estimated from temperature traverses made in 1959.

The $\Delta T_{G}$ values calculated above from the 1964 data are consistent with observations made in 1959 of the thermal stratification in par pond, as shown in Figure 7. The difference between the surface temperature and the average temperature over a 20 - ft depth, calculated from these 1959 data, are given in rable VI. These differences should be greater than $\Delta \mathrm{T}_{\mathrm{G}}$, since the depth of the underflow is not thought to be as great as $20 \mathrm{ft}$; but the values are seen to be remarkably similar. Thus, for the months in 1959 in which temperature profiles in depth were taken, the difference between the surface and the average temperature over a 20 ft depth was as follows:

\begin{tabular}{|c|c|c|c|c|c|c|}
\hline & Jan & Apr & May & June & July & Aug \\
\hline$\Delta \mathrm{TG}_{\mathrm{G}},{ }^{\circ} \mathrm{C}$ & 0.4 & 0.6 & 2.2 & 1.4 & 2.6 & 2.0 \\
\hline
\end{tabular}

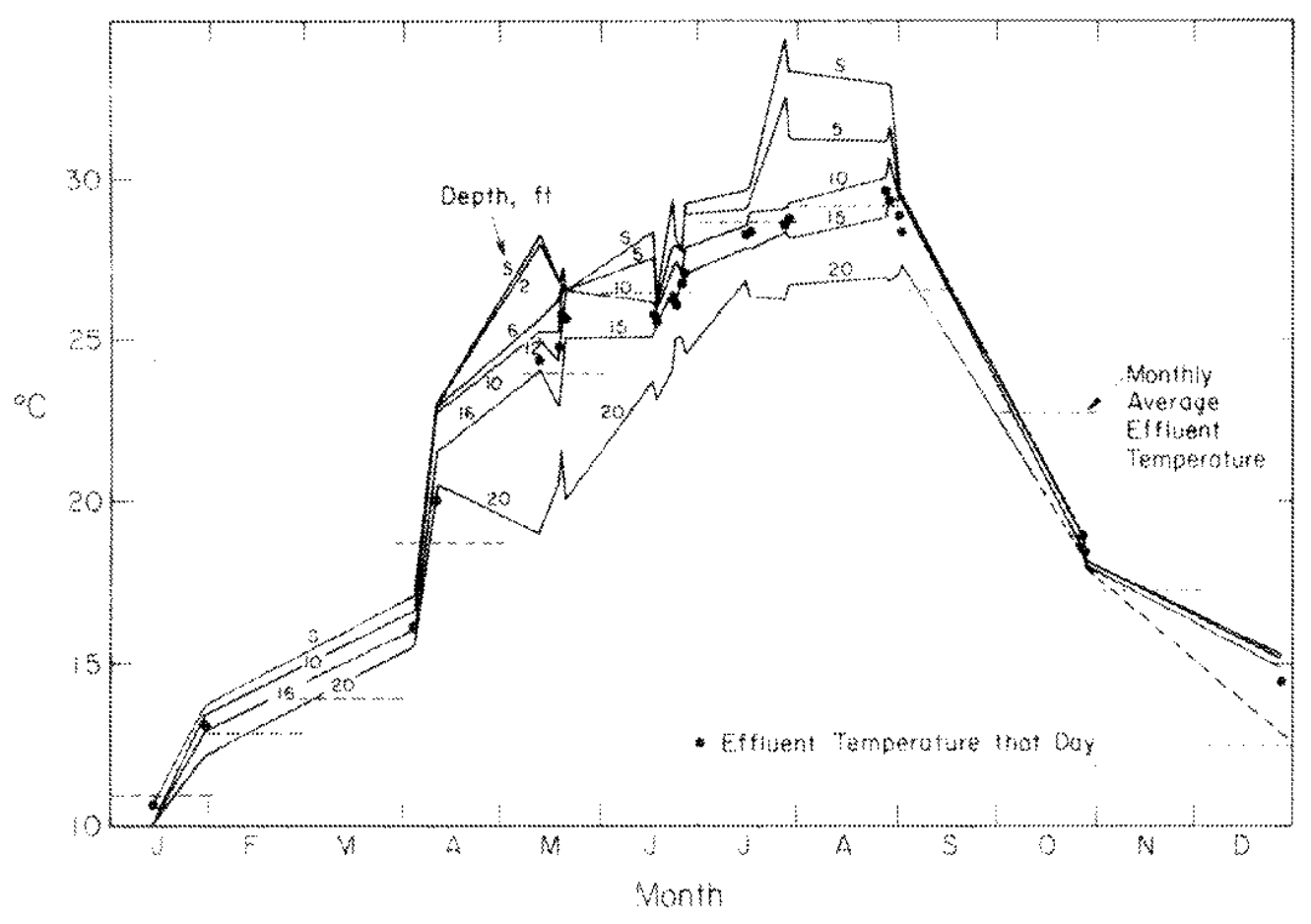

FIGURE 7. Stratification in Par Pond 
TABLE VI

Stratification in Par Pond

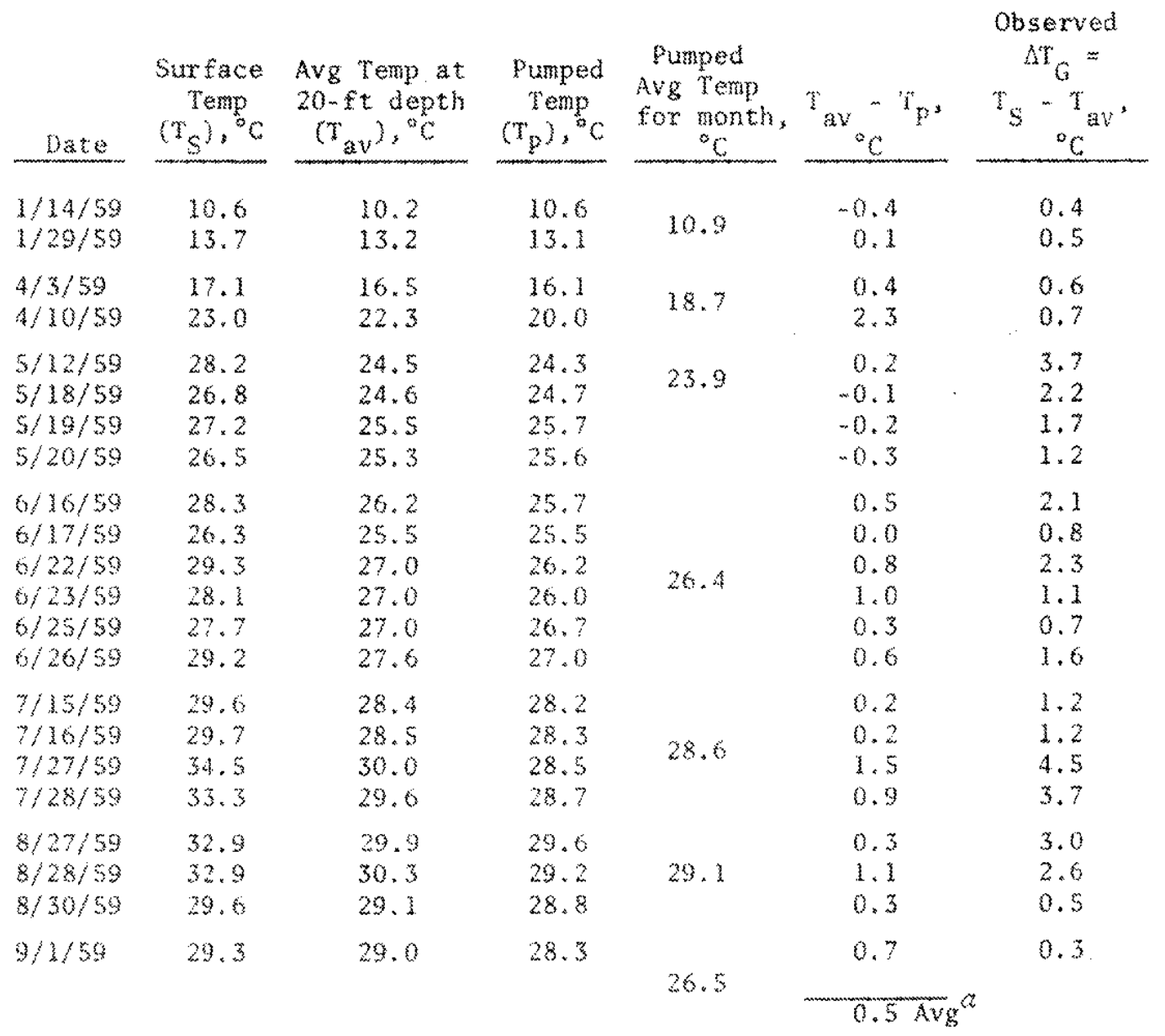

a. The temperature of the water whthraw at the mump house (Tp) averaged $0.5^{\circ} \mathrm{C}$ lower than the average temperature from the surface to a 20 fo depth $\left(\mathrm{T}_{2 \mathrm{y}}\right)$. This may have been due to selective withdrawal from the stratified reservoin, or it nay be the result of wind stress (in view of the wide variation in $T_{a v}-T_{p}$.

$-45-$ 
The period of appreciable thermal stratification is shown in Figure 7 to be from April through August. In the light of the results obtained by application of Equation Aw13a to the 1964 data and the observations in 1959, it is suggested tentatively that $\Delta T_{G}$ be taken as $1^{\circ} \mathrm{C}$ from september through March and as $2^{\circ} \mathrm{C}$ from April through August.

The correlation in tems of these $\Delta T_{G}$ values is given with some reservations. First, the variation in $\Delta \mathrm{T}_{G}$ is substantial, As shown in Equation A-21 che average discharge temperature $\mathrm{Tp}$ depends linearly on $\Delta T_{3}$ with a coefficient $k_{5}$; Table $V$ shows $k 5$ to be about -0.7 . Thus, an uncertainty of $1^{\circ} \mathrm{C}$ in $\Delta T_{G}$ means an uncertainty in $\mathrm{T}_{\mathrm{p}}$ of $0.7^{\circ} \mathrm{C}$, which is substantially greater than what is hoped for in the prediction of pond pexformance. of greater concern, however, are the fuctuations that are observed in the pond discharge temperature. The fluctuation in the discharge temperature from par pond recorded daly from January through May in 1964 is shown in Figure 8. The fluctuation is attributed more to fluctuating wind stress at the surface of the stratified pond than to the fluctuations in the weather and in SRP operating conditions. More is said about wind stress latex under "Areas for Further Investigation." For the analysis given in Table $V$, the data were averaged for onemonth intervals. The temperatures $\mathrm{T}_{1}$ and $\mathrm{T}_{\mathrm{d}}$ wexe the average of the three days prem ceding and the three days following the start of the month, in oxder to iron out some of the fluctuation. These temperatures are the circled points joined by dashed lines on figure 8 . The average discharge temperature tp for the month is shown in Figure 8 by the horizontal dashed lines. It is seen that the afference between $\mathrm{T}_{\mathrm{p}}$ and average of $\mathrm{T}_{1}$ and $\mathrm{T}_{\mathrm{d}}$ is as follows by months:

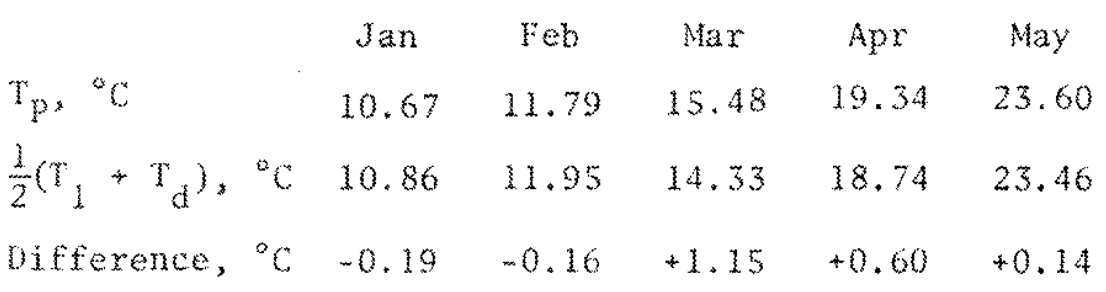

The difference is greatest in March and April. As shown in Table $V$,

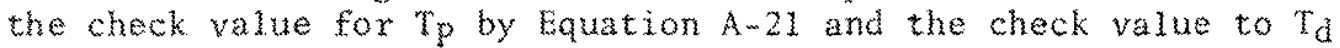
by Equation $A-18$, when using the $\Delta T_{G}$ values calculated in Table $V$, show the greatest deviations for March and April. 


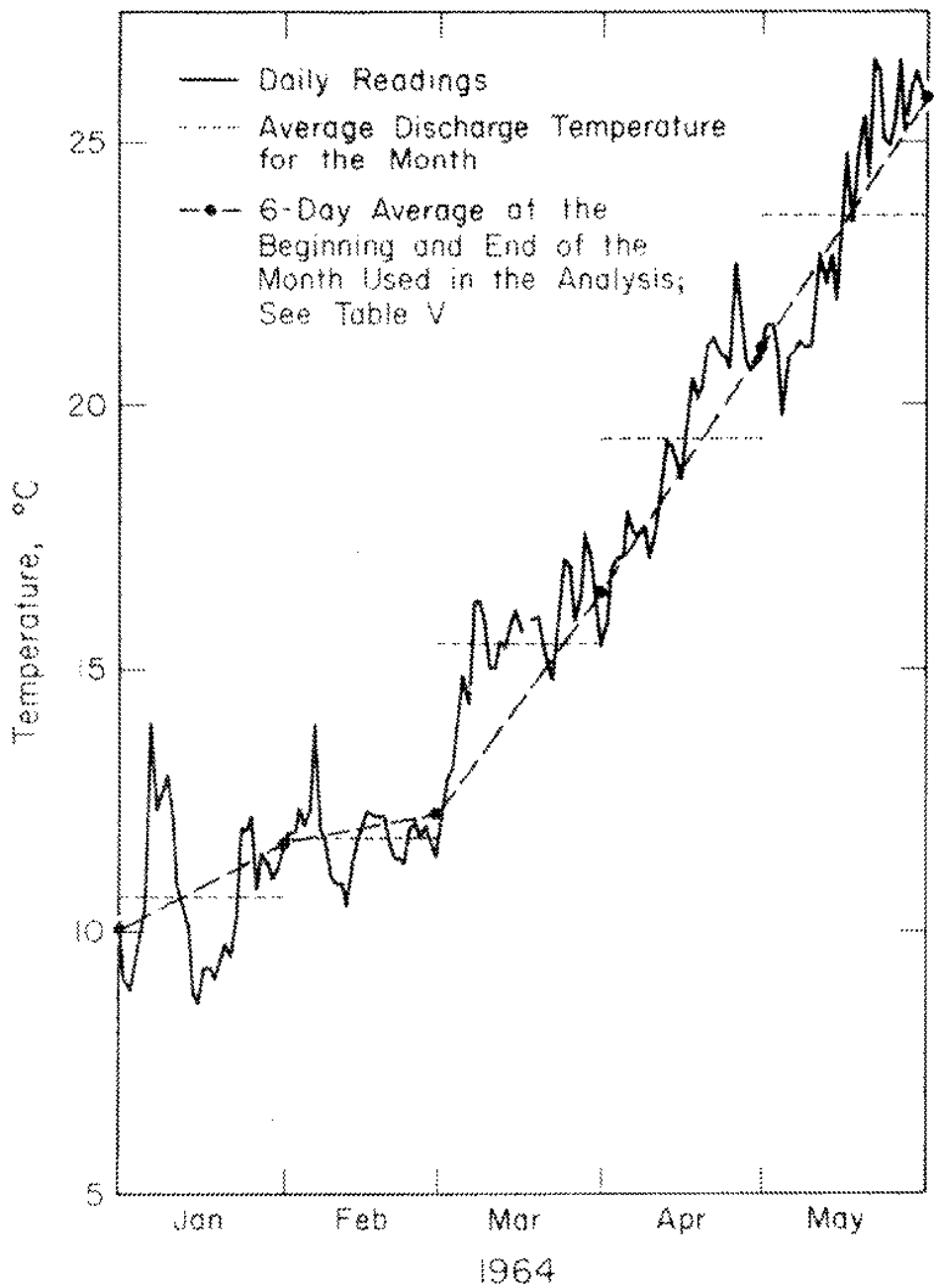

FIcuRE 8. Par Pond Temperature, Jamuary Through May 1964 


\section{The Energy Budget for Par Pond}

The average values for the quantities $\mathrm{H}_{\mathrm{S}}, \mathrm{H}_{\mathrm{C}}$, Hg, and $\mathrm{H}_{\mathrm{q}}$ in the energy budget for Par pond for the months of January through May 1964, from the analysis given in 'able $v$, are as follows:

\begin{tabular}{lcc} 
& \multicolumn{2}{c}{ pets $/\left(\mathrm{hrmt}^{2}\right)$} \\
& $\mathrm{H}_{\mathrm{S}}-\mathrm{H}_{\mathrm{C}}+\mathrm{H}_{\mathrm{F}}=\mathrm{H}_{\mathrm{T}}$ \\
Jan & $19.1-2.7+23.9=40.3$ \\
Feb & $24.1-1.0+28.4=51.5$ \\
Mar & $30.0-7.2+25.8=48.6$ \\
Apr & $38.9-8.2+21.7=52.4$ \\
May & $43.9-8.3+21.3=57.0$
\end{tabular}

$H_{S}$ and $H_{C}$ come directly from Table $V$; $H_{p}$ is calculated by Equation A-6 and $H_{T}$ by Equation Am4. The Imposed heat load HF from the flow is relatively constant while the solar heat load hs more than doubles as sumex is approached. The imposed heat load Hp exceeds the solar heat load in winter, but is only about hall the solar heat load as sumer is approached. The heat load $\mathrm{HC}_{\mathrm{C}}$ from the change in stored heat varies $8 \mathrm{~m}$ fold, but does not exced $25 \%$ of the solar heat load.

The energy budget diagram for the month of May 1964 is given in Figure 9. The diagram shows the variation in surface heat flux ${ }_{1} \mathrm{~T}$ as the surface temperature varies from $\mathrm{T}_{1}{ }^{*}$ to $\mathrm{T}_{\mathrm{O}}{ }^{*}$. The imm portant effect of the mixing ratio in reducing the canal effluent temperature $T_{i}$ to the pond temperature $\mathrm{r}_{\mathrm{i}}$ at the warm end is avident. Note also the effect of $\Delta T_{G}$ in shifting to a highex surace heat transfer rate, and note the differences between $\mathrm{T}_{\mathrm{p}}$ $\mathrm{T}_{\mathrm{e}}$, and $\mathrm{T}_{0}$. This information has been translated in Figure 10 to show the variation in the pond heat transfer rate over the surface area. 


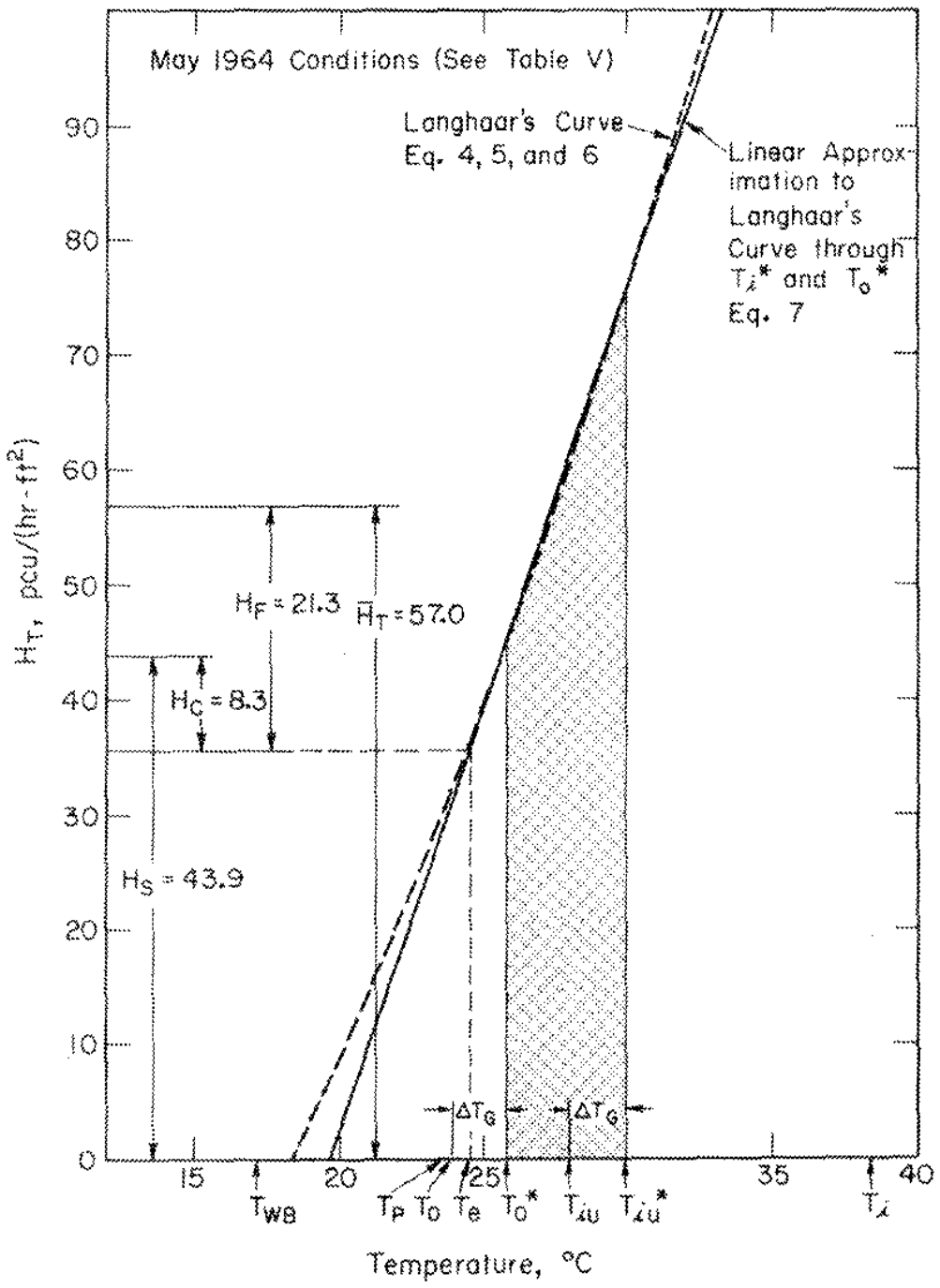

FUGRE 9. Energy Budget Diagram for Par Pond 


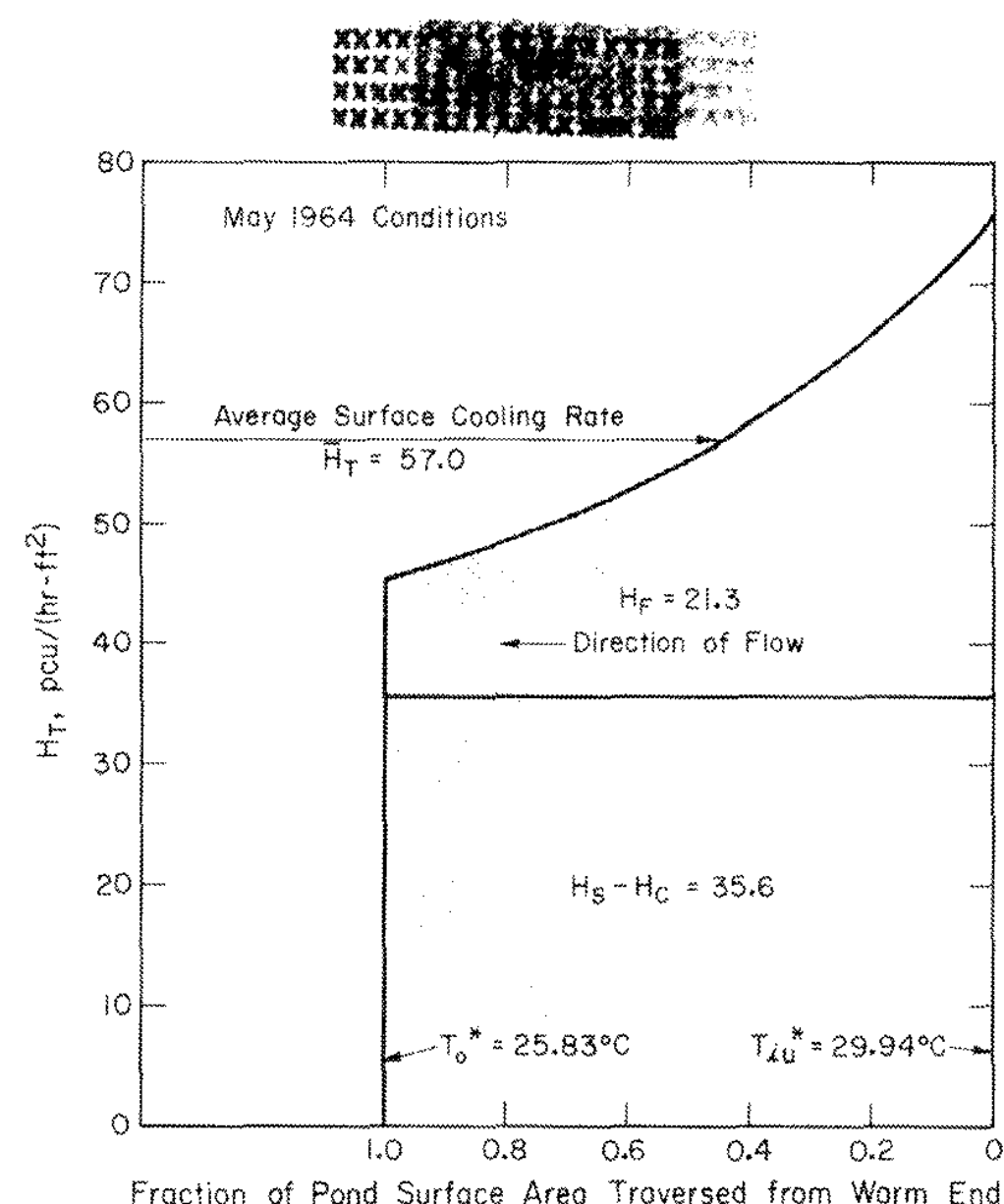

FIGURE 10. A Variation of the Energy Budget Diagram

The Approach to Equilibrium Temperature in Par Pond

The surface tempexature $T_{0}$ * calculated for the cool end of Par pond in Table $V$ exceeded the natural equilibrium cemperature for those months (Figure 1), but barely in April $\left(0.4^{\circ} \mathrm{C}\right.$ ) and in May $\left(0.2^{\circ} \mathrm{C}\right)$. The surface tempexature $T_{0}^{*}$ compares with the natural equilibrium temperature and with the apparent equilibrium temperature as follows:

$\begin{array}{lllllll} & & \text { Jan } & \text { Feb } & \text { Mar } & \text { Apr } & \text { May } \\ \text { Surface tamperature }{ }^{*}{ }^{*},{ }^{\circ} \mathrm{C} & & 12.1 & 13.0 & 17.4 & 22.4 & 25.8 \\ \text { Natural equil temp (Figure 1), }{ }^{\circ} \mathrm{C} & 9.6 & 10.0 & 16.2 & 22.0 & 25.6 \\ \text { Apparent equil temp (Table V), } \mathrm{T}_{\mathrm{e}},{ }^{\circ} \mathrm{C} & 9.3 & 10.1 & 15.2 & 20.9 & 24.5\end{array}$

The natural equilibrium temperature was defined above as the steadystate temperature for a shallow stagnant pond. The apparent equilibrium temperature may be greater or less than the natural equilibrium temperature depending on the magnitude and sign for 


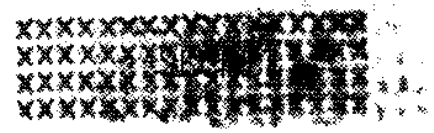

the rate of change in stored heat $\mathrm{H}_{\mathrm{C}}$ and on the deviation of the straight-line fit to langhaar's curve in the vicinity of $H_{\mathrm{T}}=\mathrm{HS}_{\mathrm{S}}$ - H. In April and May, the apparent equilibrium temperature was lower than the natural equilibrium temperature by about 1. ${ }^{\circ} \mathrm{C}$. Remember that the surface cooling rate in par pond is proportional to the difference between the water surface temperam ture and the apparent equilibrium temperature, according to Equations 12 and 13 . It is possible, as explatined above in connection with the concept of an apparent equilibrium temperature, for the surface temperature of a deep cooling pond to be less than the natural equilibrium temperature.

\section{Selective Withdrawal from Par Pond}

Selective withdrawal from a stratified reservoix is claimed if the discharge temperature is lower than the avexage temperature to the deptir of the intake slot at the pump house. Data taken on occasion in the vicinity of the pump house (i.e." in the "intake chamel") to relate the discharge tempexature to the vertical profile of temperature in pax pond have been inconclusive. The andasis of Pax pond performance, however, does infer selective whtherawal. Thus, by Equations $A-1 B$ and $A w 12$, the difference between the average temperature of the upperflow at the cool end of the pond and the discharge temperature realized at the pump house is formulated to be

$$
T_{0}-T_{P}=\left(\frac{R_{q P}+2 F^{2}-F_{p}}{u\left(F_{R q p}+F_{r}\right)+F_{p}}\right) \Delta T_{G}
$$

From the data in rable $V$ the values of $\left(T_{0}-T_{p}\right)$ are as follows (rox 1964):

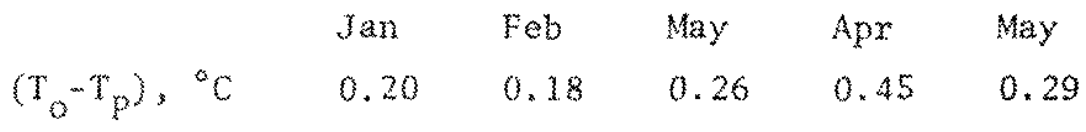

Fox comparison, the 1959 data given in Table VI showed the discharge tempexature to average $0,5^{\circ} \mathrm{C}$ below the average temperature over a $20-f$ depth.

\section{COOLING IN THE SRP STREAMS}

\section{Description of the SRP Effluent Streams}

A map of the streams on the SRP site that are used to conduct the esfluent cooling water from the reactors - specifically, $C, K$, and b reactors - to the swamp in the Savannah Rivex flood plain is given in Figure 11. Four Mile Creek can be followed from C reactor 


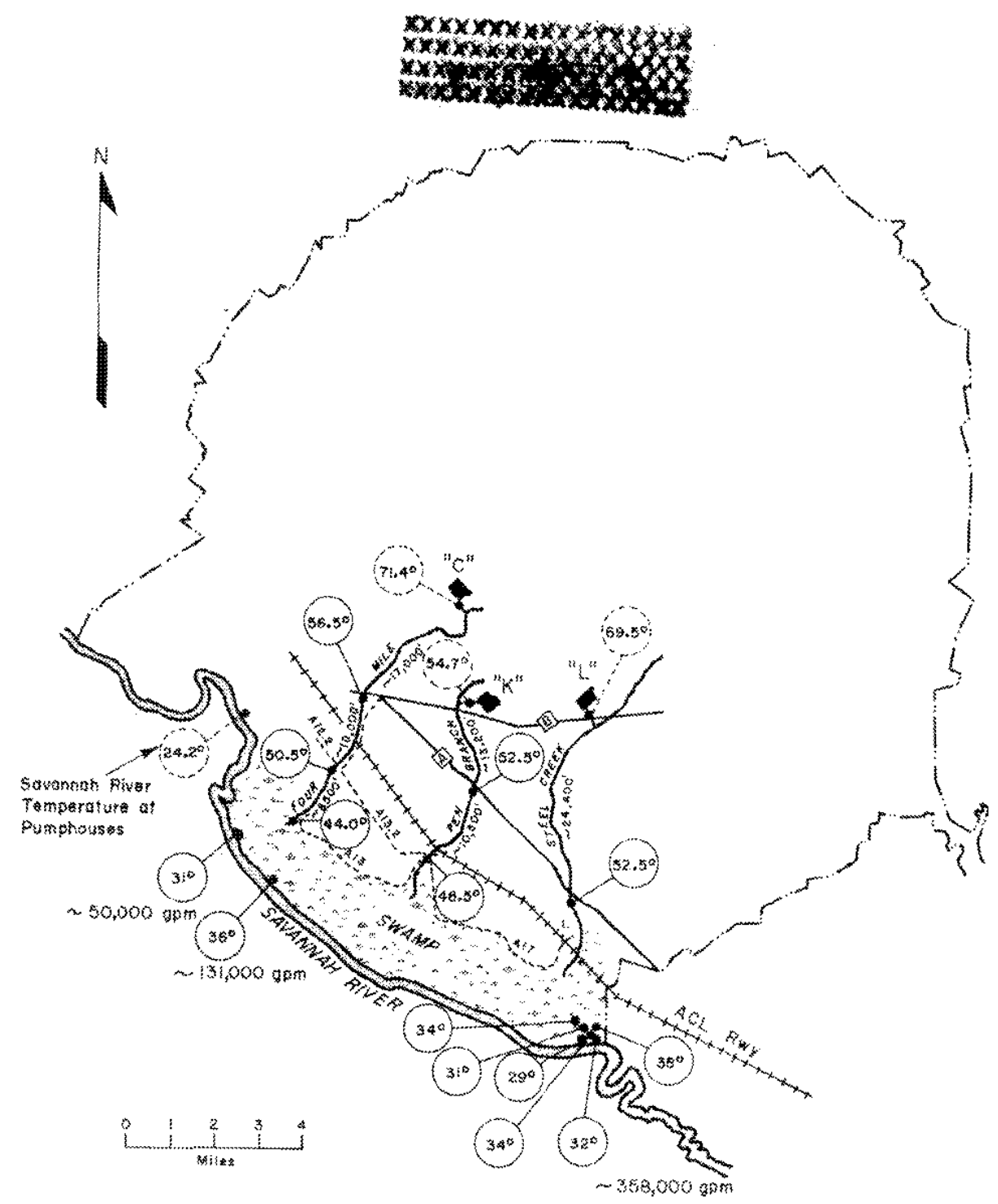

FIGURE 11. Temperatures Along $C, K$, and L Effluent Streams to the Savannah River

for a distance of about 6.7 miles, at which point it disappears into the swamp. Pen Branch can be followed from $K$ reactor for a distance of about 4.5 miles to the swam, at which point it is still about 3 miles from the river. After penetrating the swamp about 1.5 miles, the main portion of pen Bxanch appears to make a right-angle turn and to nore-ox-less parallel the river for a distance of about 5 miles until it joins steel creek about 0.5 miles from the outlet at the river. Steel Creek can be followed from $L$ reactor for a distance of about 4.6 miles to the swanp. at which point it is about $3.4 \mathrm{miles}$ from the river. The width of these streams is about 150 et in the vicinity of the reactors, widening to about 400 ft as the swamp is approached, with numerous islands. The natural flow in these three streams duxing the summer is small compared to the imposed flow of effluent cooling water from the reactors. 


\section{Performance of the SRP Effluent streams}

Temperatures observed along the three effuent streams in August 1966 have been spotted on the map (Figure 11). The surface cooling rate predicted by Equations 4,5 , and 6 for the weather conditions are given in Figure 12. Assuming slug flow and a zero rate of change in stored heat, as was done above the SRP effuent canals, the effective areas of the stream between any two points where the temperature is known can be calculated by Equation 14 . The effective areas between temperature points from Figure 11 are given in Table VIT. These areas, together whith Equation 14, constitute the correlation for the cooling process in the SRP effluent streams. Using these areas, the temperature of the $\mathrm{C}, K$, and $L$ effluent water at the points shown in Figure 11 along the streams leading to the swanp can be calculated for othex combinations of reactor power, rivex temperature, cooling water flow, air temperature, humidity, and wind speed.

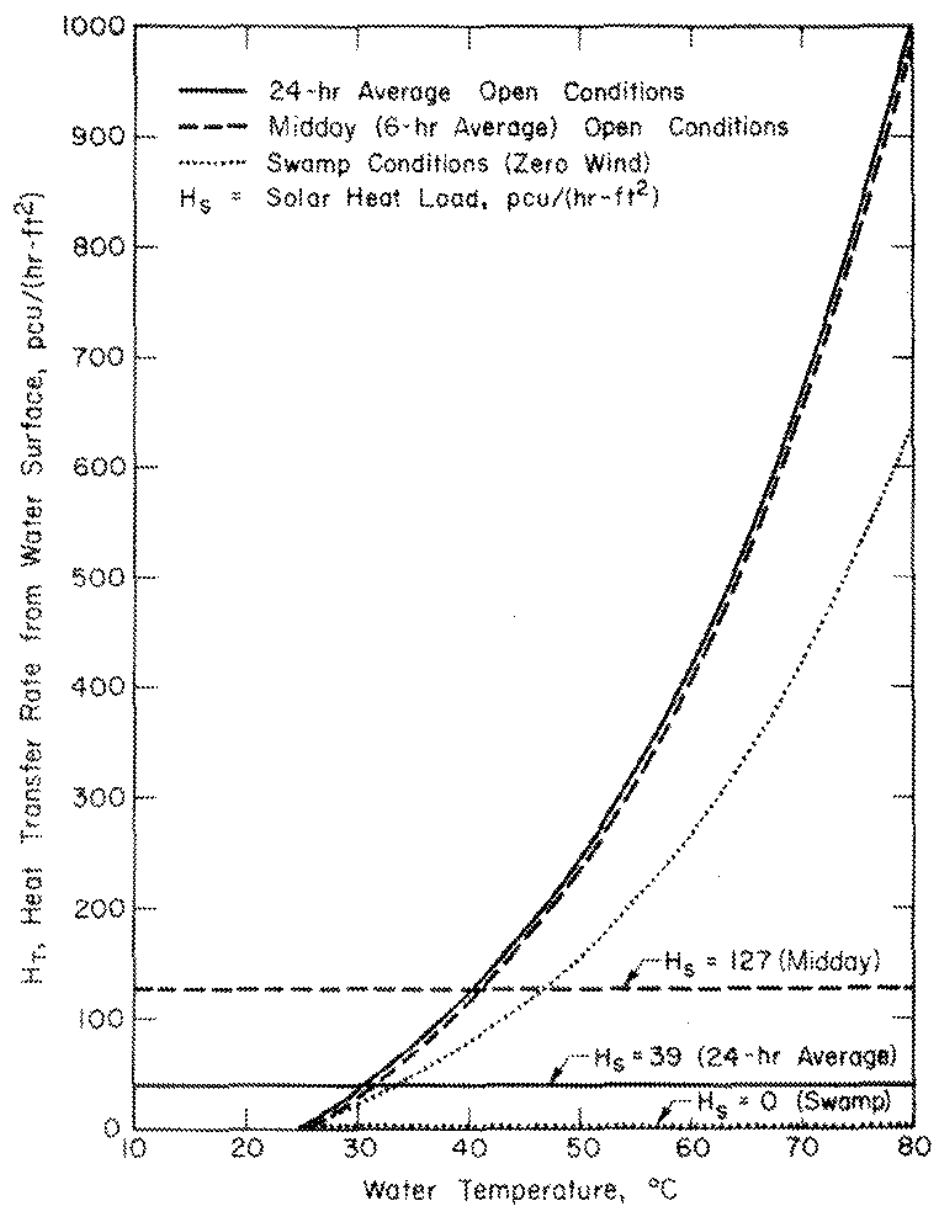

FIgURE 12. Surface Cooling Rate, August 1966

(The difference between open conditions and swamp conditions is destribed on page page 60.)

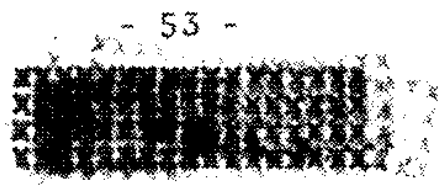




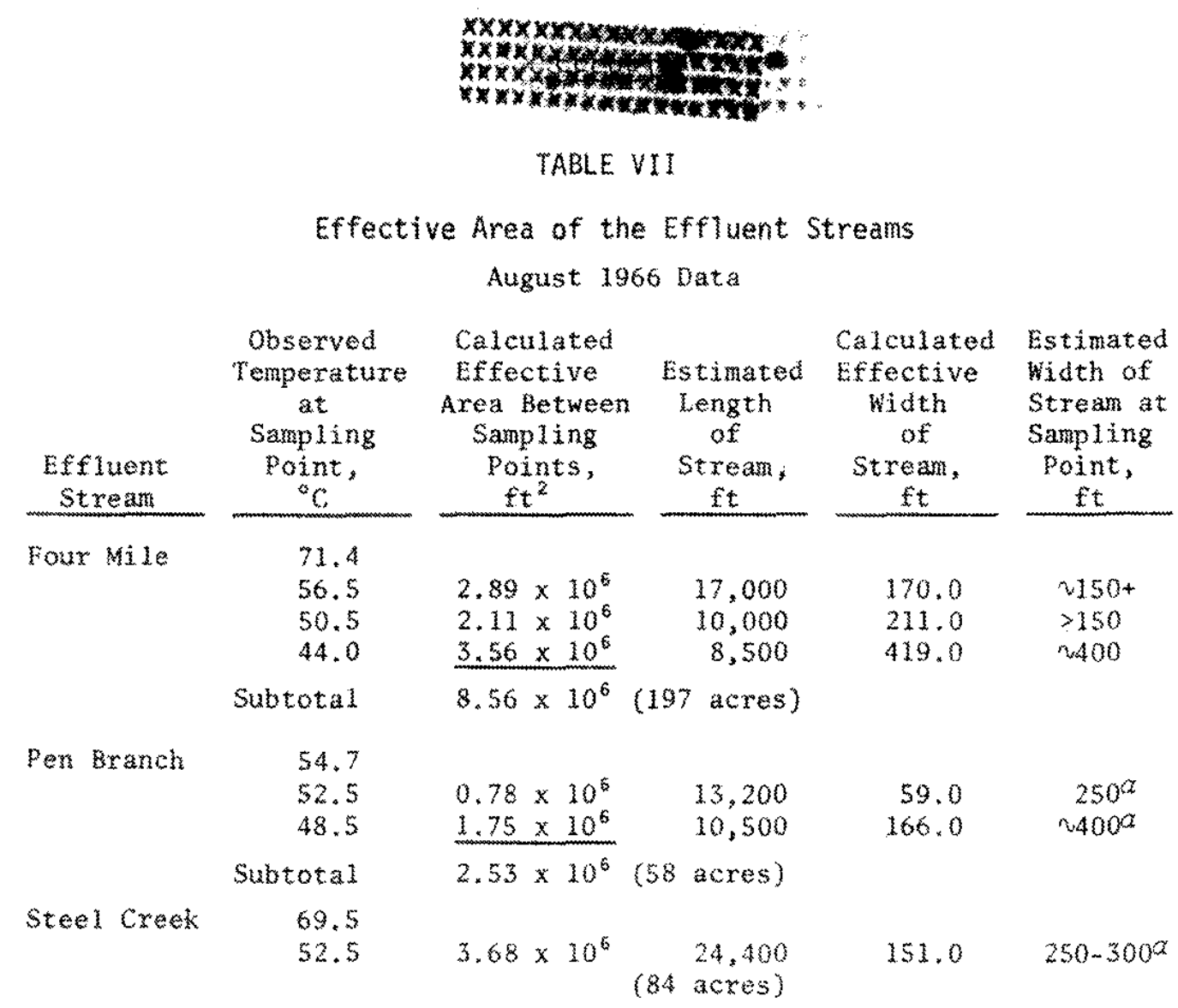

Q. This estimated width did not allow for the numerous islands.

From the effective area and the estimated length of the stream between temperature points, the effective width of the stream can be calculated for that reach. The comparison of the effective widths with rough estimates of the width of the streams is also given in Table VIX. Considexing that the actual streams have numerous islands, the comparison is satisfactory.

\section{COOLING IN THE SRP SWAMP}

\section{Description of the SRP Swamp}

A swampy region lies in the flood plain along the Savannah River for a distance of about 10 miles, averaging about $1.5 \mathrm{mi}$ in breadth, for a total area of about $15 \mathrm{mi}^{2}$. The location of the swamp in relation to the SRP boundaxies and to the three streams that conduct reactor effluent watex into the swamp is shown in Figure 11. Aerial photographs of the swamp are given in Figures 13, 14, and 15. They show a mottled region of wet areas and areas of forest and other vegetation.

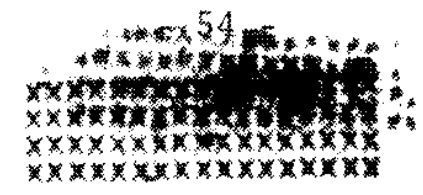




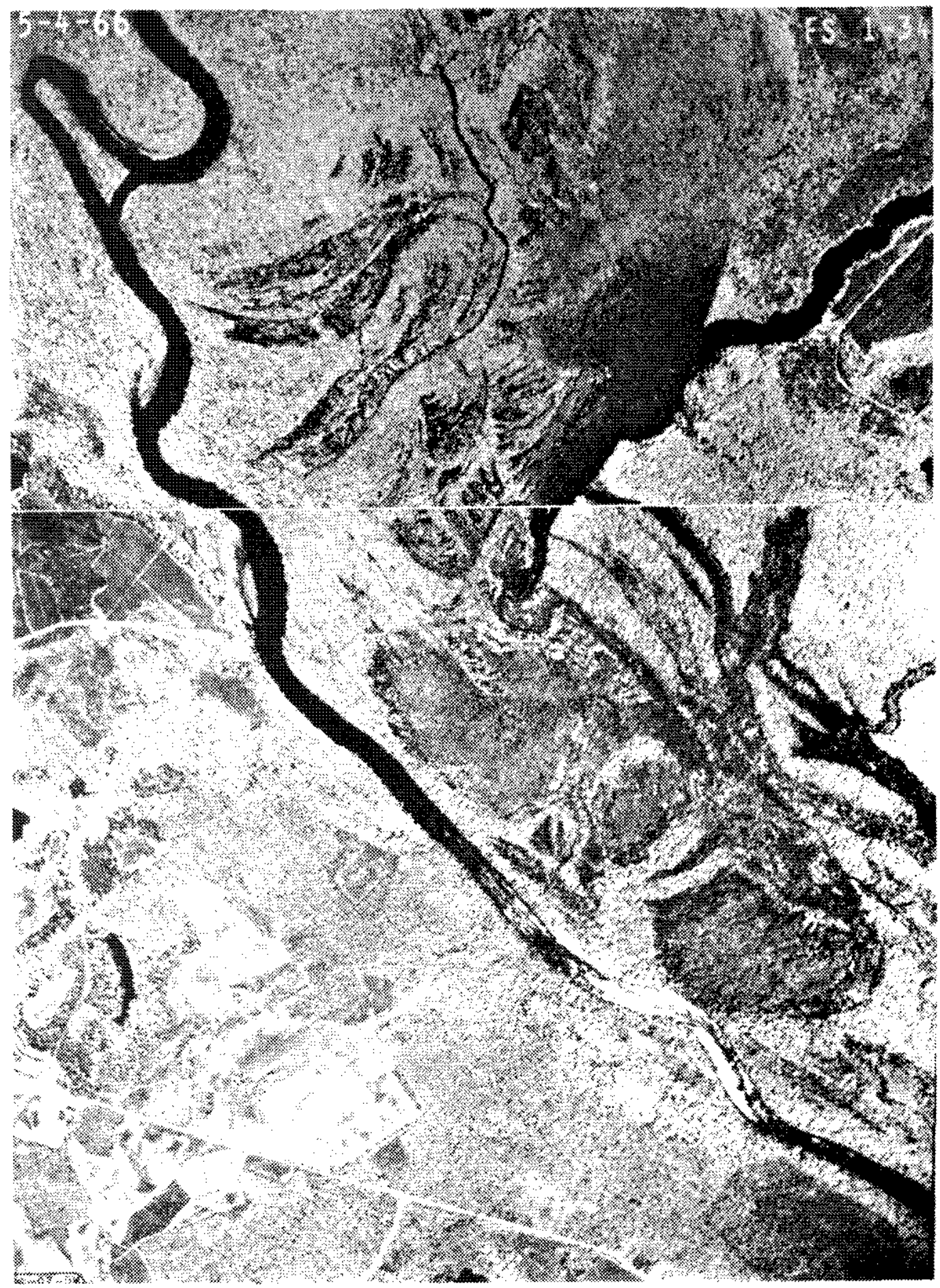

FIGURE 13. Aerial View of Four Mile creek outlet into the SRP Swamp 


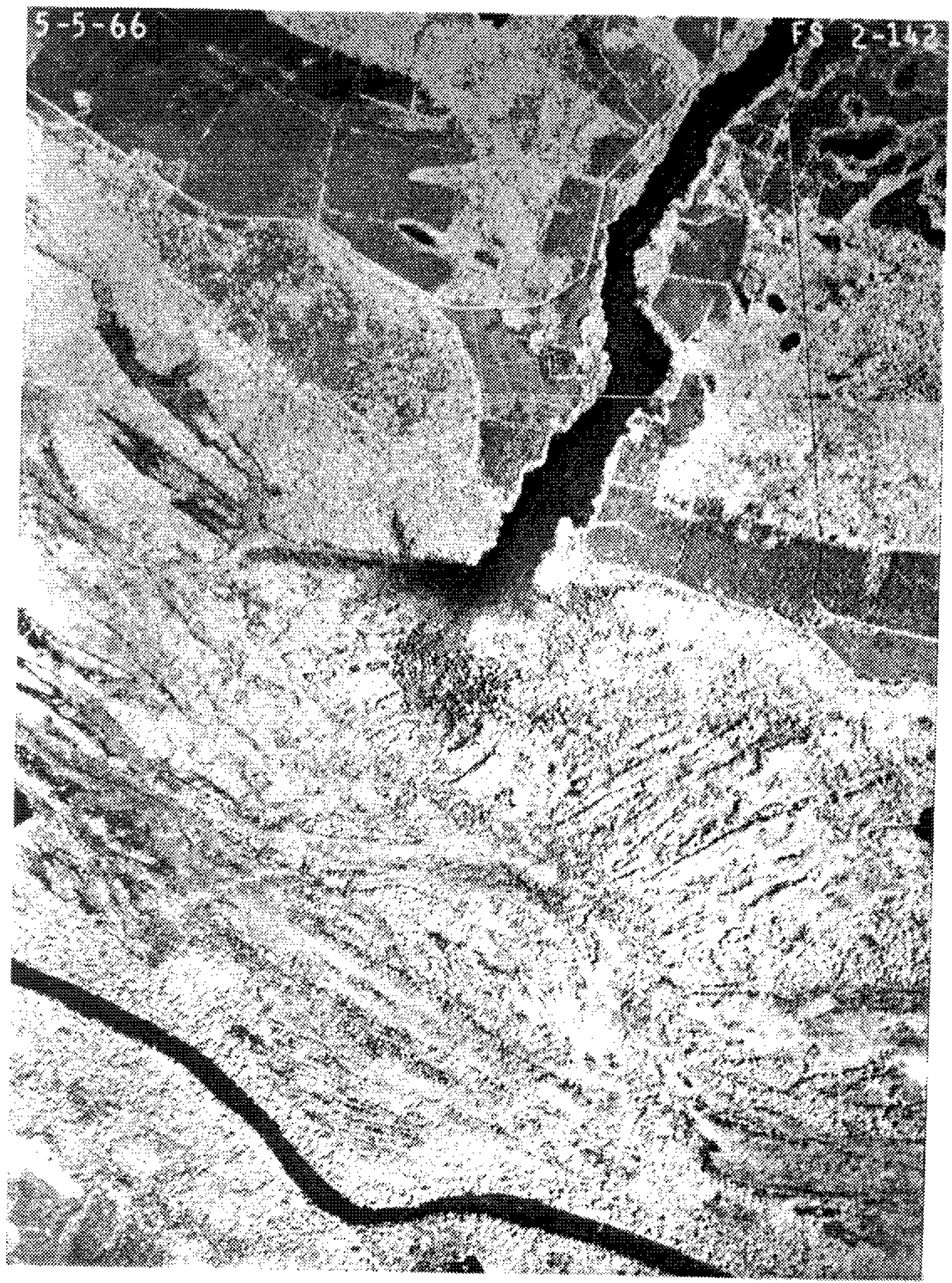

FrGuRE 14. Aertal View of Pen Branch outlet into the SRP Swamp 


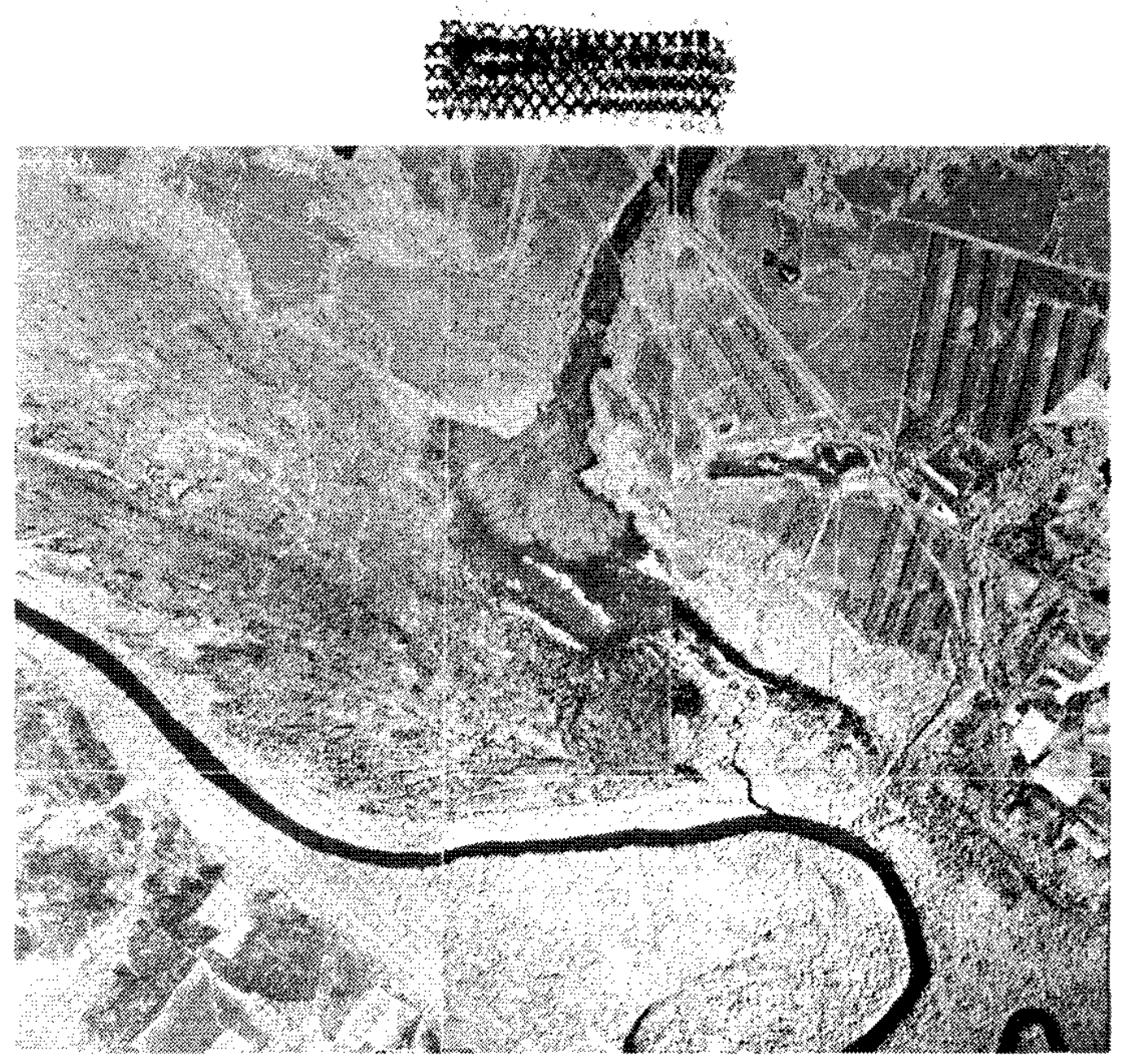

FlGURE 15. Aerial View of Steel creek outlet into the SRP Swamp

The swamp is separated from the river by a relatively high bank (90 ft msl) which has only three significant openings to the river. When the river reaches the $90-5 \mathrm{t}$ stage, which corresponds to a flow of about 11,000 $\mathrm{ft}^{3} / \mathrm{sec}$, the swamp becomes flooded. Nomally, the reactor effluent watex emerges from the swamp and enters the river through the three openings.

Thus, water discharges from the swamp at three points along the Savannal svex. The flow from two of these points, which are opposite Four Mle creek, accounts for the C reactor effluent. The discharge point farther downstream, which is considered to be Steel Creek outlet, accounts for the $K$ and $L$ reactor effluent. The tempexatures and estimated flows of the water discharging into the river, observed in August 1966, are shown in Figure 11 . The temperatures and lows observed in the exploration up Steel Creek from the outlet at the river are slown on Figure 16; note the two forks foud in this stream. Thus, it was observed that: (1) the effluent water from $C$ reactor reached the river at temp exatures of $31^{\circ} \mathrm{C}(28 \%$ of the flow from $\mathrm{C})$ and $36^{\circ} \mathrm{C}(72 \%$ of the

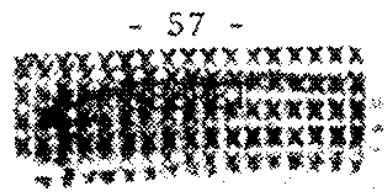




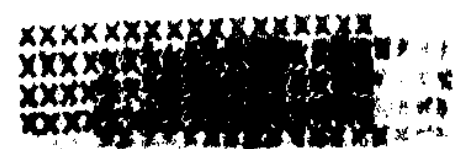

flow from C) for an average temperature of $34.6^{\circ} \mathrm{C}$; (2) the effluent water from $K$ and $L$ reactors reached the river at a mixed temperature of $32^{\circ} \mathrm{C}$; (3) up Steel Creek from its outlet at the river substantial flows were found having temperatures of $29^{\circ} \mathrm{C}$, $31^{\circ} \mathrm{C}, 34^{\circ} \mathrm{C}$, and $38^{\circ} \mathrm{C}$; (4) the coolest water was flowing from the direction of Pen Branch (K reactor), which was farthest away; and (5) the hottest water was flowing from the direction of Steel Creek (L reactor). The distribution of the flow conjured from these observations is given in Figure 17.

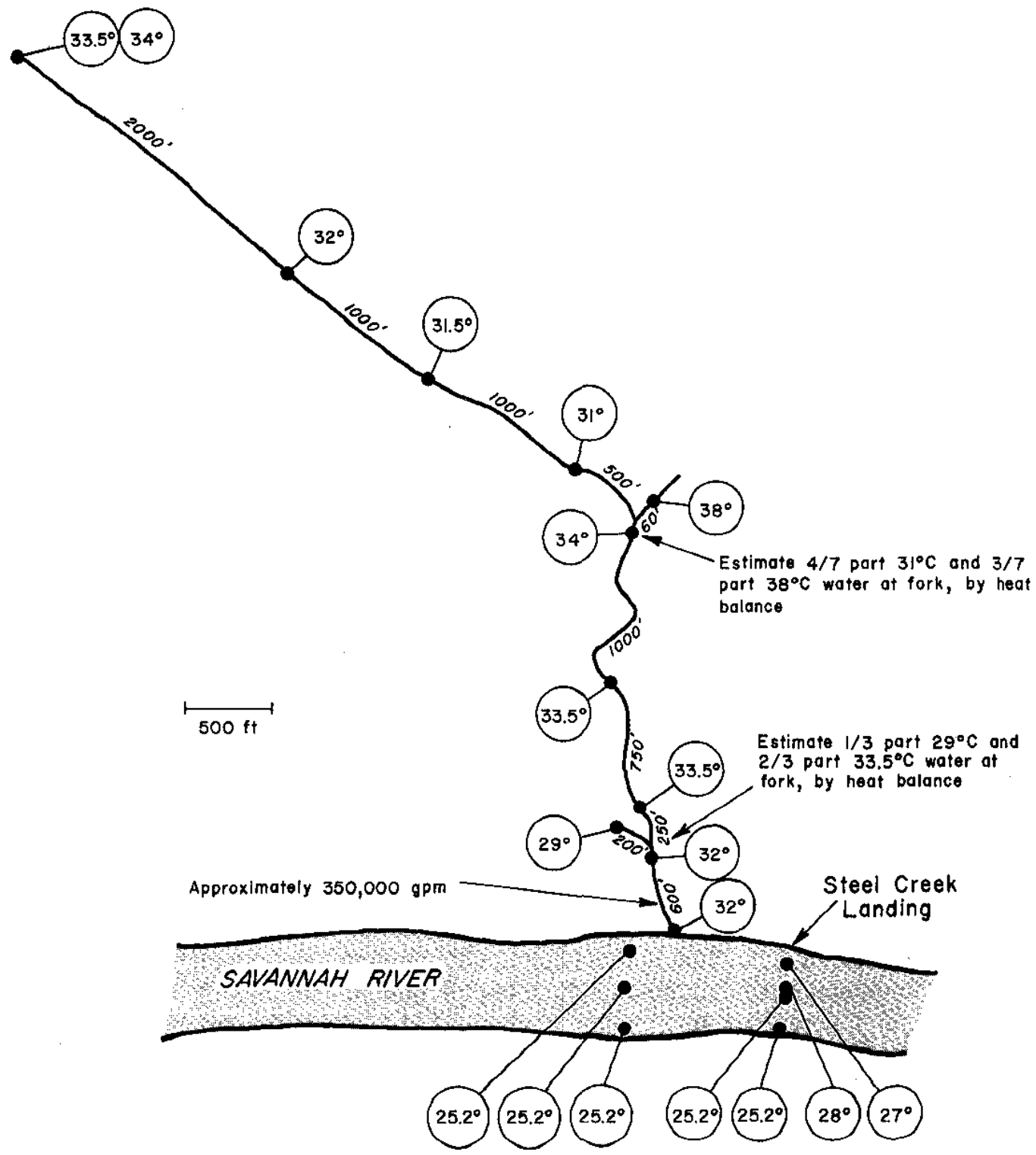

FIGURE 16. Temperatures Up Steel Creek from the Savannah River

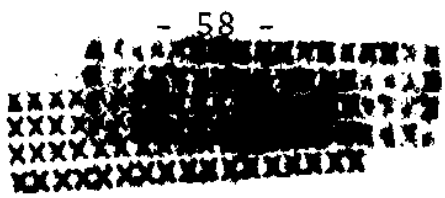



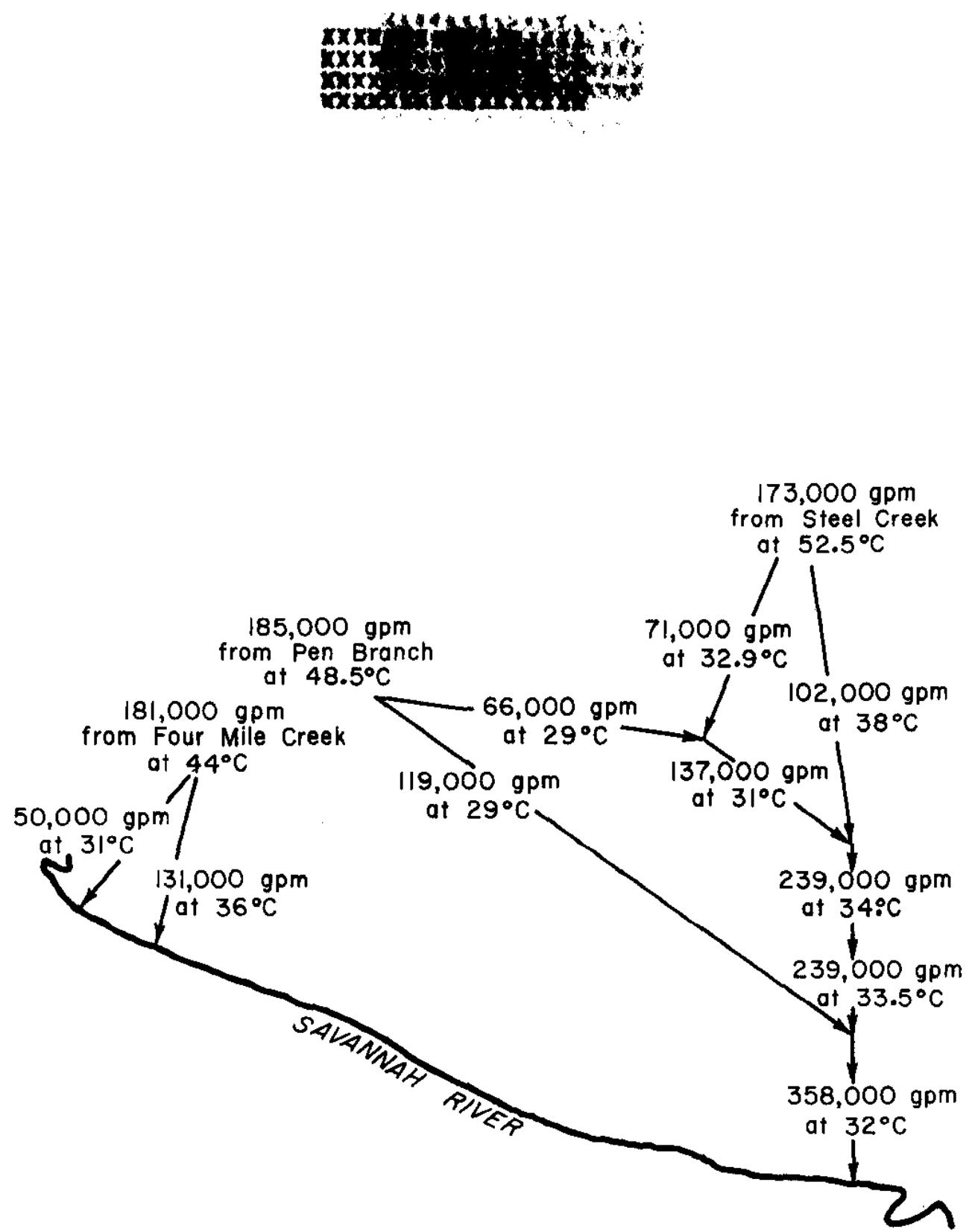

FIGURE 17. Flow of $C, K$, and $L$ Effluent Cooling Water Through the SRP Swamp

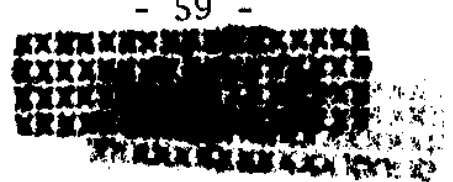




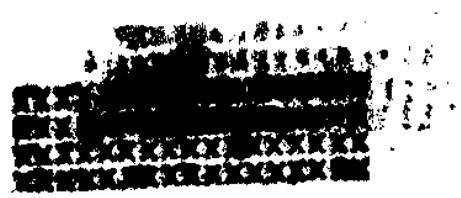

Performance of the SRP Swamp

The water cooling process in the swamp differs from that described above for the streams, canals, and ponds. The clue is that a substantial flow of water was found in the swamp in the August 1966 survey at a temperature of $29^{\circ} \mathrm{C}$. As shown in Figure 12 , the natural equilibrium temperature for the effluent streams at this time was $30.5^{\circ} \mathrm{C}$. According to Equation 15 it takes an infinite surface area to cool water down to the equilibrium temperature. The explanation is that the equilibrium temperature in the swamp is lower than in streams, canals, and ponds because the water is shaded by the vegetation. Admittediy, this vegetation causes a lower surface cooling rate, by Equation 5 and 6 , because the surface is sheltered from the wind. But given enough shaded surface area, a lower temperature can be obtained for the water from the swamp than is possible with an infinite surface area in open streams, channels, and shallow ponds that are heated by the sun.

In the application of the theory to the swamp, the solar heating rate and the wind speed were taken to be zero. The lower wind speed causes the lower surface cooling rate shown in Figure 12 for the August 1966 conditions than the surface cooling rate for open conditions. However, as shown in Figure 12 at the intersection of the curve with the horizontal line at $H_{S}=0$, the water in the swamp approaches a natural equilibrium temperature of $26^{\circ} \mathrm{C}$ rather than $30.5^{\circ} \mathrm{C}$ which occurs for "open" conditions.

The effective cooling area in the swamp can be calculated by Equation 15, which is for the slug flow model, from the flows and temperatures shown in Figure 17 as entering and leaving the swamp, together with Figure 12 for the surface cooling rate under swamp conditions. These effective areas for the swamp regions are shown in Figure 18; also posted are the effective areas for the open regions, i.e., the effluent streams which were discussed in the preceding section. Thus, the effective cooling area in the swamp is $58.4 \times 10^{6} \mathrm{ft}^{2}$, or 1341 acres, or $2.1 \mathrm{mi}^{2}$. The effective cooling area calculated from the observed performance of the swamp cannot be readily compared with actual measurements of the wet areas in the swamp. However, an effective cooling area of $2.1 \mathrm{mi}^{2}$ is about $14 \%$ of the $15 \mathrm{mi}^{2}$ swamp region, which is consistent with the percentage wet area apparent from the aerial photographs.

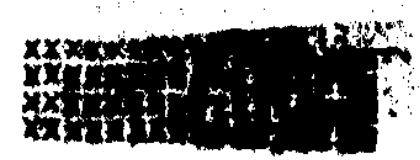




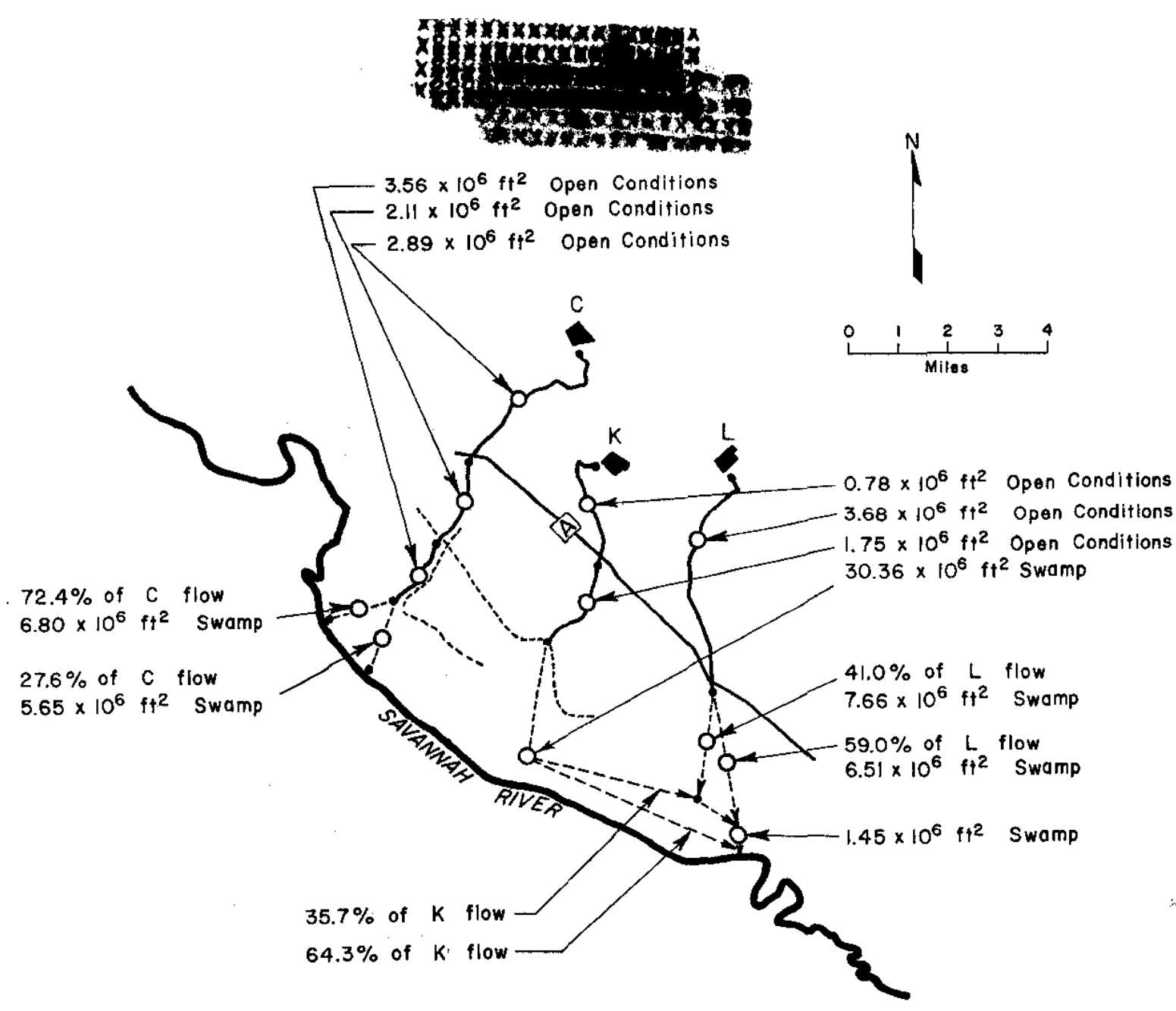

FIGURE 18. Effective Cooling Surface and Flow Split for the $C, K$, and $L$ Effluent Streams and SRP Swamp

The assumptions of zero wind speed and zero solar heating in the SRP swamp are an exaggeration. However, they have opposite or compensating effects on the effective area that is calculated from the observed temperatures and flows, or, on the effluent temperature predicted for other conditions once the effective area has been determined. Moreover, the calculated effective surface area in the swamp increases exponentially as the estimated equilibrium temperature increases toward the observed $29^{\circ} \mathrm{C}$ water temperature; the calculated area can become unreasonably large.

\section{SRP DISCHARGE TO THE SAVANNAH RIVER}

The temperature of the effluent cooling water emerging from the SRP swamp and entering the river at the three major cuts in the river bank, as shown in Figure 11 , averaged $32.9^{\circ} \mathrm{C}$ for a typical day in August 1966. From the analysis of the cooling process in the SRP effluent streams and swamp, given in the

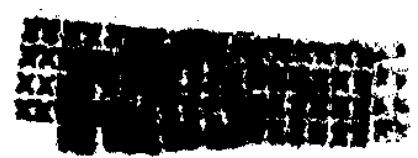




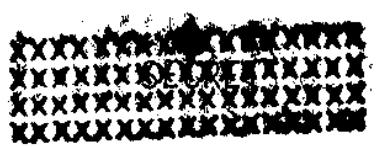

preceding sections, it is possible to calculate the effluent temperatures entering the river under what is regarded as the most severe summer conditions encountered at SRP according to the records of prior years. These most severe conditions occurred in August 1959. The temperature of the SRP effluent cooling water entering the river under the severe summer conditions was calculated to be $34.6^{\circ} \mathrm{C}$. The details of the comparison are given in Table VIII.

TABLE VIII

SRP Effluent From the Swamp Entering the Savannah River

Date

Air dry-bulb temperature

Relative humidity

Wind speed

Solar heat load

Natural equilibrium temperature

River temperature at SRP intake

River flow at SRP intake

Reactor power/cooling water flow

Four Mile Creek outlets (C reactor)

Steel Creek outlet (K \& L reactors

$C, K, L$ mixed effluent

River temperature downstream of

$C, K, L$ effluent at actual river

flow from above

River temperature downstream of $\mathrm{C}, \mathrm{K}, \mathrm{L}$

effluent at minimum river flow

of $6100 \mathrm{ft}^{3} / \mathrm{sec}$

Typical August
(Observed)
$8 / 18-19 / 66$
$27.3^{\circ} \mathrm{C}$
$78^{\circ}$
$6 \mathrm{mph}$

$39 \mathrm{pcu} /\left(\mathrm{hr}-\mathrm{ft} \mathrm{t}^{2}\right)$

$30.5^{\circ} \mathrm{C}$ (Fig. 12)

$24.2^{\circ} \mathrm{C}$

$7368 \mathrm{ft}^{3} / \mathrm{sec}$

$2256 \mathrm{MW} / 181,000 \mathrm{gpm}$

$1494 \mathrm{NW} / 185,000 \mathrm{gpm}$

$2062 \mathrm{MN} / 173,000 \mathrm{gpm}$

$$
\begin{aligned}
& \text { Severe August } \\
& \text { (Calculated) } \\
& 8 / 25-26 / 59 \\
& 30.9^{\circ} \mathrm{C} \\
& 65^{\circ} \\
& 3.8 \mathrm{mph}
\end{aligned}
$$

$60 \mathrm{pcu} /\left(\mathrm{hr}-\mathrm{ft}^{2}\right)$

$35.5^{\circ} \mathrm{C}$ (Fig. 19 )

$27.8^{\circ} \mathrm{C}$

$6850 \mathrm{ft}^{3} / \mathrm{sec}$

$2250 \mathrm{NW} / 180,000 \mathrm{gpm}$ $2100 \mathrm{MW} / 180,000 \mathrm{gpm}$ $2100 \mathrm{MW} / 180,000 \mathrm{gpm}$

The river temperature upstream of SRP during the severe conditions in August 1959 was $27.8^{\circ} \mathrm{C}$, the highest observed in recent history. The weather conditions governing atmospheric cooling at the water surface were also more severe at that time, i.e., higher air temperature and lower wind speed, although the relative humidity was somewhat lower than in the August 1966 case. The surface cooling rate under these severe conditions is given in Figure 19. When Figure 12 is compared with Figure 19, the surface cooling rate is seen to be lower under the severe conditions for the same water temperature. Moreover, for the

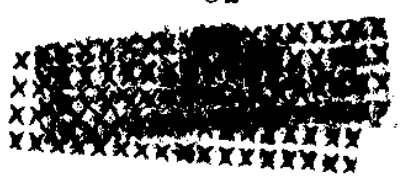




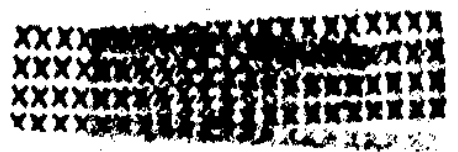

calculation of the SRP effluent temperature under the most severe conditions, a solar heating rate of $60 \mathrm{pcu} /\left(\mathrm{hr}-\mathrm{ft}^{2}\right)$ was taken because this high rate [compared with $39 \mathrm{pcu} /\left(\mathrm{hr}-\mathrm{ft}^{2}\right.$ ) for the typical August 1966 conditions] has a relatively frequent occurrence in the summer months. Also, the reactor power levels for the case with severe conditions were somewhat higher than for the typical conditions; the reactor powers were the actual ratings for the cooling water temperature of $27.8^{\circ} \mathrm{C}$, which existed at the time of the severe conditions.

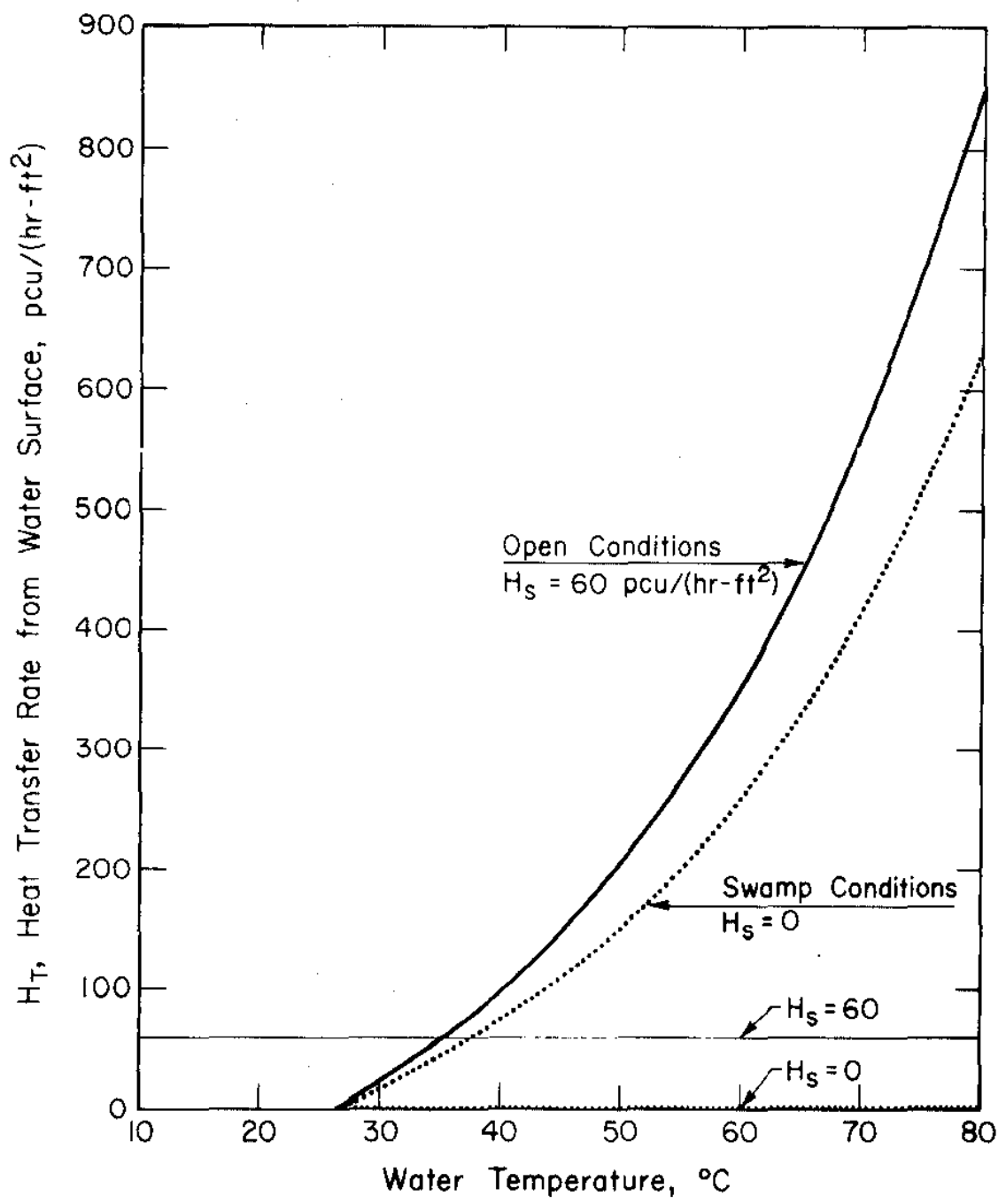

FIGURE 19. Surface Cooling Rate Under the Severe Conditions That Existed in August 1959

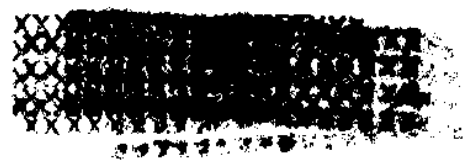


Thus, the mixed effluent from $C, K$, and $L$ reactors reached the river at a temperature of $32.9^{\circ} \mathrm{C}$ under typical midsummer conditions and $34.6^{\circ} \mathrm{C}$ under severe summer conditions. These temperatures are warmer than the river temperature by $8.7^{\circ} \mathrm{C}$ and $6.8^{\circ} \mathrm{C}$, respectively. The temperature of the river after mixing with the warmer SRP effluent water depends on the river flow, which is discussed next.

The flow in the Savannah River is regulated by the U. S. Army Corps of Engineers through their operation of the Hartwel1, Clark Hil1, Stevens Creek, and Augusta dams. Additional dams above SRP are under construction or in planning. It is the stated intent of the Corps of Engineers, since October 30, 1963, to provide not less than $6100 \mathrm{ft}^{3} / \mathrm{sec}$ at SRP and to exceed $6300 \mathrm{ft}^{3} / \mathrm{sec} 75 \%$ of the time. This intent must necessarily be qualified to cover circumstances beyond their control, such as a major drought. Since 1954 the lowest river flow recorded is $3850 \mathrm{ft}^{3} / \mathrm{sec}$

(February 1956). The lowest river flow since October 1963 is 6200 $\mathrm{ft}^{3} / \mathrm{sec}$. The improvement is attributed to the advent of Hartwell Dam. For the cases shown in Table VIII, SRP drew $1200 \mathrm{ft}^{3} / \mathrm{sec}$ from the river for $\mathrm{C}, \mathrm{K}$, and $\mathrm{L}$ reactors; $\mathrm{L}$ reactor has been shut down since early 1968. Thus, the increase in temperature of the Savannah River in passing by SRP is less than one-fifth of the increase in temperature of the SPP conling water from the intake point at the river pump houses to the discharge points from the SRP swamp. Mixing of the SRP effluent with the river water is essentially complete about two miles downstream.

The river temperature downstream of SRP after mixing is shown in Table VIII to be $25.6^{\circ} \mathrm{C}$ under the observed August 1966 conditions, when the river flow was $7368 \mathrm{ft}^{3} / \mathrm{sec}$, and $29.0^{\circ} \mathrm{C}$ under the severe August 1959 conditions, when the river flow was 6850 $\mathrm{ft}^{3} / \mathrm{sec}$. This corresponds to an increase in the temperature of the river passing SRP of $1.4{ }^{\circ} \mathrm{C}$ for the typical August conditions and $1.2^{\circ} \mathrm{C}$ for the severe August conditions, respectively. At the minimum $6100 \mathrm{ft}^{3} / \mathrm{sec}$ flow in the river, the increase in river temperature would have been $1.7^{\circ} \mathrm{C}$ and $1.3^{\circ} \mathrm{C}$, respectively. Note that the increase in the temperature of the river in passing SRP is less under the more severe summertime conditions. The higher temperature of the river under the severe conditions is the more important consideration, however.

Independent observations, with the SRP operation as a black box, are available from the records of the U. S. Geological Survey. ${ }^{7}$ These records show that, for the fiscal years 1959 through 1965, the maximum increase in the Savannah River temperature attributable to SRP operations ranges from 1.9 to $3.2^{\circ} \mathrm{C}$ from year to year and more importantly, as a confirmation of this study, that the maximum yearly river temperature downstream of SRP ranges from $25.3^{\circ} \mathrm{C}$ to $29.4^{\circ} \mathrm{C}$. 


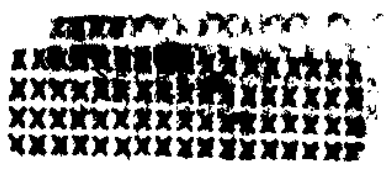

Temperatures above $31^{\circ} \mathrm{C}$ are considered to be deleterious to fish and algae. ${ }^{8}$ Thus, by virtue of the natural cooling within the SRP boundaries and the operation of Clark Hill Reservoir, SRP has not caused an objectionable increase in the river temperature.

\section{WARMING IN THE SAVANNAH RIVER}

As the Savannah River flows past SRP on its way to the Atlantic Ocean, its temperature is generally increasing, regardless of the SRP thermal contributions. This is because, throughout two-thirds of the year and particularly during the summer months, the Clark Hill Reservoix upriver discharges water that is colder than the temperature in natural streams and ponds. The reservoir has about a 4-month inventory of water, and the water is released from a depth of 60 to $80 \mathrm{ft}$. The water released in the summer is collected in early spring and is stored in the deeper regions by virtue of thermal stratification. The temperature of the discharge at Clark Hill Reservoir is about $8^{\circ} \mathrm{C}$ cooler in the summer months, than the natural river temperature in prior years. At SRP, the temperature of the river during the summer is about $4^{\circ} \mathrm{C}$ lower than it was before the advent of the reservoir, and about $2.5^{\circ} \mathrm{C}$ lower on an annual average basis. ${ }^{5}$ Thus, the river temperature is generally approaching the equilibrium temperature from the cold side as it flows past SRP.

The formulation for the warming process in the river is the same as that outlined above for the SRP effluent canals and streams. By Equation 15, the difference between the river temperature at some point downstream from SRP and the equilibrium temperature is the fraction $e^{-\alpha}$ of the difference from equilibrium that exists in the river after mixing with the SRP effluent. The exponent $\alpha$ is given by Equation 16 in terms of the slope $m$ of the Langhaar cooling rate curve near the equilibrium temperature, the area $A$ of the river, and the river flow $F$. From Figure 12, $\mathrm{m}=8.0 \mathrm{pcu} /\left(\mathrm{hr}-\mathrm{ft}^{2}-{ }^{\circ} \mathrm{C}\right)$ for typical August conditions. At the minimum guaranteed flow of $6100 \mathrm{ft}^{3} / \mathrm{sec}$ in the river, the "attenuation area" - that is, the river surface area required to reduce the temperature in excess of the equilibrium by a factor of $e=2.718$ - is therefore

$$
\frac{500 \times 6100 \times 60}{8 \times .1337}=171 \times 10^{6} \mathrm{ft}^{2}
$$

Since the width of the river is about $330 \mathrm{ft}$, which corresponds to $1.74 \times 10^{6} \mathrm{ft}^{2} / \mathrm{mi}$, the "attenuation distance" is

$$
\frac{171 \times 10^{6}}{1.74 \times 10^{6}}=98 \mathrm{miles}
$$

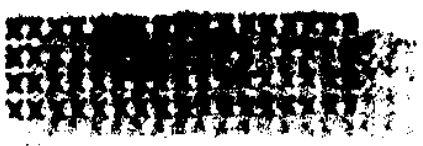


Thus, the difference from equilibrium at a point 98 miles downstream from SRP will be $1 /$ e of the difference that exists at SRP. This applies whether the river temperature is above or below the equilibrium temperature; the difference must be in the same sense. At higher river flows than $6100 \mathrm{ft}^{3} / \mathrm{sec}$, the attenuation distance is greater than 98 miles. (The probable chilling effect of rainfall runoff below SRP has been neglected here.)

The two-day average weather conditions and solar heating rate in Table VIII is used for calculating the rate of heat transfer to the atmosphere $\left(\mathrm{H}_{\mathrm{T}}\right)$. The velocity in the river is about $2 \mathrm{ft} / \mathrm{sec}$ at 7000 to $8000 \mathrm{ft}^{3} / \mathrm{sec}$. Distances by river from the SRP boundary are roughly 23 miles to Millhaven (Route 301 crossing), $81 \mathrm{miles}$ to Clyo (Route 110 crossing), and $120 \mathrm{miles}$ to Savannah (Route 17 crossing). The transit times are 17, 59, and 88 hours, respectively.

Thus, the temperature in the river may continue to increase downstream of SRP or it may decrease depending on whether or not the boost that it gets from SRP takes it to a temperature below or above the equilibrium temperature. For the situations presented in Table VIII, the equilibrium temperature was higher than the mixed temperature in the river below SRP. The natural equilibrium temperature for the typical conditions in August 1966 was calculated to be $30.5^{\circ} \mathrm{C}$, whereas the effluent from SRP ( 1200 $\mathrm{ft}^{3} / \mathrm{sec}$ ) was calculated to be $32.9^{\circ} \mathrm{C}$, and the river temperature, $24.2^{\circ} \mathrm{C}$. Under these conditions the temperature of the Savannah River would continue to increase downstream from SRP as long as the river flow was greater than $1700 \mathrm{ft}^{3} / \mathrm{sec}$. Under the severe conditions seen in August 1959, the calculated natural equilibrium temperature was $35.5^{\circ} \mathrm{C}$, whereas the calculated effluent from SRP was $34.6^{\circ} \mathrm{C}$, which was actually less than the natural equilibrium temperature because of the contribution of $29.9^{\circ} \mathrm{C}$ water from $\mathrm{K}$ reactor via the swamp. The river temperature on that severe day in August 1959 would have continued to increase downstream from SRP even if SRP had taken the entire river flow.

\section{APPLICATIONS AT SRP}

Questions arise regarding the effect of changes in SRP operations or of the diurnal and seasonal variations in the atmospheric conditions on the temperatures in the canals, ponds, streams, and swamp. In order to answer such questions, the correlations presented above have been composited in a single computer program LIMN, which is given in Appendix B. This program is written in FORTRAN IV for the IBM System/360 computer. The independent variables are the reactor power levels (in megawatts), the respective flows of cooling water (in $10^{6} \mathrm{gpm}$ ), the weather conditions, the solar heat load, the river temperature, and the

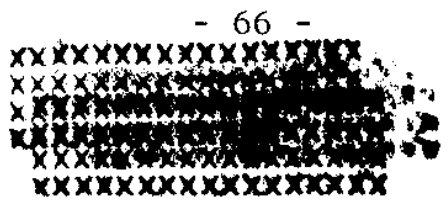


initial temperature of the discharge from Par Pond. The time interval is also specified; this time is needed only for Par Pond. The temperature of the effluent cooling water is computed for the points shown on the map (Figure 20). The evaporation that occurs along the way is also computed. Any combination of reactors can be selected for evaluation by LIMN.

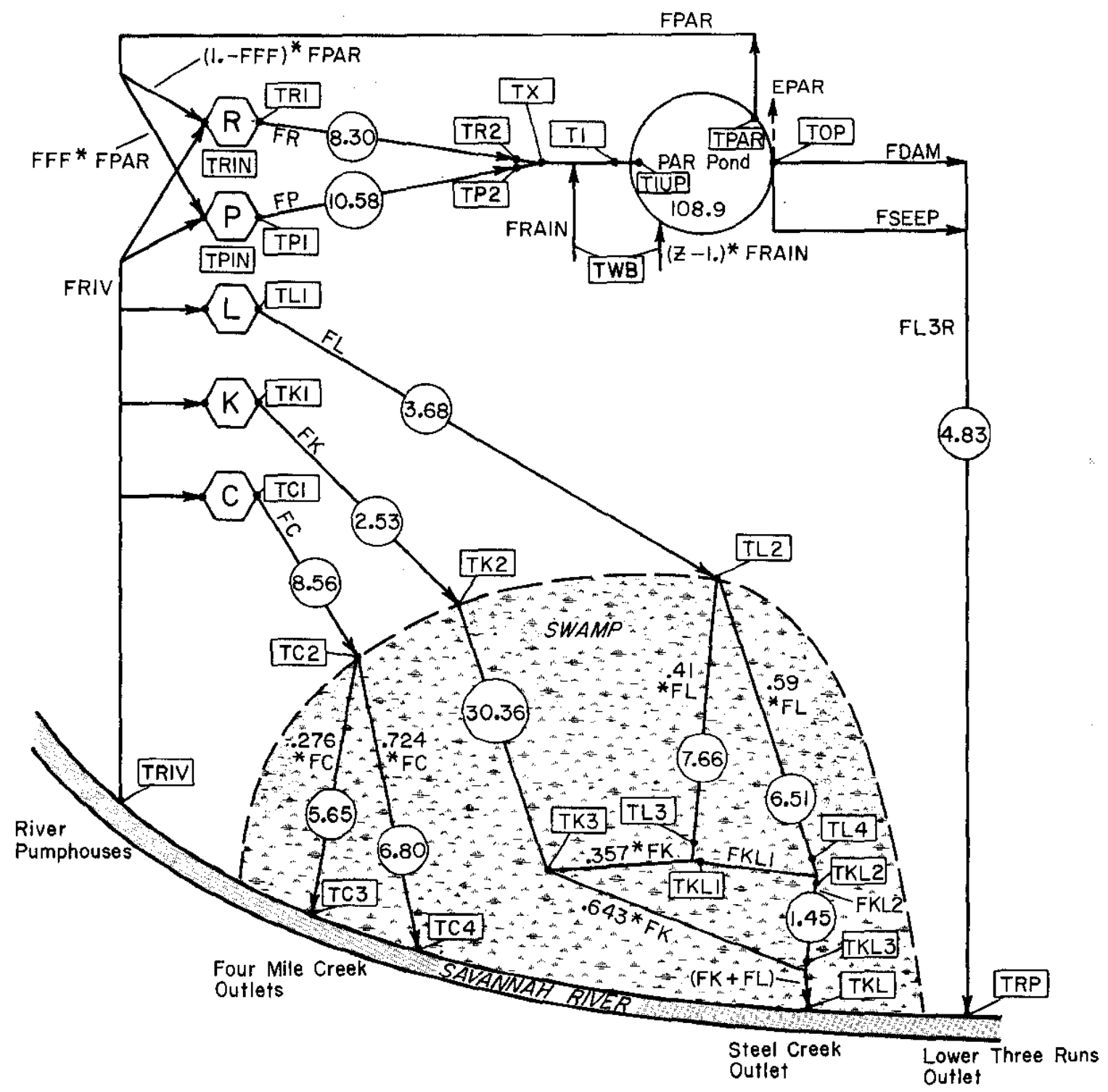

FIGURE 20. SRP Map for Computer Program LIMN 


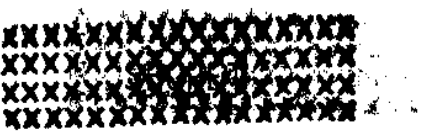

This program first calculates the surface cooling rate by Langhaar's Equations 4,5 , and 6 at temperatures in $10^{\circ} \mathrm{C}$ intervals from 5 to $95^{\circ} \mathrm{C}$ for the particular set of weather conditons that are read into the computer. A straight-line approximation (Equation 7) is then made for each $10^{\circ} \mathrm{C}$ segment of Langhaar's curve. The slope $\mathrm{m}$, intercept $\mathrm{b}$, and equilibrium temperature $\mathrm{T}_{\mathrm{e}}$ (by Equation 13) are calculated for each segment and stored (as well as printed out), first for the open conditions that exist in the canals, ponds, and streams, and then for the shaded conditions of the swamp. The rate of change in heat content $\mathrm{H}_{\mathrm{C}}$ needed to calculate the equilibrium temperature is zero except for Par Pond. For Par Pond, $\mathrm{H}_{\mathrm{C}}$ depends on the pond discharge temperature at the end of the specified time interval; this temperature is found by trial values for the average discharge temperature during the time interval. The equilibrium temperatures for Par Pond corresponding to the segments of the Langhaar curve are therefore tabulated separately.

The map (Figure 20) is systematically evaluated by LIMN. The temperature of the water entering a particular region shown on the map, and the related flow, are supplied to the subroutine JWL, which then calculates the temperature at the downstream end of that region, and also the evaporation that occurs. JWL considers slug flow (Equations 15 and 16) to occur in the canals, small ponds, streams, swamp, and the upperflow region of Par Pond; the effective areas (in $10^{6} \mathrm{ft}^{2}$ ) by this model for the various regions are the numbers given on the map (Figure 20). The subroutine JWL first finds the segment on Langhaar's curve that contains the input temperature. It then calculates the surface area required for the water to cool to the upper boundary of the next lower segment; then, it calculates the surface area required to cool over that segment; and so on, until the total surface area equals or exceeds the effective surface area prescribed for that region. Only part of the last segment is traversed in reaching the prescribed effective surface area, which then gives the temperature at the downstream end of the region. With each increment of surface area there is an increment of evaporation, which is accumulated for that region by JWL. The main program LIMN then picks up the downstream temperature and the evaporation for that region and proceeds to the next region on the map. Note that for Par Pond the average discharge temperature for the prescribed time interval is calculated in LIMN by trial-and-error, rather than analytically as in Table $\mathrm{V}$, in order to utilize the particular segments of Langhaar's curve that are initially set up in LIMN.

The LIMN Printout 1 in Appendix $B$ gives the case for Par Pond in May 1964 when both $R$ and $P$ reactors were in operation. The average discharge temperature is calculated to be $23.4^{\circ} \mathrm{C}$, as compared with $23.6^{\circ} \mathrm{C}$ given in Table V. Printout 2 gives the hypothetical case for Par Pond in May 1964 if only p reactor were

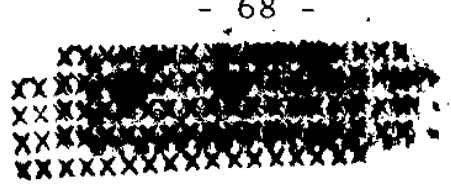


in operation. Shutting down $R$ reactor resulted in a calculated discharge temperature of $22.7^{\circ} \mathrm{C}$, or $0.7^{\circ} \mathrm{C}$ lower than with both reactors in operation. The water balance in Printout 2 shows that, with an estimated seepage $10 \mathrm{ss}$ of $2800 \mathrm{gpm}$, about $7500 \mathrm{gpm}$ makeup water from the river is needed to maintain the level in Par Pond, i.e., for zero overflow at the dam, since the shutdown of $\mathrm{R}$ reactor. (Actually, the seepage loss is estimated from the observed makeup water requirement.) Note that as a result of the lower temperature of the Par Pond overflow at the dam, since the shutdown of $R$ reactor, the temperature of the overflow increases $0.9^{\circ} \mathrm{C}$ before reaching the river via Lower Three Runs Creek.

Printout 3 gives the temperatures and evaporation of the effluent cooling water for $C, K$, and $L$ reactors in August 1966 for comparison with the observations given in Figure 11. Printout 4 gives the temperatures and evaporation for the CKL effluent cooling water calculated for the severe August 1959 conditions for comparison with the hand calculations in Table VIII.

\section{AREAS FOR FURTHER INVESTIGATION}

The Langhaar equation for the rate of heat transfer to the atmosphere, equated to the rate of heat input minus the rate of heat accumulation, was applied to a model of the apparent flow pattern to provide a mathematical description of the cooling process extant in the SRP canals, ponds, streams, and swamp. correlation of the SRP performance was then readily obtained using relatively few data on water temperatures, water flow, and atmospheric conditions; the correlation was in terms of only a few derived factors, such as, the effective surface area and the excess temperature at the surface attributed to thermal stratification. The factors obtained by substituting the plant data into the mathematical description of the cooling process have physical significance; they are not simply empirical terms in a correlation. The factors are subject to the requirement that they have a reasonable correspondence to the actual system. The simple description of the cooling process and the derived correlating factors are adequate for most purposes at SRP. The effect of variations in SRP operating conditions and in the weather conditions on the temperature of the SRP effluent at the Savannah River or from Par Pond can be readily evaluated by this description using the computer program LIMN.

One might proceed to evaluate more of the same kind of data by the above formulations, for instance, to find the standard deviation from actual performance or to improve on the derived factors in order to reduce the standard deviation. Such a step at this time would be largely an exercise, however, in view of the stated adequacy of the present description for practical purposes at SRP. Rather 


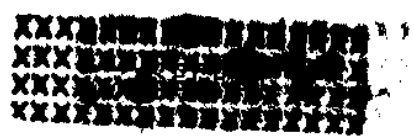

than to engage in obtaining a better fit to this simple model with more extensive data, efforts might better be devoted to certain fundamental investigations which offer the possibility of extending our understanding and of refining the mathematical description of the cooling process.

\section{The Partial Differential Equation for Natural Cooling}

The energy budget Equation 1 together with Equations 2, 3, 4, 5 , and 6 and the vapor pressure relation (Reference 9) lead to the following partial differential equation:

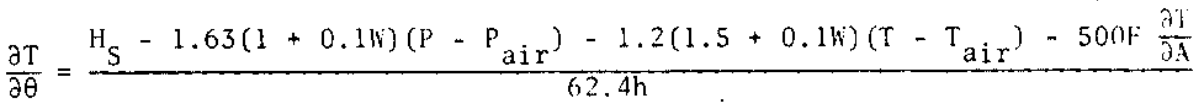

where

$$
\begin{aligned}
& \log _{10}\left(\frac{E}{P}\right)=\left(\frac{X}{T+273.16}\right)\left(\frac{A+B X+C X^{3}}{1+D X}\right) \\
& X=374.11-T \\
& A=3.2437814 \\
& B=0.00586826 \\
& C=0.011702379 \times 10^{-6} \\
& D=0.0021878462 \\
& E=165807.0
\end{aligned}
$$

In Equation 26 the parameters $\mathrm{H}_{\mathrm{S}}, \mathrm{P}_{\mathrm{air}}, \mathrm{T}_{\mathrm{air}}, W$, and $\mathrm{F}$ vary with time $\theta$. It would be constructive to develop the finite difference form of Equation 26 for solving by computer with data input for short time intervals. The computer program would calculate the temperature $T$ as a function of time $\theta$ and space $A$.

\section{Stratification Algorithm}

A computer code is needed that can take the hourly data on atmospheric conditions and solar radiation intensity at the pond site and calculate the vertical temperature profile as a function of time. Consider a natural pond, i.e., neglect any imposed thermal load. Consider the pond as a rectangular parallelepiped having a depth equal to the average depth. Divide it into horizontal slabs. This is then a one-dimensional model in space, with time as another independent variable. The solar radiation is attenuated, for instance, by Lambert's Law: $d I=-\mu I d z$ where $\mu$ is the attenuation coefficient. Surface cooling occurs according to Langhaar's equation. Start with a uniform temperature in the early spring. The input data are the air dry-bulb and wet-bulb temperatures, the wind speed, and the solar radiation intensity

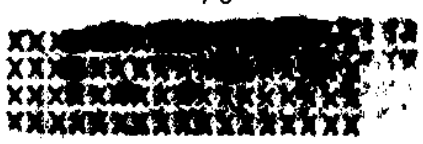




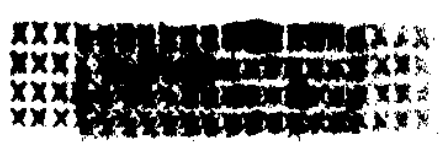

at the pond surface. Except for the solar radiation intensity, these data are available in three-hour intervals from the National Climatic Center. ${ }^{10}$ Regarding solar radiation, see the following section. At the end of each time interval, calculate the new temperature in each $\mathrm{slab}$, ignoring conduction and convection effects other than from the surface of the top slab. Then, interchange the slabs so as to have a stable temperature distribution. That is, the density must increase with depth. The convection mechanism that physically accomplishes this restructuring need not be formulated.

Such an algorithm should reproduce the observed stratification in a pond. It should also predict the inversion that occurs in the fall when the pond temperature again becomes relatively uniform. Integrating over the vertical temperature profile will give an estimate of the pond heat content at that particular time, which is important for the energy budget equation. The predicted stratification can be the basis for the $\Delta \mathrm{T}_{\mathrm{G}}$ term that was used in the Par Pond model above, and it can be the basis for predicting the mixed temperature of the underflow in the intake channel to the pump house (see section on Stratified Flow below).

\section{Solar Radiation Measurements}

A continuous record at SRP of the solar radiation intensity, measured by a pyrheliometer, is highly desirable. A way of calibrating the instrument should be available. Hourly readings should be tabulated. Since the solar radiation intensity for clear arid conditions is known as a function of latitude and altitude, the actual radiation intensity might be estimated from the "sky cover" which is available from the records of the National Climatic Center. The rate of evaporation of water from an open pan exposed to the atmosphere, which is obtained at some meteorological stations, might be converted to solar radiation intensity by using Langhaar's equations to estimate the ratio of total heat transfer to heat transfer by evaporation. Some study should be made of the extent that solar radiation is reflected from the water surface and of the attenuation of the solar radiation as a function of water quality and depth, particularly, for the stratification algorithm discussed above.

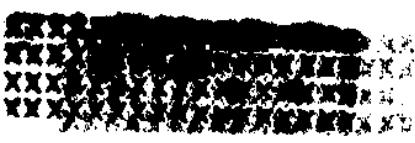




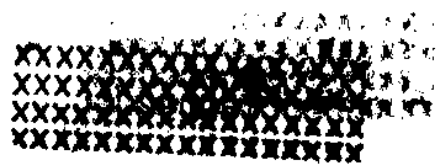

\section{Stratified Flow}

The existence of an underflow in the stratified pond was postulated in the model described above for Par Pond. The underflow was the source of cool water for mixing with the hot influent at the warm end of the pond and for the discharge at the pump house at the cool end. An improved model for a cooling pond requires consideration of the conditions needed for stratified flow. A theory for the selective withdrawal of water from a stratified reservoir has been developed recently. ${ }^{11}$ This theory needs to be verified by observations of the temperature of water withdrawn through a submerged intake slot from a deep reservoix in relation to the thermal stratification and to the discharge rate.

\section{Mixing of the Influent to the Pond}

It is desirable to spread the hot influent onto the surface of a cooling pond with as little mixing as possible in order to benefit from a higher surface temperature for a greater rate of heat transfer to the atmosphere. The structure at the bypass road embankment at the warm end of Par Pond was designed with this objective in mind. Still, temperature surveys in the pond have shown that there is considerable mixing. The mixing factor $u$, which was employed in the model for Par Pond, was calculated from these data as the ratio of the underflow of cool water to hot influent. The values for $u$ ranged from 1.0 to 4.5 ; the value $u=2.3$, which was used in the correlation, was the average of 13 surveys. The variation seen for the given structure might be caused by the variation in stratification and in the wind. The variation may also have been the result of an inadequate temperature survey. A better understanding of the mixing process should enable a better design of the inlet structure for future cooling ponds.

\section{Wind Stress}

The fluctuation of Par Pond discharge temperature, shown in Figure 8 for the daily readings from January through May 1964, was attributed in large measure to the action of the wind. Subsequent to those data, other observations of the pond discharge temperature have been taken, such as is shown in Figures 21 and 23. The effluent temperature was observed to change by severa1 degrees centigrade in a period of one hour up to three days; the maximum amplitude (minimum to maximum) observed for such fluctuations has been about $5^{\circ} \mathrm{C}$.

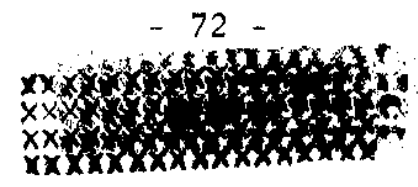




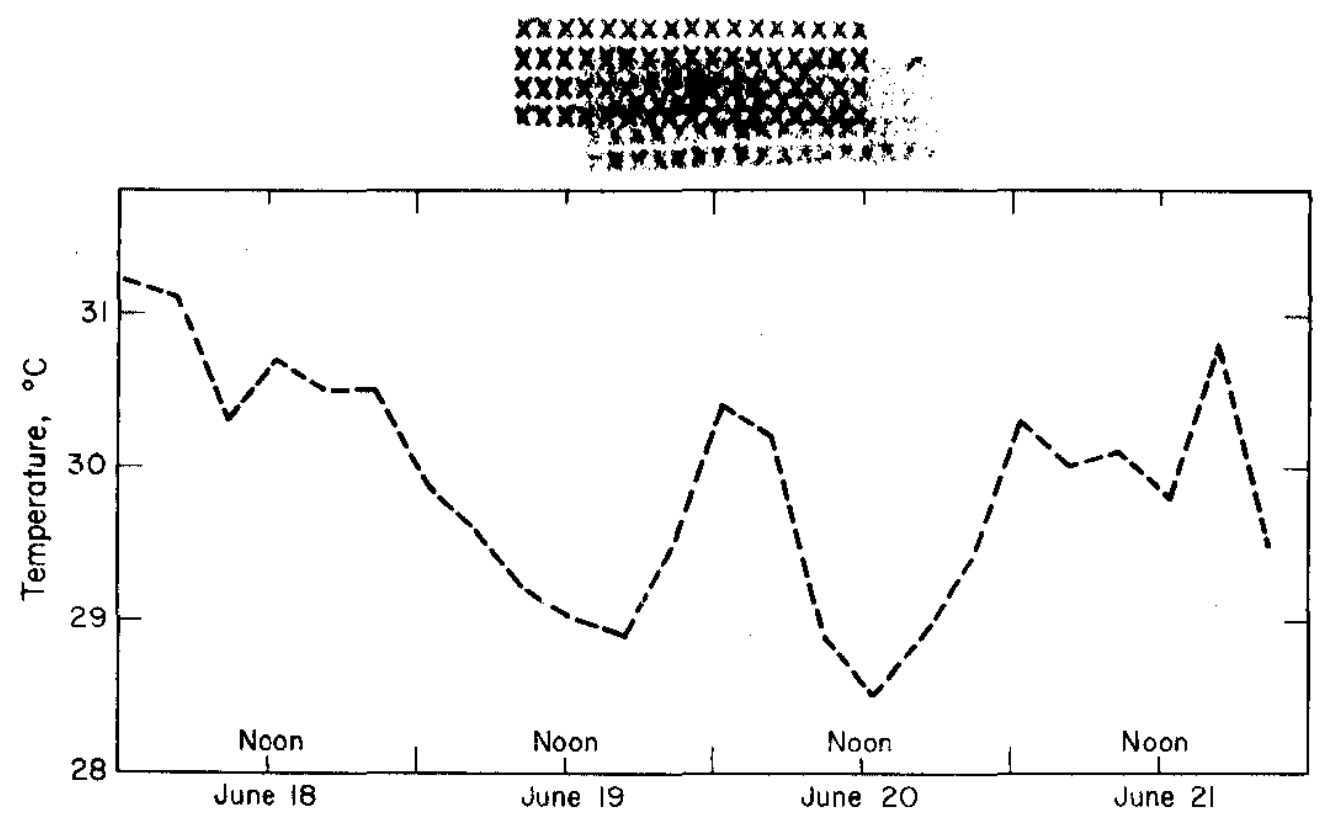

FIGURE 21. Fluctuation in Pond Effluent Temperature

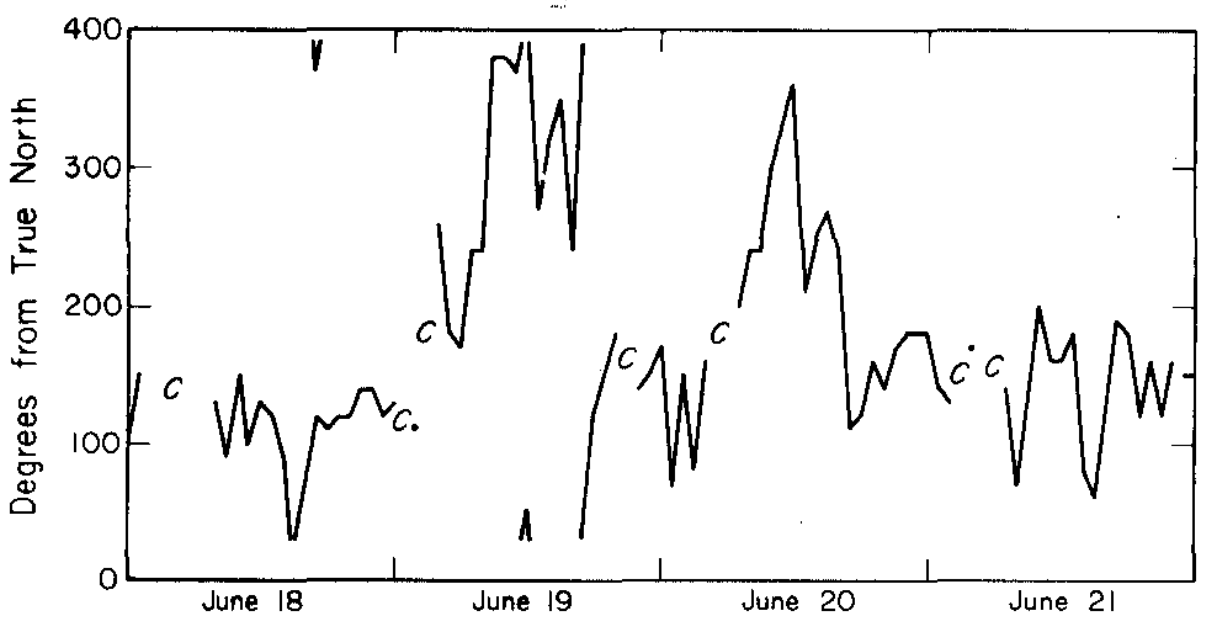

FIGURE 22. Fluctuation in Wind Direction

The simultaneous fluctuation in wind direction is shown in Figure 22 for the temperature fluctuations shown in Figure 21 . Superposition of the two figures shows that the peaks in the wind direction correspond to the valleys in the pond effluent temperature. A wind direction of $120^{\circ}$ from north in Par Pond corresponds to the wind flowing directly toward the pump house along the axis of the pump house arm of the pond. Similarly, a wind direction of $300^{\circ}$ from north corresponds to the wind blowing directly away from the pump house. In Figure 22, the wind direction is plotted from $30^{\circ}$ to $390^{\circ}$ rather than from $0^{\circ}$ to $360^{\circ}$ from north; thus, 
below the median direction of $210^{\circ}$ from north, which corresponds to the wind blowing directly across the pump house arm, there is a positive component of the wind from the pond toward the pump house. Above the median direction of $210^{\circ}$ from north, there is a positive component of the wind away from the pump house. The relation between the component of the wind velocity vector along the axis of the pump house arm and the pond discharge temperature is shown in Figure 23 from data taken at another time than that for Figures 21 and 22 .

The temperature fluctuation in the pond as a result of the wind is well known to limnologists. ${ }^{12}$ As observed along the shore, colder water is found in the upwind (windward) direction; warmer water is found in the downwind (leeward) direction. That is, when the wind blows during the period of thermal stratification, the warmer water congregates downwind, and the colder isotherms break the surface at the upwind end. The action of the wind is shown in Figure 24 for a two-zone body of water. The interface between the two zones is like the thermocline in an actual body of water. When the wind hlowa steadily in one direction across
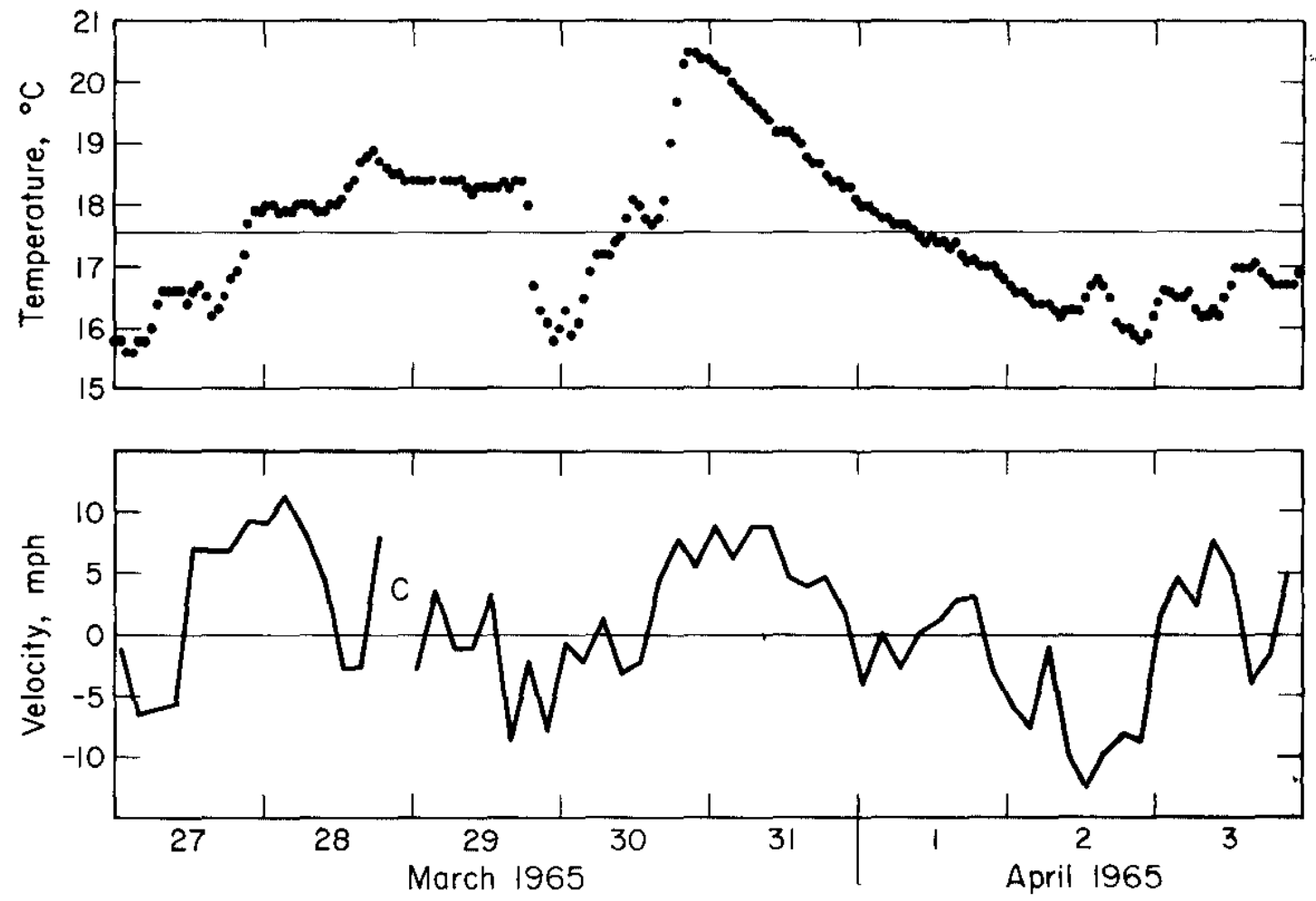

FIGURE 23. Fluctuation in Wind Vector and Pond Effluent Temperature 
the pond, the drag force of the wind on the surface is counterbalanced by the difference in hydrostatic head at one end of the pond from that at the other end as a result of the different vertical temperature profiles. When the wind stops, the thermocline does not immediately come to rest in a horizontal position, but, due to the inertia of the flow that occurs in returning to the horizontal, the thermocline proceeds to about the same maximum gradient in the opposite dixection; then the flow reverses. Thus, the action of the wind on the pond is analogous to the compression of a spring. Damped harmonic motion occurs when the compressing force is released. If the wind velocity component is a function of time, the case is analogous to forced harmonic motion. If the wind blows and then stops, when there was initially a uniform temperature gradient in the pond, a sinusoidal-like variation in the temperature occurs at any given point in the pond except at the node. The wave in the isotherm surface as a result of the wind action is called an internal seiche. Since the wind takes all directions over a period of time, the crisscrossing of the internal seiches can be expected to produce a complex isotherm surface.

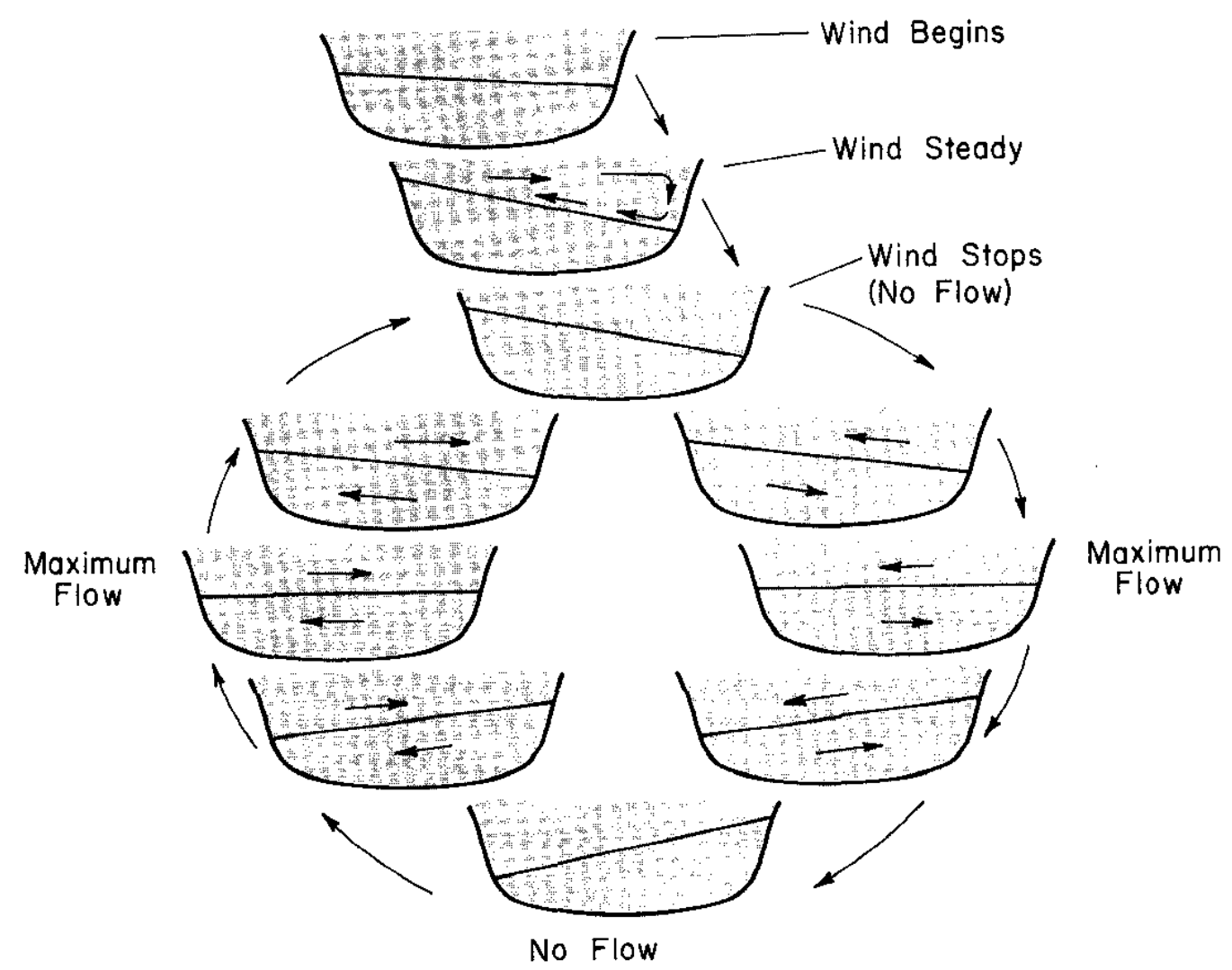

FIGURE 24. Wind Stress and Internal Seiche ${ }^{12}$ 


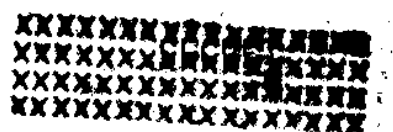

The action of the wind is seen to result in short-time variations in the effluent temperature from a pond that are large compared to the deviations that can be expected in the predicted effluent temperature by the theory and application sections above. The effect of the wind action was smeared over, in the evaluation of the Par Pond model, by taking monthly average data. When dealing with shorter time intervals, which is required for a better description of the cooling process in the pond, the action of the wind must be accounted for. Therefore, it is desirable that a program be instituted to collect data on Par Pond discharge temperature and on the wind direction and speed at frequent time intervals. These dates can then be used to calculate the component of the wind velocity acting along the axis of the pump house arm of the pond, and to seek a correlation between the component velocity and the discharge temperature.

\section{Velocity Measurements}

The study of Par Pond has been deficient in that there have been no measurements of the local velocity of the water. Traverses in the vicinity of the inflow structure at the warm end of the pond for the velocity field as well as the temperature distribution would enable a better understanding of the mixing process (for the $u$ factor in the Par Pond model, for example). Traverses in the intake channel to the Par pump house for the vertical velocity profile would help to demonstrate the existence of an underflow; the vertical profiles for velocity and temperature might be related so as to verify the theory of stratified flow. A periodic variation in the velocity at a point out in the reservoir would corroborate the existence of an internal seiche. In general, the circulation pattern in a pond or in the vicinity of structures and restrictions, such as a culvert, might better be observed by velocity measurements than inferred from temperature measurements.

\section{Swamps}

The cooling process in a swamp ought to be studied further, particularly because the swamp region àt SRP might be modified at a reasonable cost to effect a further reduction in the temperature of the SRP effluent to the river. The lower cooling rate expected in a swamp is not of concern so long as compensating surface area is available at low cost. The lower equilibrium temperature expected in a swamp makes the swamp potentially as effective as an expensive cooling tower. 


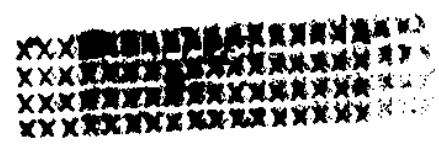

In the application of the theory for natural cooling to the SRP swamp, the solar heat load and the wind speed were taken to be zero. Admittedly the vegetation in a swamp is not uniformly distributed, nor is it completely effective in shading the water and in screening out the wind. The reduction in the rates of convection and evaporation to the atmosphere because of the sheltering from the wind acts to increase the equilibrium temperature, depending on the magnitude of the solar heat load, whereas the reduction in the solar radiation intensity by the vegetation acts to decrease the equilibrium temperature. Thus, as a first step, the equilibrium temperature in a stagnant swamp might be compared with the equilibrium temperature in a stagnant open pond at the same time and in the same locale. The rate of heat transfer to the atmosphere from the water in the swamp environment might better be determined under flow conditions at temperatures substantially above the equilibrium temperature. The average intensity of the solar radiation reaching the swamp waters should be measured and compared with simultaneous measurements taken in the open. The type and extent of the vegetation in the swamp should be investigated as a factor governing the performance of the swamp for cooling.

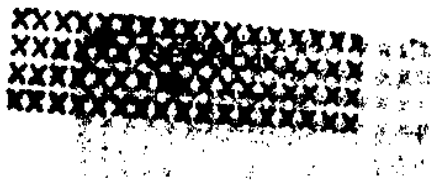


Consider the energy budget equation

$$
\mathrm{H}_{\mathrm{F}}=\mathrm{H}_{\mathrm{T}}-\mathrm{H}_{\mathrm{S}}+\mathrm{H}_{\mathrm{C}}
$$

Take $f_{A}$ as the effectiveness of the surface area, then Equation 3 becomes

$$
\mathrm{H}_{\mathrm{F}}=\frac{-500 \mathrm{~F} \text { upperflow }}{\mathrm{f}_{\mathrm{A}}}\left(\frac{\mathrm{dT}}{\mathrm{dA}}\right)
$$

Take a linear fit to the Langhaar cooling rate curve, as in Equation 7

$$
\mathrm{H}_{\mathrm{T}}=\mathrm{mT} \mathrm{T}^{*}+\mathrm{b}
$$

where $T^{*}$ is the surface temperature, which differs from the local value of the average temperature of the upperflow (T) by a constant amount $\Delta \mathrm{T}_{\mathrm{G}}{ }^{\circ} \mathrm{C}$ everywhere over the pond

$$
T^{*}-T=\Delta T_{G} \text {, constant }
$$

Hence

$$
\frac{\mathrm{dT}}{\mathrm{dA}}=\frac{\mathrm{dT}^{*}}{\mathrm{dA}}
$$

The quantity $\mathrm{H}_{\mathrm{S}}-\mathrm{H}_{\mathrm{C}}$ is considered to be constant during the time interval of d days over which temperature, flows, and atmospheric conditions are averaged.

From Equations 1, 3a, 7a, and A-2

$$
-\frac{500 \mathrm{~F} \text { upperflow }}{\mathrm{f}_{\mathrm{A}}}\left(\frac{\mathrm{dT}^{*}}{\mathrm{dA}}\right)=\mathrm{mT}^{*}+\mathrm{b}-\mathrm{H}_{\mathrm{S}}+\mathrm{H}_{\mathrm{C}}
$$

Introducing the apparent equilibrium temperature

$$
\mathrm{T}_{\mathrm{e}}=\frac{-\mathrm{b}+\mathrm{H}_{\mathrm{S}}-\mathrm{H}_{\mathrm{C}}}{\mathrm{m}}
$$

with Equation A-3 gives

$$
-\frac{500 \mathrm{~F}_{\text {upperflow }}}{\mathrm{mf}_{\mathrm{A}}}\left(\frac{\mathrm{dT} \mathrm{T}^{*}}{\mathrm{dA}}\right)=\mathrm{T}^{*}-\mathrm{T}_{\mathrm{e}}
$$


which is integrated

$$
\int_{\mathrm{Tu}}^{*} \frac{\mathrm{dT}^{*}}{\mathrm{~T}^{*}-\mathrm{T}_{\mathrm{e}}}=-\frac{\mathrm{mf} A}{500 \mathrm{~F} \text { upperflow }} \int_{0}^{\mathrm{A}} \mathrm{dA}
$$

to give

$$
T^{*}=T_{e}+\left(T_{i u}{ }^{*}-T_{e}\right) \exp \left(-\frac{m f_{A} A}{500 F_{\text {upperf } 10 w}}\right)
$$

Equation $15 \mathrm{a}$ gives the surface temperature profile over the pond.

Thus, the local value for the rate of heat transfer to the atmosphere, by Equations $7 \mathrm{a}$ and $15 \mathrm{a}$, is

$$
\mathrm{H}_{\mathrm{T}}=\mathrm{m}\left[\mathrm{T}_{\mathrm{e}}+\left(\mathrm{T}_{\text {iu }}{ }^{*}-\mathrm{T}_{\mathrm{e}}\right) \exp \left(-\frac{\mathrm{mf}_{\mathrm{A}} \mathrm{A}}{500 \mathrm{~F}_{\text {upperf } 10 \mathrm{w}}}\right)\right]+\mathrm{b}
$$

and the average value over the surface of the pond is

$$
\overline{\mathrm{H}}_{\mathrm{T}}=\frac{1}{\mathrm{~A}_{\Sigma}} \int_{0}^{\mathrm{A}_{\Sigma}} \mathrm{H}_{\mathrm{T}} \mathrm{dA}
$$

or

$$
\bar{H}_{T}=m T_{e}+b+\frac{500 F}{f_{A} A_{\Sigma}}\left(T_{i u}{ }^{*}-T_{e}\right)\left(1-e^{-\alpha f_{A}}\right)
$$

where

$$
\alpha=\frac{\mathrm{mA}_{\Sigma}}{500 \mathrm{~F} \text { upperflow }}
$$

From Equations 1, 13, and A-4

$$
\mathrm{H}_{\mathrm{F}}=\frac{500 \mathrm{~F}}{\mathrm{f}_{\mathrm{A}} \mathrm{A}_{\Sigma}}\left(\mathrm{T}_{\mathrm{iu}}{ }^{*}-\mathrm{T}_{\mathrm{e}}\right)\left(1-\mathrm{e}^{-\alpha \mathrm{f}_{\mathrm{A}}}\right)
$$

The total heat load per square foot of effective surface area, $\mathrm{H}_{\mathrm{F}}$, can also be derived independently by its own definition by reference to the model for Par Pond, Figure 6

$$
H_{F}=\frac{500}{f_{A} A}\left[\left(F_{R \& P}+F_{r}\right) T_{i}+(z-1) F_{r} T_{W B}-F_{\text {overflow }} T_{0}^{*}-F_{P} T_{P}\right]
$$




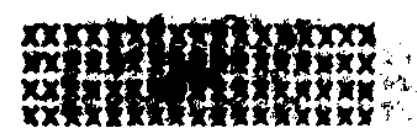

Now eliminate $H_{F}$ between Equations $A-5$ and $A-6$

$$
\begin{aligned}
& \mathrm{F}_{\text {upperflow }}\left(\mathrm{T}_{i u^{*}-\mathrm{T}_{\mathrm{e}}}\right)\left(1-\mathrm{e}^{-\alpha \mathrm{f}_{\mathrm{A}}}\right) \\
& =\left(\mathrm{F}_{\mathrm{R} \& \mathrm{P}}+\mathrm{F}_{\mathrm{r}}\right) \mathrm{T}_{i}+(\mathrm{z}-1) \mathrm{F}_{\mathrm{r}} \mathrm{T}_{W B}-\mathrm{F}_{\text {overflow }} \mathrm{T}_{0}^{*}-\mathrm{F}_{\mathrm{P}} \mathrm{T}_{\mathrm{P}}
\end{aligned}
$$

Some of the variables in Equation A-7 are not measured directly, so proceed with the analysis of the model as follows:

From Equation $\mathrm{A}-1$

$$
\begin{aligned}
& \mathrm{T}_{\mathrm{iu}}{ }^{*}=\mathrm{T}_{\mathrm{iu}}+\Delta \mathrm{T}_{\mathrm{G}} \\
& \mathrm{T}_{\mathrm{o}}{ }^{*}=\mathrm{T}_{\mathrm{O}}+\Delta \mathrm{T}_{\mathrm{G}}
\end{aligned}
$$

From the definition of $u$

$$
\mathrm{F}_{\text {underflow }}=\mathrm{u}\left(\mathrm{F}_{\mathrm{R} \text { GP }}+\mathrm{F}_{\mathrm{r}}\right)
$$

Thus, by flow balance,

$$
F_{\text {upperflow }}=\left[u+1+(z-1)\left(\frac{F_{r}}{F_{R \xi P}+F_{r}}\right)\right]\left(F_{R \& P}+F_{r}\right)
$$

and

$$
\mathrm{F}_{\text {overflow }}=\mathrm{F}_{\mathrm{RGP}}+\mathrm{zF}_{\mathrm{r}}-\mathrm{F}_{\mathrm{P}}
$$

By heat balance at the upstream (warm) end of the pond, using Equations A-8, A-9, and A-la

$$
T_{i u}^{*}=\frac{u T_{P}+T_{i}+(z-1)\left(\frac{F_{r}}{F_{R \& P}+F_{r}}\right) T_{W B}}{u+1+(z-1)\left(\frac{F_{r}}{F_{R \& P}+F_{r}}\right)}+\Delta T_{G}
$$

By heat balance at the downstream (cool) end of the pond, using Equations A-8, A-9, A-10, and A-1b

$$
\mathrm{T}_{\mathrm{O}} *=\mathrm{T}_{\mathrm{P}}+\left[1+\frac{\mathrm{F}_{\mathrm{R} q \mathrm{P}}+\mathrm{zF}_{r}-\mathrm{F}_{\mathrm{P}}}{\mathrm{u}\left(\mathrm{F}_{\mathrm{R} Q \mathrm{P}}+\mathrm{F}_{\mathrm{r}}\right)+\mathrm{F}_{\mathrm{P}}}\right] \Delta \mathrm{T}_{\mathrm{G}}
$$

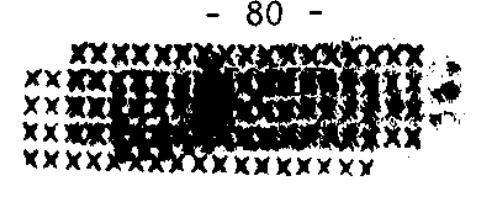


Substituting from Equations A-9, A-10, A-11, and A-12 into Equation A-7 gives

$$
K_{0} T_{P}+K_{2} T_{i}+K_{3} T_{W B}+K_{4} T_{e}+K_{5} \Delta T_{G}=0
$$

where

$$
\begin{aligned}
& K_{0}=-\left[u\left(1-e^{-\alpha f_{A}}\right)+\frac{F_{R \xi P}+F_{r}}{F_{R \xi P}+F_{r}}\right] \\
& K_{2}=e^{-\alpha f_{A}} \\
& K_{3}=\left(\frac{F_{r}}{F_{R \xi P}+F_{r}}\right)(z-1) e^{-\alpha f_{A}} \\
& K_{4}=\left(1-e^{-\alpha f_{A}}\right)\left[u+1+(z-1)\left(\frac{F_{r}}{F_{R \xi P}+F_{r}}\right)\right] \\
& K_{5}=-\left\{K_{4}+\left[\frac{F_{R \xi P}+z F_{r}-F_{P}}{F_{R \& P}+F_{r}}\right]\left[1+\frac{F_{R \xi P}+F_{r}-F_{P}}{u\left(F_{R \xi P}+F_{r}\right)+F_{P}}\right]\right\}
\end{aligned}
$$

or

$$
\Delta \mathrm{T}_{\mathrm{G}}=\frac{1}{-\mathrm{K}_{5}}\left(\mathrm{~K}_{0} \mathrm{~T}_{\mathrm{P}}+\mathrm{K}_{2} \mathrm{~T}_{i}+\mathrm{K}_{3} \mathrm{~T}_{W B}+\mathrm{K}_{4} \mathrm{~T}_{\mathrm{e}}\right)
$$

To calculate $\mathrm{T}_{e}$ by Equation 13 for use in Equation A-13a, it is necessary to know $\mathrm{HC}_{\mathrm{C}}$

$$
\mathrm{H}_{\mathrm{C}}=62.4 \mathrm{~h}\left(\frac{\overline{\mathrm{T}}_{\mathrm{d}}-\overline{\mathrm{T}}_{1}}{24 \mathrm{~d}}\right) \mathrm{f}_{\mathrm{C}}
$$

Assume that the change in the average pond temperature $\left(\bar{T}_{d}-\bar{T}_{1}\right)$ is the same as the change in the discharge temperature

$$
\overline{\mathrm{T}}_{\mathrm{d}}-\overline{\mathrm{T}}_{1} \cong \mathrm{T}_{\mathrm{d}}-\mathrm{T}_{1}
$$

where $\mathrm{T}_{1}$ is the discharge temperature observed at the pump house at the start of the time interval, and $T_{d}$ is the discharge temperature observed at the end of the interval ( $\mathrm{d}$ days). Both $\mathrm{T}_{1}$ and $T_{d}$ are available from the data on Par Pond performance.

Further, in calculating $\mathrm{T}_{\mathrm{e}}$ by Equation 13 take 


$$
\begin{aligned}
& \mathrm{m}=\frac{\mathrm{H}_{\mathrm{T}, \mathrm{iu}}-\mathrm{H}_{\mathrm{T}, \mathrm{o}}}{\mathrm{T}_{\mathrm{iu}}{ }^{*}-\mathrm{T}_{\mathrm{o}}{ }^{*}} \\
& \mathrm{~b}=\mathrm{H}_{\mathrm{T}, \mathrm{iu}}-\mathrm{mT}_{i u^{*}}{ }^{*}
\end{aligned}
$$

where $\mathrm{H}_{\mathrm{T}}$, iu and $\mathrm{H}_{\mathrm{T}}, \mathrm{o}$ are calculated by Equations 4,5 , and 6 and the known vapor pressure of water. Since both $T_{i u}$ * by Equation A-11 and $T_{O}{ }^{*}$ by Equation $A-12$ require knowing $\Delta T_{G}$, a trial-and-error solution of Equations A-13a, 2a, A-14, 4, 5, 6, A-11, A-15, A-16, 13, 16a, and A-12 is entailed. The results of such an analysis of Par Pond data are given in Table $\mathrm{V}$.

The contribution from runof $f, z$ and $F_{r}$, are calculated as follows: If 13.3 square miles drains through the $R$ and $P$ effluent canal systems, and the total drainage area for Par Pond is 36 square miles, then

$$
z=36 / 13.3=2.71
$$

and, for $r$ inches of rainfall in d days with runoff fraction $f_{r}$

$$
F_{r}=160,500 \frac{r f_{r}}{d}
$$

where

$$
160,500=\frac{13.3 \times 5280^{2}}{12 \times \cdot 1337 \times 24 \times 60}
$$

Thus, the correlation of the pond performance is presented as the function for $\Delta \mathrm{T}_{\mathrm{G}}$ versus the season of the year. Once the $\Delta \mathrm{T}_{\mathrm{G}}$ function has been determined, the correlation can be used to calculate the discharge temperature at other conditions of imposed flow, canal effluent temperature, and atmospheric conditions. In this case, the discharge temperature $\mathrm{T}_{1}$ at the start of the time interval will be known. To solve for the average discharge temperature $T_{p}$ during the time interval by Equations A-13 and 13, which uses $\mathrm{H}_{C}$, it is necessary to choose a time interval smal1 enough that it is a good approximation to say

$$
\mathrm{T}_{\mathrm{P}} \cong \frac{1}{2}\left(\mathrm{~T}_{1}+\mathrm{T}_{\mathrm{d}}\right)
$$

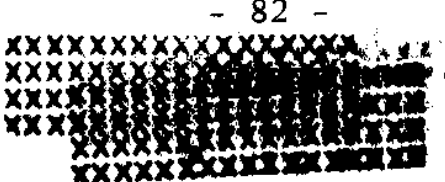




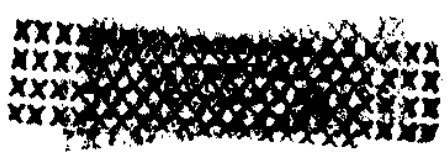

Then from Equations 2a, A-14, and A-18

$$
\mathrm{H}_{\mathrm{C}}=5.2\left(\frac{\mathrm{hf}}{\mathrm{d}}\right)\left(\mathrm{T}_{\mathrm{P}}-\mathrm{T}_{1}\right)
$$

where

$$
5.2=\frac{2 \times 62.4}{24}
$$

From Equations A-19, 13, and 10

$$
\begin{aligned}
& T_{e s}=\frac{-b+H_{S}}{m} \\
& T_{e}=T_{e s}-5.2\left(\frac{h f_{C}}{m d}\right)\left(T_{P}-T_{1}\right)
\end{aligned}
$$

From Equations $\mathrm{A}-20$ and $\mathrm{A}-13$

$$
\mathrm{T}_{\mathrm{P}}=\mathrm{k}_{1} \mathrm{~T}_{1}+\mathrm{k}_{2} \mathrm{~T}_{i}+\mathrm{k}_{3} \mathrm{~T}_{W B}+\mathrm{k}_{4} \mathrm{~T}_{e s}+\mathrm{k}_{5} \Delta \mathrm{T}_{\mathrm{G}}
$$

where

$$
\begin{aligned}
\mathrm{K}_{1} & =5.2\left(\frac{h f_{C}}{\mathrm{md}}\right) \mathrm{K}_{4} \\
\mathrm{k}_{0} & =-\left(\mathrm{K}_{0}-\mathrm{K}_{1}\right) \\
\mathrm{k}_{0} \mathrm{k}_{1} & =\mathrm{K}_{1} \\
\mathrm{k}_{0} \mathrm{k}_{2} & =\mathrm{K}_{2} \\
\mathrm{k}_{0} \mathrm{k}_{3} & =\mathrm{K}_{3} \\
\mathrm{k}_{0} \mathrm{k}_{4} & =\mathrm{K}_{4} \\
\mathrm{k}_{0} \mathrm{k}_{5} & =\mathrm{K}_{5}
\end{aligned}
$$

where $K_{0}, K_{2}, K_{3}, K_{4}$, and $K_{5}$ are the coefficients in Equation A-13.

Starting with the discharge temperature $T_{1}$ at time zero, the average discharge temperature $T_{P}$ for the first interval of $d$ days is calculated by Equation A-21. Then the discharge temperature $T_{d}$ at the end of that time interval, which is calculated by Equation $A-18$, becomes the new value for $T_{1}$ at the start of the next time interval. 


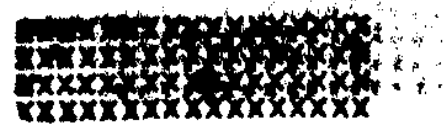

(Blank)

- 84 -

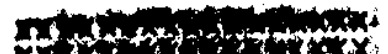

F. Wh

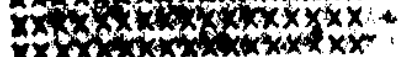




\section{COMPUTER PROGRAM LIMN}
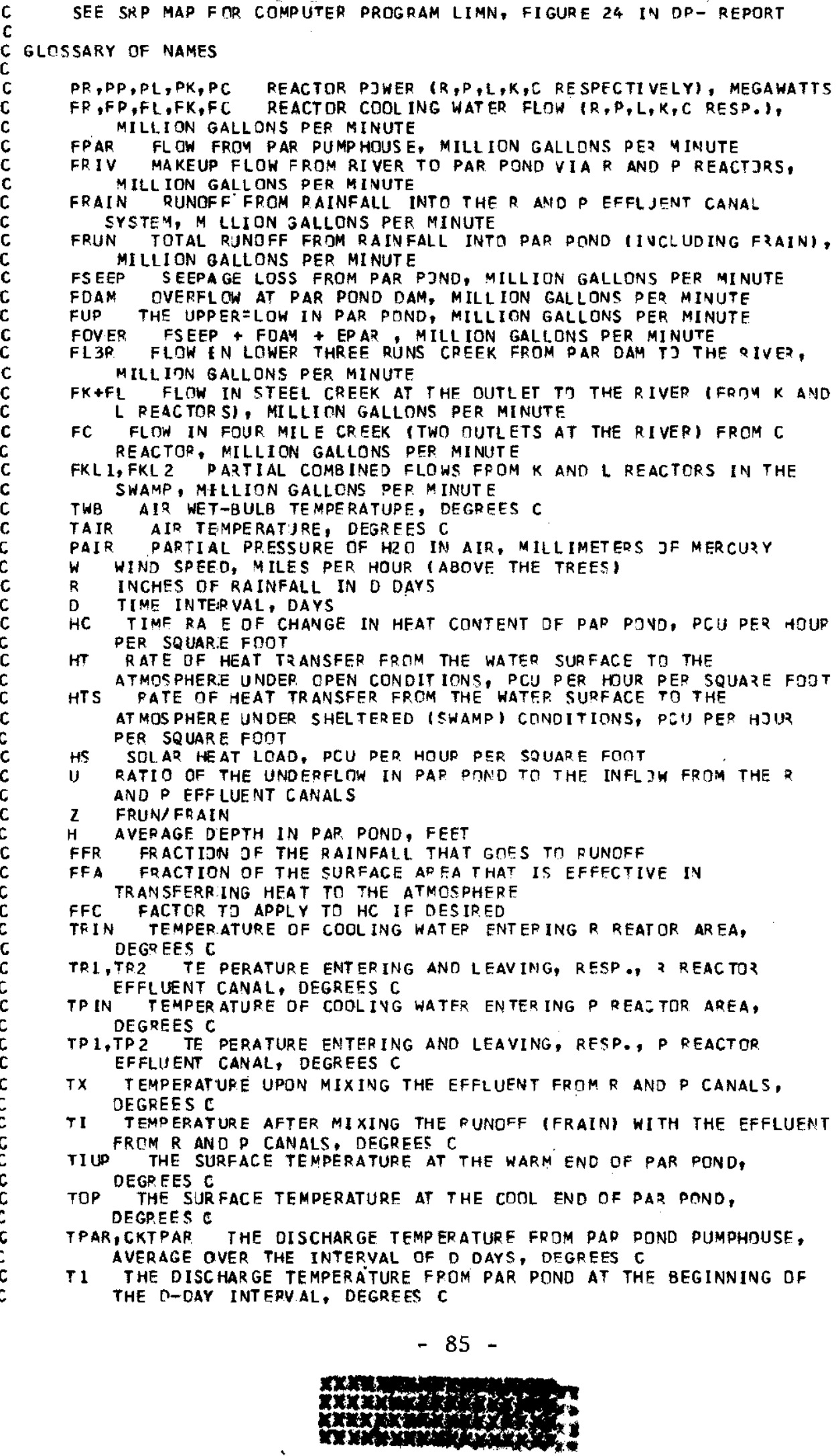
C TD THE DIS:HARGE TEMPERATURE FRDM PAR POND AT THE END OF THE D-DAY INT'ERV AL, DEGREES C

TPIV TEMPERATURE OF THE SAVANNAH RIVER AT THE RIVER PUMPHOJSE, DEGREES C

TC1,TC2,TC3,TC' TEMPERATURES OF C EFFLUENT COOL IVG WATER AS IT TRAVERSE FOUR MILE CREEK AND THE SHAMP ON ITS WAY TO THE RIVER, DEGREES C

TC TEMPERATURE OF C EFFLUENT COOL ING WATER WHEN IT REACHES THE SAVANNAH RIVER VIA FOUR MILE CREEK (TWO OUTLETS), DEGREES C

TK1, TK2,TK3 TEMPERATURES OF K EFFLUENT COJLING WATER AS IT TRAVER SES PEN BRANCH AND THE SWAMP, DEGREES C

TL1,TL2,TL3,TL4 TEMPERATURES OF L EFFLUENT CDOLINJ WATER AS IT TRAVERSE : STEEL CREEK AND THE SW AMP, DEGREES C

TKL 1, TKL 2, TKL 3 TEMPERATURES OF PARTIALLY MIXED EFFLUENT WAT ER FROM $K$ A NO L REACTORS, AS FDUNO IN THE SWAMP. DEGREES C

TKL TEMPERATURE OF THE MIXED K AND L EFFLUENT COOL ING WATER WHEN IT REACHES THE SAVANNAH RIVER VIA THE DUTLET FOR STEEL CREEK, DEGREES C

TRP TEMPER TURE OF THE DVERFLOH AND SEEPAGE FROM PAR POND IR AND P RFACTORSI WHEN IT REACHES THE PIVER VIA LOWER THREE RUNS CREEK, DEGREES C

DTG THE DIFFERENCE BETWEEN THE SURFACE TEMPERATURE AND THE AVERAGE TEMPERATURE OF THE J PPERFL OW IN PAR POVD, DEGREES C

TE APPARENT EQUILIBRIUM TEMPERATURE UNDER OPEN CONDITIONS, DEGREES $C$

TES APPARE T EQUILIBRIUM TFMPERATURE UNDER SHELTERED (SHAMP CONDITIONS, DEGREES C

TEQ APPARENT EQUIL IBRIUM TEMPERATURE (SUBROUT INE JWL)

EM,EMS,EMQ SLOPE OF THE STRAIGHT-LINE FIT TO THE LANGHAAR CDOLING RATE CURVE FOR OPEN CONDITIONS, SHELTERED CONOITIONS, AND SUBR CUTINE, RESPECT IVELY

B, BS, BQ INTERCEPT OF THE STRAIGHT-LINE FIT TO THE LANGHAAR COOLING RATE CURVE FOR OPEN CONDITIONS, SHELTERED CONDITIJNS, AND SUBROUTINE, RESPECTIVELY

F FLDW IN SUBRDUTINE JWL, MILLION GALLONS PER MINUTE

ATOT EFFECTIIVE SURFACE AREA IN SUBROUT INE JWL, MILL ION SQUARE FEET

TIN,TRUT TEMPERATURES ENTER ING AND LEAVING, RESP, A REGION HAVING ATOT (FOR SUBROUT INE JWL), DEGREES C

ESUM EVAPORATION BETWEEN TIN AND TOUT OVER ATOT IFOR SUBROUTINE JWL), MILLION GALLONS PER MINUTE

ER 2 EVAPOR ATION BETWEEN TRI AND TR2 IN THE R EFFLUENT CANAL, MILLION GALLONS PER Y IVUTE

EP2 EVAPRRATION BETWEEN TP1 AND TP2 IN THE D EFFLJENT CANAL. MILLION GALLONS PER MINUTE

EDP EVAPORATION FROM PAR POND, MILLICN GALLONS PER MINUTE

EPAR TOTAL FVAPORATION FROM PAR POND AND R AND P EFFLUENT CANALS, MILLION GALLONS PER MINUTE

EL3R EVAPORATION IN LOWER THREE RUNS CREEK BETWEEN PAR POND AND THE SAVANNAH RIVER, MILLION GALLONS PER MINUTE

EC 2 EVAPORATIJN IN FDUR MILE CREEK ( C EFFLUENT COOLING WAT ER) BETWEEN TC1 AND TC2, MILLIDN GALLONS PER MINUTE

EC 3,EC4 EVAPORATION OF C EFFLUENT COOLING HATER IN THE SWAMP BETWEEN TC2 AND TC3 AND BETWEEN TC2 AND TC4, RESP. MILLION GALLONS PER MINUTE

EC TITAL EVAPORATION OF C EFFLUENT COOLING WATER IN TRAVERS ING FOUR MILE CREEK AND THE SWAMP TO THE SAVANNAH RIVER. MILLION ALLONS PER MINUTE

EK 2, EK 3 EVAPORATION OF K EFFLUENT COOLING WATER IN PEN BRANCH AND THE SHAMP BETWEEN TK1 AND TK2 AND BETWEEN TK2 AND TK3, RESP., MILLION.GALLONS PER MINUTE

EL2, EL 3, EL4 EVAPORATION JF L EFFLUENT CDOLING WATER IN STEEL CREEK AND THE SWAMP BETWEEN TLI AND TL2, TLZ AND TL3, AND TL 2 AND TL4, RESP \& MILLICN GALLONS PER MINUTE

EKL3 EVAPORAT IDN OF L EFFLUENT COOL ING WATER AND DART OF K EFFLUENT COOLINS WATER IN THE SWAMP ( NEAR STEEL CREEK OJTLET) BETWEEN TKL 2 AND TKL 3, MILL ION GALLONS PER MINUTE

EKL TOTAL EVAPORATION FOR $K$ AND L EFFLUENT COOL ING WATER BEFORE REACHING THE SAVANNAH RIVER, MILLION GALLONS PER MINUTE

HFG LATENT HEAT OF EVAPDRAT ION FOR WATER, PCU PER POUNO

PCU POUND-EENTIGRADE HEAT UNIT, I.E. THE AMOUNT OF HEAT NEEDED TO RAISE THE TEMPERATURE DF DNE POUND OF WATER BY ONE DEGREE C

FORTRAN LISTING 
I SN 0002

ISN 0003

ISN 0004

I SN OCO5

ISN COO6

ISN DON 7

I SN ONOB

ISN 0009

ISN OA10

I SN 0011

ISN 0012

I SN $0 \mathbb{N}_{13}$

ISN 0014

ISN 0215

ISN 0016

ISN $\operatorname{COI} 7$

ISN OO18

I SN OO1

ISN 0020

I SN 0021

ISN OC, 22

ISN CO23

I SN $\mathrm{CO} 24$

ISN OO 25

ISN 01126

ISN 0027

ISN IN 2 .

ISN COL 29

ISN 0030

ISN OM 3 I

ISN OLI2

ISN Cr:33

ISN CC 34

ISN OC35

ISA COB6

ISN 00137

ISN

I SN $0 \mathrm{C} 3$

ISN $\mathrm{COC}^{\circ}$

ISN 0,41

I SN 0042

ISN $\because$ ? 43

I SN $6 \times 44$

ISN Cr 45

ISN $\mathrm{C}: 46$

ISN IS 47

I SN $\quad 098$

ISN 0049

I SN 0055

ISN 0051

ISN 0052

ISN 0053

ISN C054

I SN C:5 55

ISN 0056

I SN 2057

ISN 0058

ISN 005

ISN CC6O

ISN 0 n6 1

I SN 006 62

ISN 1063

I SN 0064

I SN C065

ISN 9066

I SN 0067

ISN C268
DIMENSION TT(1C), VP(I0), HT (13),EM(9),B(9),TE(9), HTS (10), EMS(9), BS( 19), TES (9), EMJ (9), BQ(9), TEQ(9), TEP(9)

CCMMON TIN,TOUT, F, AT OT, TT, EMQ, BQ, T EQ, ESUM, IJK, GB, TA IR

$\operatorname{READ}(5,101)$ (TT(J), J $=1,10)$

PEAD $(5,101)$ ( VP(J),J $=1,10)$

101 FORMAT (1)F 8.3)

7 REAO( $5,100, E N D=8 I \cap)$ IR, IP,IL,IK,IC

100 FCIRMAT (5I1))

RFAD $(5,110)$ PR, PP,PL,PK,PC

110 FORMAT (5F10.0)

READ $(5,120)$ FP, FP, FPAR, FSEEP, FFF

120 FORMAT (4F $12,6, F 10.4)$

RFAD $(5,130) \mathrm{FL}, \mathrm{FK}, \mathrm{FC}$

130 FORMAT (3F12.6)

PEAO $(5,140)$ TR IV,TI,DTG

140 FORMAT (3FIO.2

PEAD $(5,150)$ TAIR, TWB, PAI $, W, H S, P, 0$

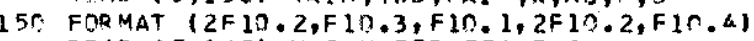

READ $(5,16$ C) $U, 2, H, F F R, F F A, F F C$

160 FTPMAT (6F10, 21

$E \times 2=0$.

EK $3=0$.

$E L 2=$ ?

$E \mathrm{~L} 3=0$.

$\mathrm{Ft} 4=0$.

EP 2 $=3$.

EP2 $=1$ ?

WP I TE $(6,17$ ह $)$

170 FOFMAT (1H1.5HINPUT

W' ITF $(\leqslant, 171)$

FORMAT I 1HA,5SH IR IP IL IK

C)

WPITE $(6,1, W)$ IF, IF, IL, IK, IC

WFI TE $(6,172$ :

172 FORMAT (1H,4\%H PF

WPITE $(6,110)$ PR, PP, PL, PK, PC

WP. ITE $(6,173)$

173 FPPMAT IIHT.57H FP FP

1 FFFI

FR

WFITF $(6,120)$ FR, FP, FPAP, F SEEP, FFF

WRTY 16,174$)$

$W=I T F(E, 13 n) F L, F K, F C$

WRI TE $(6,178)$

178 FORMAT (IHT,3IH TRIV

WOITE $(6,140)$ TRIV,TI, DT

WFI TE $(6,175)$

175 FIRMAT (IHN,66H

TAIR

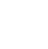

D)

WT ITF $(6,150)$
WEITF $(6,176)$

172 FOFMAT (1H 6 OH

I $F F C$ )

WFITE $(6,160) U, Z, H, F F G, F F A, F F C$

WE I TE $(6,177)$

177 FCRMAT I1H^,6HJUTPUT

$G A=1,63 *(1 .+01 * W)$

$\mathrm{GB}=1.22 *(1.5+.1 * \mathrm{w})$

$\mathrm{GAS}=1 \cdot \leftarrow 3$

$G B S=1.8$

DC $185 \quad I=1,10$

$H T(I)=G A *(V P(I)-P A I R)+G B *(T T(1)-T A I P)$

$185 \mathrm{HTS}(I)=\mathrm{GAS} *(\mathrm{P}(\mathrm{I})-P A I F)+\mathrm{GBS} *(T T(I)-T A I P)$

DO $190 \quad \mathrm{~J}=1,9$

$I=\mathrm{J}+\mathrm{I}$

$E M(J)=\left(H^{\top}(J)-H^{\top}(I)\right) /(T T(J)-T T(I))$

$B(J)=H T(J)-E M(J) * T T(J)$

EMS $(J)=($ HTS $(J)-H T S(I)) /(T T(J)-T T(I))$

$B \leqslant(J)=H r \leqslant(J)-E M S(J) * T T(J)$

$T F(J)=(-8(J)$ HS $) / F M(J)$

$190 \operatorname{TES}(J)=-B S(J) / F M S(J)$

WF ITE $(t, 191)$ 
ISN 0069

ISN 0070

ISN 0071

ISN 0072

ISN 0073

ISN 0074

I SN 0075

ISN 0076

I SN 0077

ISN 0078

ISN 0079

ISN 0580

ISN 0081

ISN 0082

ISN 0083

ISN 0084

ISN 0085

I SN 0086

ISN CO87

ISN 0088

ISN CC89

ISN 0090

I SN 0091

ISN 0092

I SN 0094

ISN 0095

I SN 0097

ISN 0098

ISN 0099

ISN 0100

ISN 0101

ISN C1n2

I SN 0103

IS N 0104

ISN 0105

ISN 0107

ISN 0108

ISN 0109

ISN 0110

ISN 0111

ISN 0112

IS N 0113

ISN 0114

ISN 0115

ISN C116

ISN 011 ?

ISN 0119

I SN 0120

ISN 0121

ISN 0122

I SN 0123

ISN 0124

ISN 0126

I SN $\mathrm{Cl} 27$

ISN 0128

I SN 0129

ISN 0130

ISN 0131

I SN 0132

ISN 0133

ISN 0134

ISN 0135

I SN 0136 ISN 0137

ISN 0138

ISN 0140

ISN 0141
191 FORMAT I 1 HO,49HLANGHAARS COD.ING RATE CUR VE FOR OPEN CONDITIONS' WR ITE $16,192 \mathrm{~K}$ (TT (I), I =1,10)

192 FORMAT (1HO, 9HDEGREES C, $4 \times, 10 F 10.2)$

WRITE: $(6,193)$ (HT $(1),[=1,10)$

193 FORMAT $(1 \mathrm{H}, 2 \mathrm{HHT}, 11 \times, 10 \mathrm{O} 10.2)$ WR ITE $(6,194)$ (EM $(I), I=1,9)$

194 FORMAT' (1HO,2 HEM, $21 X, 9 F 10.4)$ WR ITE ( 6,195$) \quad(B(I), I=1,9)$

195 FORMAT (IHO, 1 HB, $22 X, 9 F 10.2$ )

WFITE $(6,196) \quad(T E(I), 1=1,9)$

ISO FORMAT (1HO,2HTE, $21 \times, 9 F 10.4)$ WR ITE $(6,157)$

197 FMRMAT (1 HO, 5 OHLANGHAARS COOLING RATE CURVE FOP SWAMP CONOITIONS') WD ITE $(6,198)$ (TTII), I $=1,10)$

198 FORMAT $(1 \mathrm{H}, 9$ HDEGPEES $c, 4 x, 10 \mathrm{~F} 10.2)$ WPI TE $(6,199) \quad$ (HTS(1), $1=1,10\}$

199 FIFMAT (1HO, 3HHTS, $10 \times, 10 \mathrm{H} 10.2)$ WRITE $(6,200)$ (EMS (I), I =1,9)

200 FORMAT $11 \mathrm{HO}, 3 \mathrm{HEMS}, 20 \mathrm{X}, 9 \mathrm{~F} 13.41$ WRITE $(6,20)$ (BS (1), I=1,9)

201 FORMAT $(1 \mathrm{HO}, 2 \mathrm{HBS}, 21 \times, 9 \mathrm{FlO} .2)$ WRITE $(6,202)$ (TES(I) $, I=1,9)$

c

202 FORMAT $(1 \mathrm{HO}, 3$ HTES, $23 \times, 9 \mathrm{~F} 10.4)$

IF (IC.LT.I) GJ TO 250

TC $1=T R I V+1.897 * P C / 500.1 F C$

IF (TC L.GT.TT(1)) GO TO 797

DO $210 \quad L=1,9$

$T F Q(L)=T E(L)$

$E M Q(L)=E M(L)$

$210 \quad B Q(L)=B(L)$

$T I N=T C I$

$F=F C$

ATQT $=8.56$

CALL JWL

IF (IJK.GT.O) GO TO 797

TC $2=$ TOUT

$E C 2=E S U M$

DO $220 \mathrm{~L}=1,9$

$T E Q(L)=T E S(L)$

$E M O(L)=E M S(L)$

$220 B Q(L)=B S(L)$

$T$ IN $=T C 2$

$F=.276 * F C$

ATOT $=5.65$

CALL JWL

IF (IJK.GT.0) GD TO 797

TC 3=TOUT

$E C_{3}=E S U M$

$\mathrm{F}=.724 * \mathrm{FC}$

$\triangle T O T=6.80$

CALL JWL

IF (I JK.GT.OK GO TO 797

TC4 = T OUT

$E C 4=E S U M$

$T C=.276 * T C 3+.: 724 * T C 4$

$E C=E C 2+E C 3+E C 4$

WQ ITE 16,230 .

230 FOFMAT (1HO,46HTHE C EFFLUEVT CW TEMPERATURES ARE AS FOLLOWS') WRITE $(6,231)$ TC1,TC2,TC3,TC4

231 FOR $1=, F 6.21$ HR I TE $(6,232)$ TC

232 FORMAT 11 HO, 105 HTHE MIXED TEMPERATUPE OF THE TWO OUTLET STREAMS AT

2 THE RIVER FOR FOUR MILE CRFEK, FROM C REACTIRR, IS TC $=$. FG,2) WRITE 16,233 IEC

233 FOPMAT (1HO,59HTHE EVAPORATION IN FOUR MILE CREEK, FROM C REACTOF, 1 IS $E C=, F 12 \mathrm{~s})$

250 IF (IK.LT.1) GO TO 300

TKL =TRIV+1.897*PK/500./FK

IF (TKI.GT.TTII) GO TO 797 


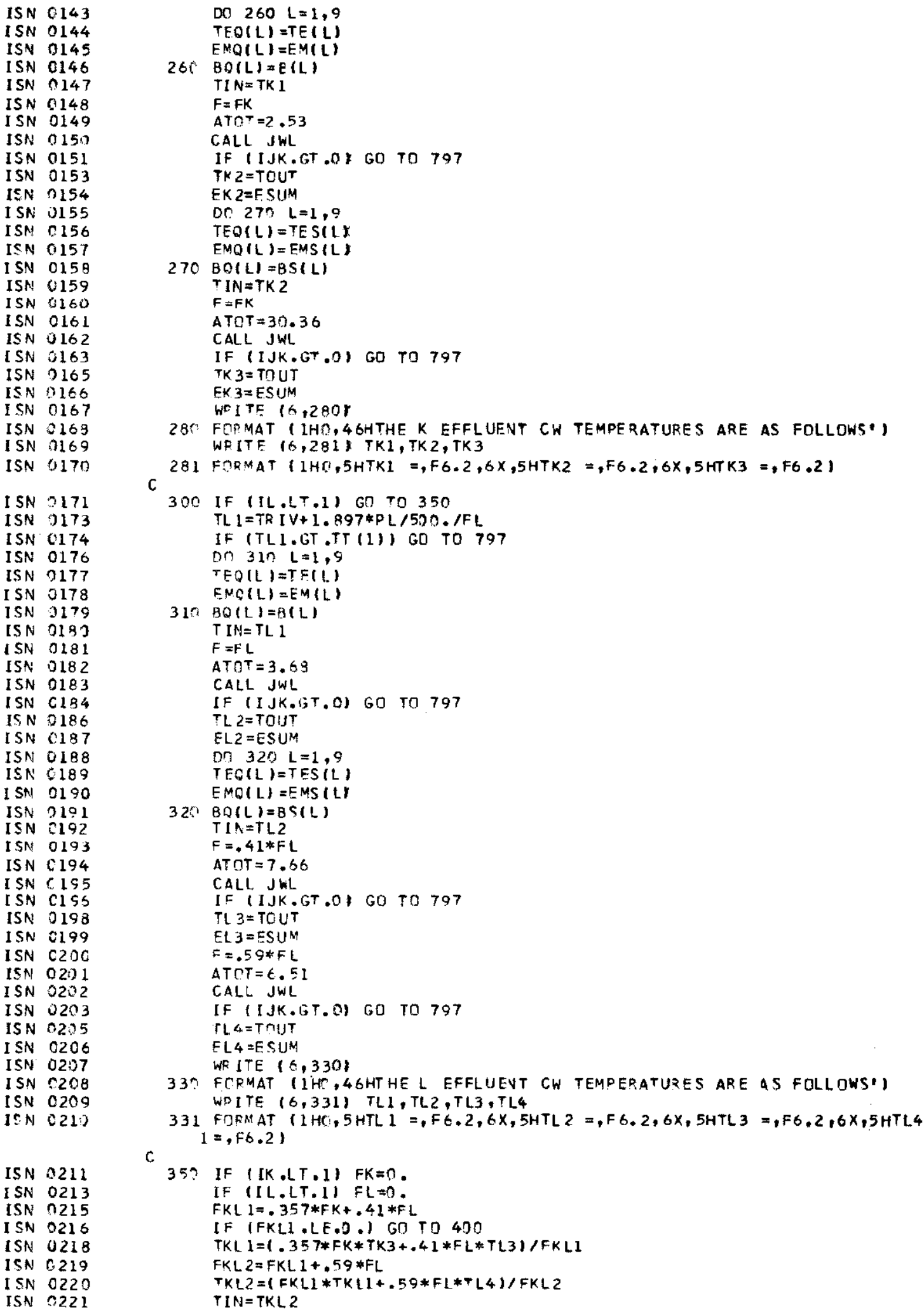

ISN 0143

ISN 0144

ISN 0145

ISN 0146

ISN $\$ 147$

ISN 0148

I SN 0149

ISN 0150

ISN 0151

ISN 0153

ISN 0154

ISN U155

ISN 0156

ISN 0157

ISN 0158

ISN 0159

ISN 160

ISN 0161

ISN 0162

[SN 0163

ISN 9165

ISN 0166

I SN 0167

ISN 0163

ISN 0169

ISN 0170

I SN 2171

ISN 0173

ISN 0174

ISN 0176

ISN 0177

I SN 3178

ISN 9179

[SN 018]

ISN 0181

ISN 0182

ISN 0183

ISN C184

IS N 0186

ISN 0187

ISN 0188

ISN 0189

ISN 0190

ISN 0101

ISN $\quad 0192$

I SN 0193

ISN C 194

I SN C 195

I SN CISS

ISN O 198

ISN 0199

ISN C2OC

ISN 0201

I SN 0202

ISN 0203

ISN 0235

I SN 0206

ISN 02,7

I SN 0208

ISN 0209

IS N O213

ISN 0211

I SN 0213

ISN 0215

I SN 0216

ISN 0218

ISN 0219

I SN 0220

ISN 9221

DO $260 L=1,9$

$T E Q(L)=T E(L)$

$E M Q(L)=E M(L)$

$260^{\circ} \mathrm{BO}(\mathrm{L})=\mathrm{E}(\mathrm{L})$

TIN $=$ TK I

$\mathrm{F}=\mathrm{FK}$

ATOT $=2.53$

CALL JWL

If I IJK.GT.OY GO TO 797

TK2 = TOUT

EK $2=$ F SUM

DC $270 \quad L=1,9$

$T E Q(L)=T E S(L X$

$E M Q(L)=E M S(L)$

$270 B O(L)=B S(L)$

TIN $=$ TK 2

$F=F K$

ATOT $=30.36$

CALL JWL

IF (IJK.GT.O) GO TO 797

TK $3=$ TOUT

EK $3=E S U M$

WEITE $(6,280)$

$28^{\circ}$ FOPMAT (IHO,46HTHE K EFFLUENT CW TEMPERATURES ARE AS FOLLOWS') WFITE 16,281 ) TK1, TK2,TK3

C (28)

300 IF (IL.LT.1) GO TO 350

$T L I=T R I V+1.897 * P L / 520 . / F L$

IF (TLI.GT.TT (1)) GO TO 797

DO 3 in $L=1,9$

TEQ (L) $=T F(!)$

$E M C(L)=E M(L)$

$31 \circ B Q(L)=A(L)$

$T I N=T L I$

$F=F L$

ATOT $=3.63$

CALL JWL

IF (I JK. $;$ T . O) GO TO 797

TL $2=T O I J T$

$E L 2=E S U M$

D) $320 \quad L=1,9$

$T E Q(L)=T E S(L)$

$E M Q(L)=E M S(L)$

$320 \quad B Q(L)=B S(L)$

$T I N=T L 2$

$\mathrm{F}=, 41 * \mathrm{FL}$

AT OT $=7.66$

CALL JWL

IF I IJK.GT.O) GO TO 797

TL $3=$ TOUT

EL $3=$ ESUM

$F=.59 * \mathrm{FL}$

$\triangle T C T=6.5 I$

CALL JWL

IF (IJK.GT.O) 60 TO 797

TL $4=T$ TUTT

$E L 4=E$ SUM

WR ITE $\{6,330\}$

33? FCRMAT (IHT, 46 GTHE L EFFLUEVT CW TEMPERATURES ARE AS FOLLOWS') WDITE $(6,331)$ TL1, TL2, TL3, TL4

331 FDFMAT $(1 \mathrm{HC}, 5 \mathrm{HTL} 1=, F 6,2,6 \mathrm{X}, 5 \mathrm{HTL} 2=, F 6,2,6 \mathrm{X}, 5 \mathrm{HTL} 3=, \mathrm{FG}, 2,6 \times, 5 \mathrm{HTL}, 4$ $1=, F 6.2$ )

35? IF $\{[K, L T, 1) \quad F K=0$.

IF (IL.LT.I) FL=0.

$F K L 1=.357 * F K+.41 * F 1$

IF (FKL].LE.O.) GO TO 400

TKL $1=(.357 * F K * T K 3+.41 * F L * T L 3) / F K L 1$

$F K L 2=F K L 1+.59 * F L$

$T K L 2=(F K L 1 * T K L 1+.59 * F L * T L 4) / F K L 2$

$T I N=T K L 2$ 
ISN 0222

ISN 0223

ISN 0224

ISN 0225

ISN 0227

ISN 0228

I SN 0229

ISN 0230

I SN 0231

ISN 0232

I SN 0233

ISN 0234

ISN 0235

IS N 0236

ISN 0237

ISN 0238

I SN 0239

ISN 0241

ISN 0242

ISN 0243

ISN 0244

I SN 0245

I SN 0246

IS N 0247

I SN 0248

ISN 0249

ISN 0250

I SN 0251

I SN 0253

ISN 0254

I SN 0255

ISN 0257

ISN. 0258

I SN 0259

ISN 0260

ISN 0261

I SN 0262

ISN 0263

ISN 0265

ISN 0266

ISN 0267

I SN 0269

ISN 0270

I SN 0271

ISN 0273

ISN 0274

I SN 0275

ISN 0276

ISN 0277

ISN 0279

ISN 0289

I SN 0281

ISN 0283

ISN 0285

ISN 0287

ISN 0288

I SN 0289

I SN 0290

ISN 0291

ISN 0292

I SN 0293

ISN 0294

ISN 0295

I SN 0296

ISN 0297

ISN 0298
$F=F K L 2$

ATOT $=1.45$

CALL JWL

IF (IJK.GT.O) GO TO 797

TKL J= TOUT

EKL $3=$ ESUM

$T K L=1.643 * F K * T K 3+F K L 2 * T K L 3) /(F K+F L)$

$E K L=E K 2+E K 3+) L 2+E L 3+E L 4+E K L 3$

WRIT E $16,355 \%$

355 FORMAT (1HO,62HTHE TEMPERATURES IN STEEL CREEK NEAR THE R.IVER ARE IAS FOLLOWS I I

WR ITE $(6,356)$ TKL1,TKL.2,TKL3,TKL

356 FORMAT 1 1HO,61-TKL $1=, F 6.2,6 X, 6 H T K L 2=, F 6.2,6 X, 6 H T K L 3=, F 6,2,5 X, 5 H T K$ $1 \mathrm{~L}=$, F6.2 WP ITE $(6,360)$ TKL

360 FORMAT (IHC, 8 3HTHE TEMPERATURE OF STEEL CREEK OUTLET AT THE RIVER, 1 FRDM K AND L REACTORS, IS TKL $=$,FG.2I

WR ITE ( $t, 365$ I EKL

365 FORMAT IIHO,79HTHE EVAPORATION IN PEN BRANCH AND STEEL CREEKS, FRO $1 M K$ AND L. REACTOR.S, IS EKL $=$,Fl2.6)

400 IF (IIR+IP).LT.L) GD TO 800

DO $403 \mathrm{~L}=1,9$

$E M Q(L)=E M(L)$

$403 B O(L)=B(L)$

$F R I V=F R+F P \rightarrow F P A R$

$M=0$

TPAR $=$ T 1

$405 T D=2 . * T P A R-T I$ $H C=62.4 * H *(T-T 1) * F F C / 24.1 D$

$00408 \quad J=1,9$

$4 ? 8$ TEP $(J)=(-B(J)+H S-H C) / E M(J)$

IF (IP.LT.1) GO TO 42 ?

TPIN = (FFF*FPAQ*TPAR+ (FP-FFF*FPAF)* $R I V$ IV FP

TP $I=T P I N+1.897 * P D / 50 N$. /FP

IF (TPI.GT.TTII)) GO TO 797

Dn $410 L=1,9$

41r TEQ(L)=TE(L)

$T$ I $N=T P$ I

$F=F P$

AT CT $=10.58$

CALL JWL

IF (IJK.GT,O) 30 TO 797

$T P Z=T$ DUT

EP $2=E$ SUM

420 IF (IR .LT.1) GO TO 430

TR IN $=(1$, -FFF $) * F P A R * T P A R+(F R-(1 .-F F F) * F P A R) * T R I V) / F 2$

TF $1=T R I N+1.897 * P R / 500 . / F R$

IF (TR1,GT .T I(1)) GO TO 797

TI $N=T R I$

$F=F R$

$A T O T=8.30$

CALL JWL

IF (IJK.GT . I GO TO 797

TR $2=T$ TOT

EP $2=E S U M$

430 IF (IP.LT.1) FP=0.

IF $(I R, L T .1) \quad F R=0$.

IF ( (FR+FP) ILE.O $)$ GO TO 800

$T X=(F R * T R 2+F F+T P 2) /(F R+F P)$

$F R A I N=.1605 * R * F F R / D$

$F U P=(U+1) *,(F R+F P+F R A I N)+(Z-1) * F P A I$,

$T I=(T X *(F R+F P)+F R A I N * T W B) /(F R+F P+F R A I N)$

$T I U P=\left(U * T P A R+T 1+(Z-1) * F R A I V * T W B /,\left(F R+F P+F^{2} A I N\right)\right) /(U+1,+(Z-1,1 * F P A I N$ $1 /(F R+F P+F R A I N))+D T G$ DO $450 L=1,9$

450 TEQ(L) $=T E P(L)$

$T I N=T I U P$

F= FUP

$A T O T=108.9$

CALL JWL

IF IJK.GT . I GD TO 797 

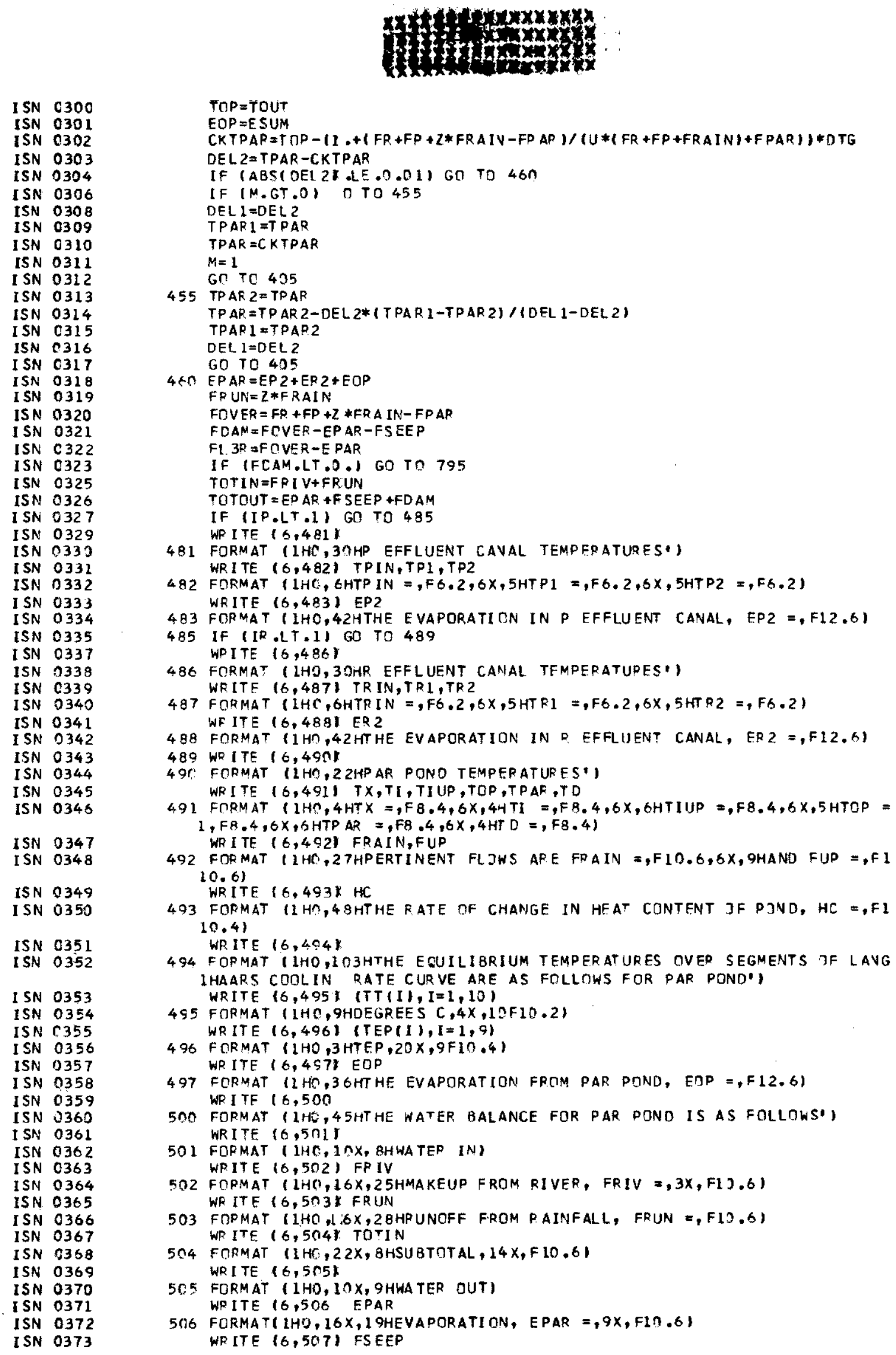


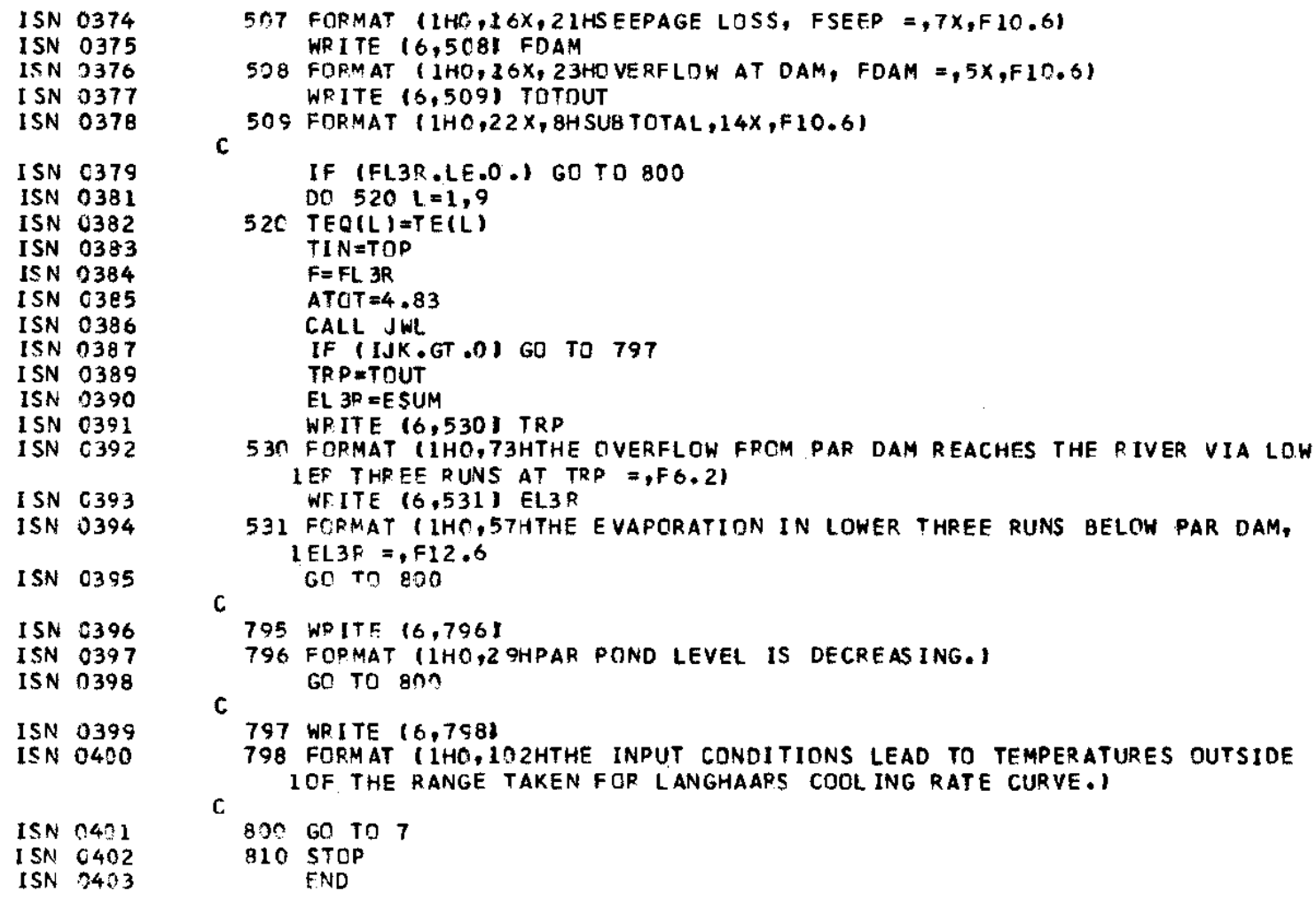




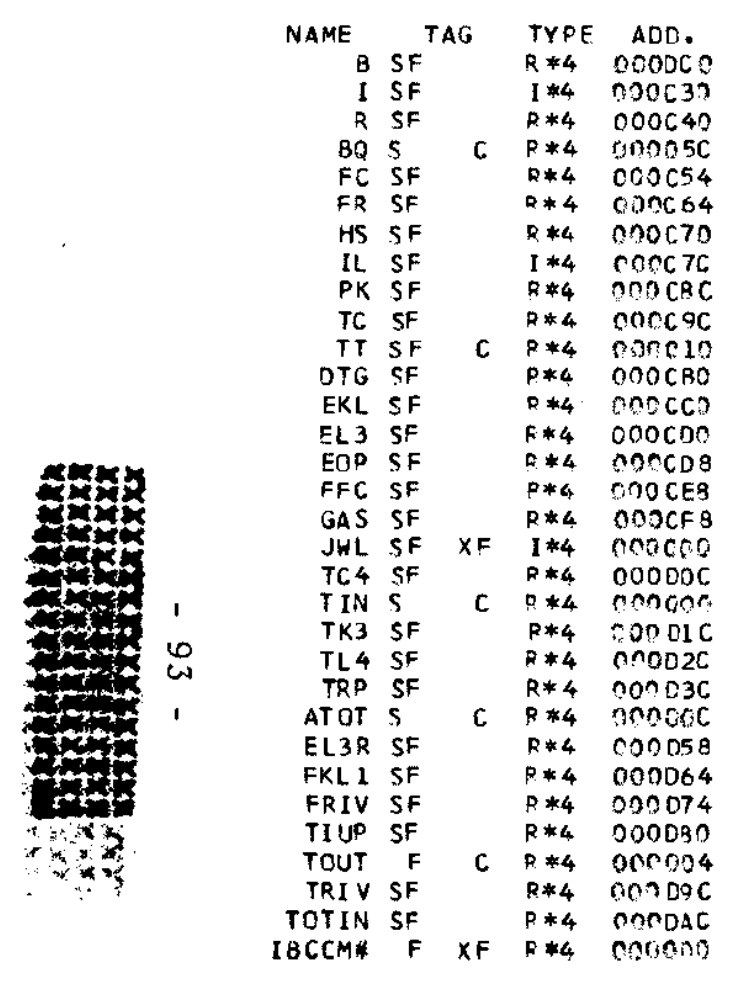

\begin{tabular}{|c|c|c|c|}
\hline NAME & $T A G$ & TYPF & ADD. \\
\hline D & SF & $R * 4$ & $000<28$ \\
\hline J & $S F$ & I*4 & $\operatorname{arcc} 34$ \\
\hline u & SF & $8 * 4$ & $010 C 44$ \\
\hline 85 & SF & $F * 4$ & OOCOE 4 \\
\hline $\begin{array}{l}\text { FK } \\
\text { GA }\end{array}$ & $\begin{array}{l}\text { SF } \\
\text { SF }\end{array}$ & $\begin{array}{l}R * 4 \\
R * 4\end{array}$ & $\begin{array}{l}\text { oonc } 58 \\
\text { nod } 68\end{array}$ \\
\hline HT & SF & $R * 4$ & DOrEZC \\
\hline IP & $\mathrm{SF}$ & $I * 4$ & 00080 \\
\hline PI. & SF & $R * 4$ & nroc on \\
\hline TO & SF & $R * 4$ & DO: CAD \\
\hline$T \times$ & $S F$ & $R * 4$ & DOCCAB \\
\hline EC2 & $S F$ & $R * 4$ & OCOCB \\
\hline EK 2 & $S F$ & $0 \neq 4$ & $\operatorname{arnce} 4$ \\
\hline EL4 & $S F$ & $P * 4$ & $D \cap 0 C 04$ \\
\hline $\begin{array}{l}\text { EP } 2 \\
\text { FFF }\end{array}$ & $\begin{array}{l}S F \\
S F\end{array}$ & $\begin{array}{l}R * 4 \\
P * 4\end{array}$ & $\begin{array}{l}\text { DNOCDC } \\
\text { DOCEC }\end{array}$ \\
\hline GB S & $\mathrm{SF}$ & $R * 4$ & DOOCFC \\
\hline TCl 1 & SF & $F * 4$ & ONCDCO \\
\hline TEP & $S F$ & $R * 4$ & DOEEC \\
\hline TKL & $\mathrm{SF}$ & $P * 4$ & nendo \\
\hline TL 1 & SF & $F * 4$ & 020020 \\
\hline TOP & $\mathrm{SF}$ & $P * 4$ & 0 0003 \\
\hline TR 1 & SF & $R * 4$ & 303040 \\
\hline DEL 1 & $S F$ & $R * 4$ & החов4C \\
\hline EPAR & $S F$ & $R * 4$ & $30005 C$ \\
\hline FKL2 & SF & $P * 4$ & $n \subset 3068$ \\
\hline FRUN & SF & $p * 4$ & 000078 \\
\hline TKLI & $S F$ & $R * 4$ & 000084 \\
\hline TPAR & $S F$ & $R * 4$ & ONODOS \\
\hline FOVER & $S F$ & $R * 4$ & COODAO \\
\hline TPAR 1 & SF & $P * 4$ & 200089 \\
\hline TOTOUT & SF & $R * 4$ & DnNDBC \\
\hline
\end{tabular}

\begin{tabular}{|c|c|c|c|c|}
\hline NAMF & & & TYPE & $A D D$. \\
\hline$F$ & $S$ & $c$ & $\begin{array}{l}P * 4 \\
1 * 4\end{array}$ & $\begin{array}{l}003038 \\
00003\end{array}$ \\
\hline L & SF & & $1 * 4$ & 000638 \\
\hline w & SF & & $2 * 4$ & $000 \mathrm{c} 48$ \\
\hline EC & $\$ F$ & & R*4 & 307053 \\
\hline $\mathrm{FL}$ & SF & & $2 * 4$ & $000 c 50$ \\
\hline$G B$ & $S F$ & c & $R * 4$ & $00004 C$ \\
\hline IC & SF & & $1 * 4$ & 202074 \\
\hline IR & $S F$ & & I *4 & $000 c 84$ \\
\hline PP & SF & & $R * 4$ & $000 C 94$ \\
\hline TE & $S F$ & & $P * 4$ & ONCE54 \\
\hline$T 1$ & SF & & $P * 4$ & SOSCAC \\
\hline$E \subset 3$ & SF & & $R * 4$ & DONCB 8 \\
\hline$E \times 3$ & SF & & $P * 4$ & $30 \cap \mathrm{CC} 8$ \\
\hline EYQ & $s$ & : & $R * 4$ & 020038 \\
\hline ER2 & SF & & $P * 4$ & BOSCE? \\
\hline FFR & SF & & $R * 4$ & DOOCFC \\
\hline HTS & $S F$ & & $R * 4$ & $300 \mathrm{EC} 4$ \\
\hline TC2 & SF & & $P * 4$ & 200004 \\
\hline IE2 & S & $=$ & $2 * 4$ & 500080 \\
\hline TKİ & $S F$ & & $P * 4$ & $3 n n 014$ \\
\hline TL2 & SF & & $9 * 4$ & 000024 \\
\hline TPl & $S F$ & & $R * 4$ & 300034 \\
\hline TR2 & $S F$ & & $8 * 4$ & 030044 \\
\hline DEL2 & SFA & & $P * 4$ & 300051 \\
\hline ESUM & $F$ & $=$ & $2 * 4$ & 000044 \\
\hline FL $3 R$ & SF & & $D * 4$ & $90006 \mathrm{C}$ \\
\hline PAIR & SF & & F.*4 4 & $90007 C$ \\
\hline TKL2 & SF & & $8 * 4$ & 000088 \\
\hline$T P I N$ & $\$ F$ & & $F * 4$ & 300094 \\
\hline FRAIV & SF & & $2 * 4$ & 000044 \\
\hline TPAR 2 & $S F$ & & $R * 4$ & 009084 \\
\hline
\end{tabular}

\begin{tabular}{|c|c|c|c|c|}
\hline NAME & & & TYPE & $\triangle D D$. \\
\hline$H$ & SF & & $R * 4$ & $300: 22$ \\
\hline 4 & $s$ & & $1 * 4$ & : \\
\hline 2 & $S F$ & & $0 * 4$ & 323040 \\
\hline EM & $S F$ & & $2 * 4$ & $030 E 08$ \\
\hline$F P$ & SF & & $D \$ 4$ & $j J)(s)$ \\
\hline to & $S F$ & & $2 * 4$ & $000: 6=$ \\
\hline $1 k$ & $S F$ & & {$[* 4$} & 32073 \\
\hline $\begin{array}{l}P C \\
P R\end{array}$ & $\begin{array}{l}S F \\
S F\end{array}$ & & $\begin{array}{l}R * 4 \\
R * 4\end{array}$ & $\begin{array}{l}330=88 \\
33638\end{array}$ \\
\hline TI & SF & & $R * 4$ & $000 C A_{4}$ \\
\hline$\checkmark D$ & SF & & $2 * 4$ & OJगE78 \\
\hline EC4 & SF & & $R * 4$ & $333 \mathrm{CBC}$ \\
\hline EL2 & SF & & $R * \ell$ & $3) C=0$ \\
\hline EMS & SF & & $R * 4$ & JUEA \\
\hline FFA & SF & & $R * 4$ & $300=4$ \\
\hline FUP & SF & & $R * 4$ & $\supset \supset C F 4$ \\
\hline I J & & $\tau$ & $1 * 4$ & 030348 \\
\hline r c3 & SF & & $2 * 4$ & 3כסכככ \\
\hline TES & SF & & $p * 4$ & נו \\
\hline$T<2$ & SF & & $R * 4$ & 300318 \\
\hline$T L 3$ & SF & & $R * 4$ & 22023 \\
\hline$T P 2$ & SF & & $2 * 4$ & 030338 \\
\hline TW3 & SF & & $R * 4$ & 000048 \\
\hline EKL 3 & SF & & $R * 4$ & 000054 \\
\hline FDAM & SF & & $R * 4$ & נטכנננ \\
\hline FPA? & $S F$ & & $2 * 4$ & 200070 \\
\hline TAIP & $S F$ & c & $P \neq 4$ & נדנכנכנ \\
\hline TKL 3 & SF & & $R * 4$ & 303036 \\
\hline TR IN & SF & & $2 * 4$ & 000398 \\
\hline FSEEP & SF & & $P * 4$ & $\supset$ DAB \\
\hline$C<T P A\rangle$ & SF & & $2 * 4$ & 020238 \\
\hline
\end{tabular}

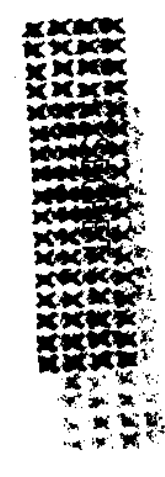

NAME OF COMMON BLOCK *

***** COMMON INFCRMATION

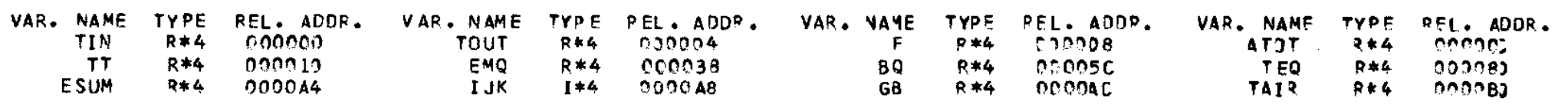




$\begin{array}{rc}\text { LABEL } & \text { ADDR } \\ 7 & 0011 C 6 \\ 220 & 001 C E A \\ 300 & 002068 \\ 400 & 002484 \\ 410 & 00261 C \\ 455 & 0029 F 4 \\ 520 & 0020 F 8 \\ 810 & \text { O02EEE }\end{array}$
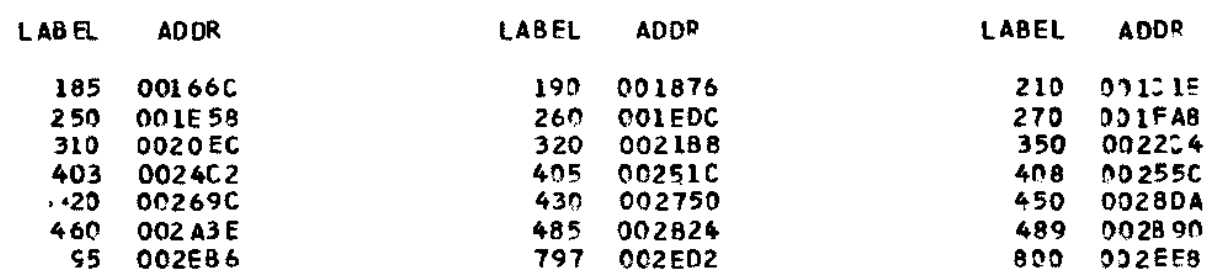

\#OPTIONS IN EFFECT*

NAME $=$ MAIN,OP T $=00$, LINECNT $=58$

*OPTIONS IN EFFECT* SOURCE, EBCDIC, NOL IST, NODECK, LOAD, MAP, NOEDIT, ID, NO XREF

* Statistics* SOURCE statements $=402$, PROgram SIzE = 12060

*Statistics* no diagnostics generiated

****** END OF COMPILATION ******

\section{LEVEL 181 SEPT 69 ।}

QS/360 FOPIYAN H

DATE $11.25 n / n 8.18 .27$
I SN 0002
ISN 0003
ISN 0004
ISN 0005
ISN 0006
ISN 0007
ISN 0008
ISN 0009
ISN 0010
ISN 0011
ISN 0012
ISN 0014
I SN 0016
ISN 0017
ISN CO18
ISN COIS
ISN 0021
(SN 0023
ISN 0025

COMPILER OPTIONS - NAME= MAIN, OPT=DO,LINECNT=58, SOURCE, EBCDIC, NOLIST, NODECK, LDAD, MAP, NDEDIT, ID, NOXREF SUBROUT INE JWL

DIMEN SION TT( 10$),$ EMO(9), BO(9), TEO(9)

COMMON TIN,T UT, F, ATOT,TT,EMQ, BQ, TEQ, ESUM, IJK,GB, TAIR

HFG $=581$.

$T=T I N$

$I J K=0$

$I=1$

SUM $=0$.

ESUM $=0$.

EHCLD $=0$.

1020 TDIF $=$ TTIII $-T$

IFITDIF.LT.0.1 G0 TO 1050

$\mathrm{I}=\mathrm{I}+1$

$1050 \quad j=1-1$

If (J.LE. O) Q OC TO 1099

If (ITT(I)-TEO(J),.LE.O.) GO TO 1080

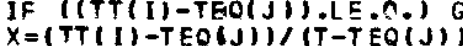

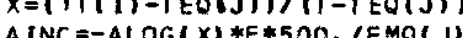

EINC= (IEMQ $(J) * T E Q(J)+B Q(J)+G B *(T A I P-T E Q(J))) * A I N C+500_{0} * F *(E M Q(J)-G$

$1 B) *(T-T E Q(J)\} *(1,-X) / E M Q(J)) / 500 . / H F G$ 


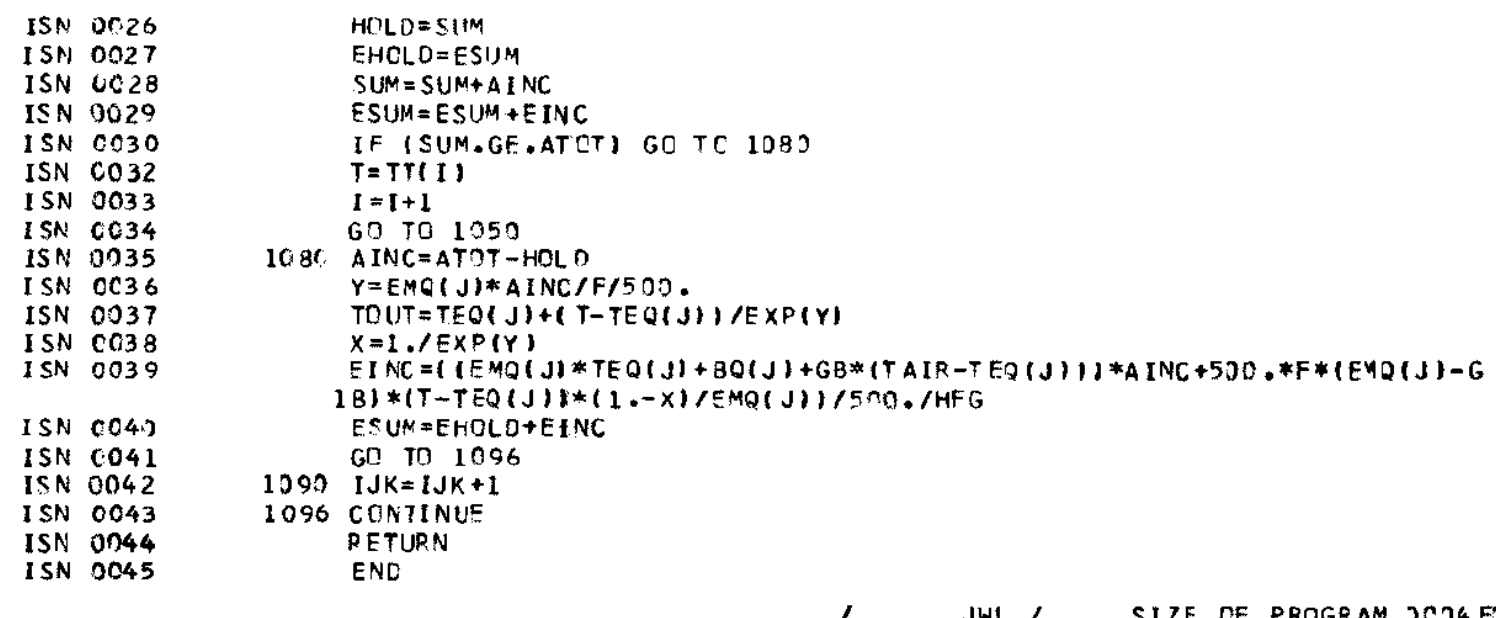

1 JWL, CIZE DF PROGRAM 3 M 4 F 2 HEXADECIMAL. BYTES PAGE 002

\begin{tabular}{rcccc} 
NAME & \multicolumn{2}{c}{ TAG } & TYPE & ADOD \\
F F & $C$ & $R * 4$ & 000008 \\
$X$ & SFA & & $R * 4$ & $0000 A 0$ \\
TT & $F$ & $C$ & $R * 4$ & 000010 \\
JWL & & & $1 * 4$ & $0000 A C$ \\
AINC SF & & $P * 4$ & 000084 \\
HOLD SF & & $R * 4$ & $0000 B C$ \\
EHCLD SF & & $R * 4$ & $0000 C 4$
\end{tabular}

$\begin{array}{rcrlr}\text { NAME } & \text { TAG } & \text { TYPE } & \text { ADD. } \\ \text { I } & \text { SF } & & 1 * 4 & 000094 \\ Y Y S F A & & R * 4 & 0000 A 4 \\ \text { EMQ } & F & C & P * 4 & 000038 \\ \text { SUM } & S F & & R * 4 & 0000 B 0 \\ \text { ATOT } & F & C & P * 4 & 00000 C \\ \text { TAIR } & F & C & R * 4 & 000080 \\ \text { EXP } & & X F & R * 4 & 000000\end{array}$

\begin{tabular}{|c|c|c|c|c|}
\hline$M E$ & \multicolumn{2}{|c|}{$T A G$} & TYDE & $A D D$. \\
\hline & SF & & $1 * 4$ & 203099 \\
\hline$B 2$ & $F$ & こ & $2 * 4$ & 000050 \\
\hline $\begin{array}{l}\text { HFG } \\
\text { TEQ }\end{array}$ & $\begin{array}{l}S F \\
F\end{array}$ & C & $\begin{array}{l}R * 4 \\
R * 4\end{array}$ & $\begin{array}{l}203048 \\
000080\end{array}$ \\
\hline $\begin{array}{l}\text { EINC } \\
\text { TOIF }\end{array}$ & $\begin{array}{l}S F \\
S\end{array}$ & & $\begin{array}{l}R * 4 \\
R * 4\end{array}$ & $\begin{array}{l}000088 \\
3000 \mathrm{C}\end{array}$ \\
\hline$A L J G$ & & $X F$ & $R * 4$ & noonno \\
\hline
\end{tabular}

\begin{tabular}{|c|c|c|c|c|}
\hline & \multicolumn{2}{|c|}{ TAG } & $Y P F$ & מסם \\
\hline & $F$ & & $R * 4$ & 30009: \\
\hline GB & 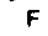 & C & $R * 4$ & ic \\
\hline $\begin{array}{l}\text { IJ } \\
\text { TIN }\end{array}$ & SF & & $\begin{array}{l}I * 4 \\
R * 4\end{array}$ & מקנ30048 \\
\hline $\begin{array}{l}\text { ESUY } \\
\text { roJT }\end{array}$ & SF & $c$ & $\begin{array}{l}R * 4 \\
R * 4\end{array}$ & $\begin{array}{l}000004 \\
030004\end{array}$ \\
\hline
\end{tabular}

***** COMMON INFORMATION

******

NAME OF COMMON BLOCK

* Size dF BLOCK OOORB 4 Hexanecimal bYtes

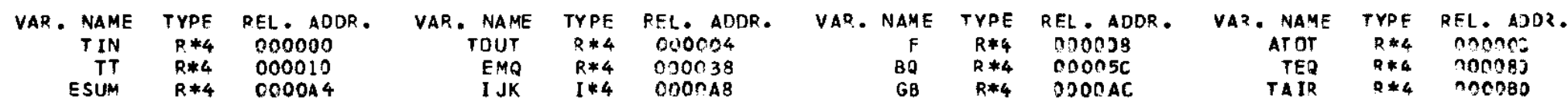




\begin{tabular}{|c|c|c|c|c|c|c|c|c|}
\hline LABEL. & ADDR & LABEL & $A D D R$ & $\angle A B C L$ & $A D D R$ & LABEL & $A D O R$ & PAGE $\cap \cap_{3}$ \\
\hline $\begin{array}{l}1020 \\
1096\end{array}$ & $\begin{array}{l}00014 C \\
0004 C A\end{array}$ & 1050 & $00017 \mathrm{C}$ & $108 n$ & ono3 358 & 1090 & $0004 \mathrm{BA}$ & \\
\hline
\end{tabular}

*OPTIONS IN EFFECT* NAME $*$ MAIN,DPT $=00, L$ INECNT $=58$

*OPTIONS IN EFFECT* SOURCE, EBCOIC, NCLIST, NODECK, LOAD, MAP, NOEDIT, ID, NOXREF

*STATISTICS* SOURCE STATEMENTS $=\quad 44$, PROGRAM SIZE $=1264$

* Statistics* no diagnost ics generated

****** END OF COMPILATION ******

* statistics* no diagnostics this step

OS/360 LOADER

OPTICNS USED - PRINT, MAP, LET, CALL, RES, SIZE $=184320, E P=$ MAIN

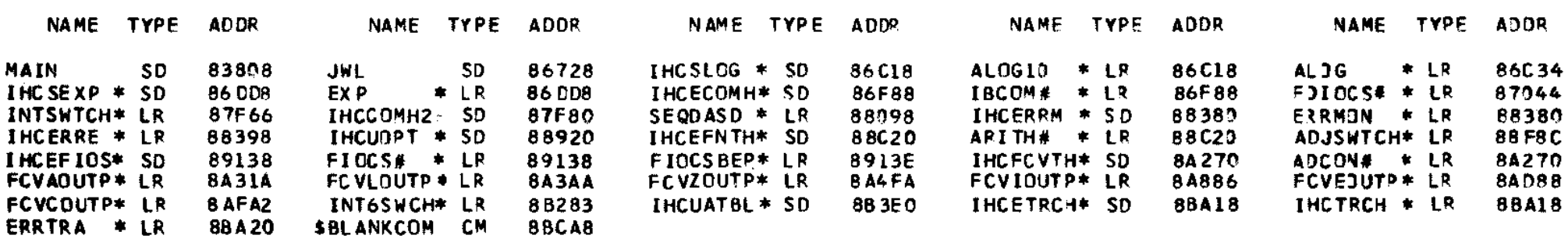

TCTAL LENGTH 8554

ENTRY ADDRESS 83808 
INPUT

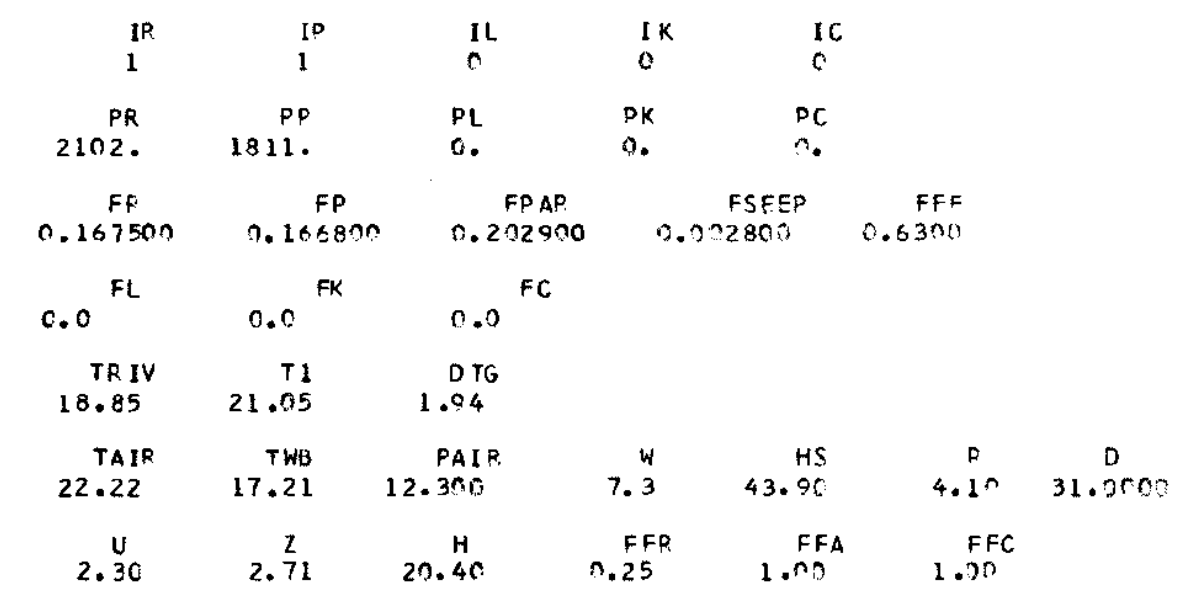

DUT PUT

LANGHAARS COOLING RATE CURVE FOR OPEN CONDIT IONS -

\begin{tabular}{|c|c|c|c|c|c|c|c|c|c|c|}
\hline DEGREES C & 95.00 & $85 . r 0$ & 75.00 & 65.00 & 55.00 & $45 . n 3$ & 35.3 & 25.30 & 15.00 & $5 . n n$ \\
\hline HT & 1947.61 & 1356.02 & 921.79 & 608.64 & 385.90 & 228.97 & 118.44 & 39.74 & -17.94 & -52.31 \\
\hline EM & & 59.1586 & 43.4235 & 31.3148 & 22.2743 & 15.6926 & 11,0525 & 7.8700 & 5.7689 & $4.437^{\circ}$ \\
\hline B & & -3672.46 & -2334.98 & -1426.83 & -839.19 & -477.20 & -268.39 & -157.21 & -134.48 & -84.50 \\
\hline TE & & 62.8202 & 54.7831 & 46.9658 & 39.6462 & 33.2066 & 28.2555 & 25.5281 & 25.7204 & 28.9383 \\
\hline \multicolumn{11}{|c|}{ LANGHAARS COOL ING RATE CUPVE FOR SNAMP CONDITIONS" } \\
\hline DEGPEES C & 95.00 & 85.00 & 75.00 & 65.00 & 55.00 & 45.00 & 35.00 & 25.00 & 15.03 & 5.37 \\
\hline HTS & 1144.21 & 799.72 & 546.19 & 362.64 & 231.36 & 138.12 & 71.70 & 23.68 & -12.20 & $-4 \cap .38$ \\
\hline EMS & & 34.4489 & 25.3535 & 18.3542 & 13.128 .5 & 9.3241 & 6.6419 & 4.8023 & 3.5878 & 2.8179 \\
\hline BS & & -2128.43 & -1355.32 & -830.38 & -499.71 & -281.46 & -160.77 & -96.38 & -66.02 & -54.47 \\
\hline TES & & 61.7852 & 53.4571 & 45.2419 & 37.3772 & 30.1868 & 24.2048 & 20.0696 & 18.4306 & 19.3296 \\
\hline
\end{tabular}


P EFFLUENT CANAL TEMPEFATURES'

$T P I N=22.34 \quad T P 1=63.53 \quad T P 2=35.16$

THE EVAPORATICN IN F EFFLUENT CANAL, EPZ = 0.037147

R EFFLUENT CANAL TEMPERATURES'

TRIN $=20.89 \quad T R I=68.50 \quad T R 2=40.54$

THE EVAPOZATION IN R FFFLUENT CAMIAL, ER2 = 0.007299

PAR PONE TEMPERATURES,

$T X=38.1745 \quad T I=37.7780 \quad T I U P=29.6114 \quad T O P=25.6264 \quad T P A Q=23.3989 \quad T D=25.7477$

PERT INENT FLOWS ARE FPAIN $=2.005307$ AND FUP $=1.129776$
THE RATE OF CHANGE IN HEAT CCNTENT OF POND, HC $=8.0377$

THE EQUILIBRIUM TEMPEPATUPES DVEF SFGMENTS DF LANGHAARS COOLING FATE CURVE ARE AS FOLLOWS FOR PAR PJVD.
DEGREES C
$95.7 \%$
85.ns 75.0 ?
65. ก)
55.00
$45.0 n$
35.70
25.20
$15.3 ?$

TEP

$62.6844 \quad 54.5980 \quad 46.7291$

39.2853

32.6944

27.5282

24.5068

24.3271

THE EVAPORATION FROM PAR POND, ERD = 0.016264

the watep balance for par pCNO IS as Foll.JWS.

WATER IN

MAKEUP FRTM RIVER, FZIV $=0.131400$

RUNOFF FROM RAINFALL, FDUN $=0.014382$

SUBTOTAL

0.145781

WATER OUT

$\begin{array}{cc}\text { EVAPORATION, FPAR }= & 0.03 n 7 n 9 \\ \text { SEEPAGE LOSS, FSEEP }= & 0.002800 \\ \text { OVERFLOW AT CAM, FLAM }= & 0.112272 \\ \text { SUB TOTAL } & 0.145781\end{array}$

THE CVERFLOW FROM PAR CAN REACHES THE RIVER VIA LOWER THREE RUNS AT TRP $=25.58$

THE EVAPORATION IN LOWER THREE RUNS BELOW PAR OAM, EL3R $=0.033589$ 


\section{LIMN Printout 2}

INPUT

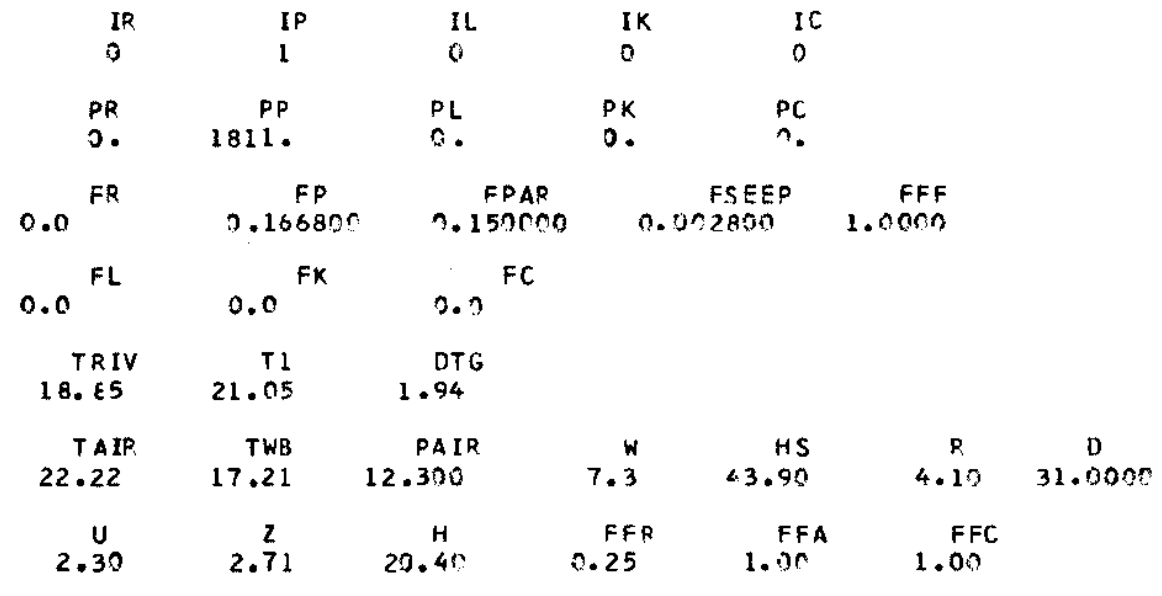

\section{DUTPUT}

LANGHAARS COCLING RATE CURVE FRR OPEN CONDITIONS'

$\begin{array}{lrrrrrrrrrrr}\text { DEGREES C } & 95.00 & 85.0 n & 75.00 & 65.00 & 55.00 & 45.09 & 35.20 & 25.00 & 15.07 & 5.1 n \\ \text { HT } & 1947.61 & 1356.02 & 921.79 & 608.64 & 385.90 & 228.97 & 118.44 & 39.74 & -17.94 & -62.31 \\ \text { EM } & & 59.1586 & 43.4235 & 31.3148 & 22.2743 & 15.6925 & 11.0525 & 7.8700 & 5.7587 & 4.4370 \\ \text { B } & & -3672.46 & -2334.98 & -1426.83 & -839.19 & -477.20 & -268.39 & -157.01 & -104.48 & -84.50 \\ \text { TE } & & 62.8202 & 54.7831 & 46.9658 & 39.6462 & 33.2085 & 28.2555 & 25.5281 & 25.7204 & 28.9383\end{array}$

LANGHAARS CODL ING RATE CURVE FOR SHAMP CONDITIONS.

$\begin{array}{lrrrrrrrrrr}\text { DEGREES C } & 95.00 & 85.00 & 75.00 & 65.00 & 55.00 & 45.03 & 35.30 & 25.00 & 15.00 & 5.00 \\ \text { HTS } & 1144.21 & 799.72 & 546.1 \mathrm{~S} & 362.64 & 231.36 & 138.12 & 71.70 & 23.68 & -12.23 & -41.38 \\ \text { EMS } & & 34.4489 & 25.3535 & 18.3542 & 13.1285 & 9.3241 & 6.6419 & 4.8023 & 3.5878 & 2.8179 \\ \text { BS } & & -2128.43 & -1355.32 & -830.38 & -490.71 & -281.45 & -160.77 & -96.38 & -66.02 & -54.47\end{array}$


P EFFLUENT CAMAL TEMPERATURES
$T P I N=22.32$
$T P 1=63.51$
$T P_{2}=36.16$

THE EVAPORATICN IN P EFFLUENT CANAL, EP2 $=0.007143$

PAR PONC TEMPERATUR ES '
$T X=36.1591$
$T_{I}=35.5748$
TIUP $=28.3989$
$T O P=24.7670$
TPAR $=22.7075$
$T D=24.3559$

PERTINENT FLOWS AFE FRAIN $=0.005307 \quad$ AND FUP $=0.577027$

THE RATE OF CHANGE IN HEAT CONTENT OF POND, HC $=5.6719$

THE EQUILIBRIUM TEMPERATURES CVER SEGMENTS OF LANGHAARS CODLING RATE CURVE ARE AS FOLLOWS FTP PA? DJVD.

$\begin{array}{lrrrrrrrrrr}\text { QEGREES C } & 95.00 & 85.00 & 75.0 n & 65.00 & 55.00 & 45.00 & 35.29 & 25.03 & 15.21 & 5.19 \\ \text { TEP } & & 62.7243 & 54.6525 & 46.7847 & 39.3915 & 32.8452 & 27.7423 & 24.8074 & 24.7372 & 27.660 n\end{array}$

THE EVAPORATION FROM PAR PONO, EOP $=0.111929$

THE WATER BALANCE FCR PAR PONC IS AS FOLLOWS,

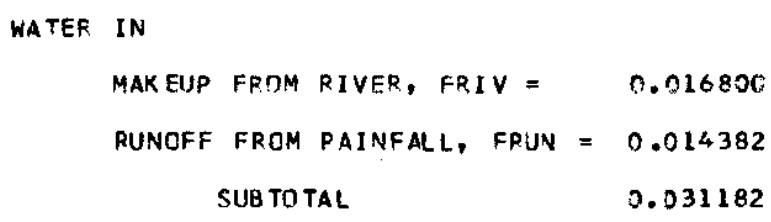

$\begin{array}{cl}\text { EVAPORATION, EPAR }= & 0.019073 \\ \text { SEEPAGE LOSS, FSEEP = } & 0.002800 \\ \text { OVERFLOW AT LAM, FCAM = } & 0.009309 \\ \text { SUB TOTAL } & 0.031182\end{array}$

THE OVERFLOW FROM PAP CAM REACHES THE RIVER VIA LJWER THPEE RUNS AT TRP $=25.71$

THE EVAPORATION IN LOWER THREE RUNS BELOW PAR DAM, EL3R $=0.033564$ 
LIMN Printout 3

I NPUT

\begin{tabular}{|c|c|c|c|c|c|c|}
\hline $\begin{array}{l}\text { IR } \\
0\end{array}$ & ${ }_{0}^{\text {IP }}$ & $\begin{array}{l}\text { IL } \\
\text { I }\end{array}$ & $\begin{array}{l}\text { Ik } \\
1\end{array}$ & $\begin{array}{l}\text { IC } \\
1\end{array}$ & & \\
\hline $\begin{array}{l}P R \\
0 .\end{array}$ & $\begin{array}{l}\text { PP } \\
0 .\end{array}$ & $\begin{array}{r}P L \\
2062 .\end{array}$ & $\begin{array}{r}\text { PK } \\
494 .\end{array}$ & $\begin{array}{r}P C \\
2256 .\end{array}$ & & \\
\hline $0.0^{F R}$ & $0.0^{F P}$ & 0.0 & 0.0 & FSEEP & $0.0^{F F F}$ & \\
\hline $\begin{array}{c}F L \\
0.173000\end{array}$ & $\begin{array}{c}\text { FK } \\
0.185000\end{array}$ & 0.1 & & & & \\
\hline $\begin{array}{l}\text { TR IV } \\
24.20\end{array}$ & $0.0^{T 1}$ & $0.0^{0 T G}$ & & & & \\
\hline $\begin{array}{c}\text { TAIR } \\
27.30\end{array}$ & $\begin{array}{r}\text { TWB } \\
24.30\end{array}$ & $\begin{array}{l}\text { PAI }{ }^{R} \\
21.2 n 0\end{array}$ & $\begin{array}{r}W \\
6.0\end{array}$ & $\begin{array}{r}\text { HS } \\
39.00\end{array}$ & $\begin{array}{r}\mathrm{P} \\
\mathrm{C} \cdot \mathrm{O}\end{array}$ & 1. nooe \\
\hline $\begin{array}{r}U \\
0.0\end{array}$ & $\begin{array}{r}2 \\
0.0\end{array}$ & $\begin{array}{r}H \\
0.0\end{array}$ & $0.0^{F F R}$ & $0.0^{F F A}$ & $0.0^{F F C}$ & \\
\hline
\end{tabular}

OUT PUT

LANGHAaRS COOLING RATE CURVE FDR OPEN CCNDITIONS'

$\begin{array}{lrrrrrrrrrr}\text { DEGREES C } & 95.00 & 85.00 & 75.00 & 65.00 & 55.00 & 45.00 & 35.33 & 25.00 & 15.00 & 5.00 \\ \text { HT } & 1768.52 & 1220.94 & 818.89 & 528.82 & 322.36 & 176.78 & 74.11 & 0.87 & -52.93 & -94.42 \\ \text { EM } & & 54.7582 & 40.2055 & 29.0067 & 20.6456 & 14.5585 & 10.2671 & 7.3237 & 5.3804 & 4.1487 \\ \text { B } & & -3433.50 & -2196.53 & -1356.62 & -813.14 & -478.36 & -285.24 & -182.22 & -133.54 & -115.16 \\ \text { TE } & 63.4152 & 55.6025 & 48.1136 & 41.2749 & 35.5363 & 31.5806 & 30.2064 & 32.0867 & 37.1598\end{array}$

LANGHAARS COOL ING RATE CURVE FOR SWAMP CONDITIONS' 


$\begin{array}{llrrrrrrrrrr} & \text { DEGREES C } & 95.00 & 85.00 & 75.00 & 65.00 & 55.00 & 45.00 & 35.00 & 25.00 & 15.00 & 5.09 \\ & \text { HTS } & 1120.56 & 776.07 & 522.54 & 338.99 & 207.71 & 114.47 & 48.95 & 0.03 & -35.85 & -64.03 \\ & \text { EMS } & & 34.4489 & 25.3535 & 18.3542 & 13.1285 & 9.3241 & 6.6419 & 4.8023 & 3.5878 & 2.8179 \\ & \text { BS } & & -2152.09 & -1378.98 & -854.03 & -514.36 & -305.11 & -184.42 & -120.03 & -89.67 & -78.12 \\ & \text { TES } & & 62.4718 & 54.3900 & 46.5304 & 39.1787 & 32.7233 & 27.7657 & 24.9945 & 24.7927 & 27.7226\end{array}$

THE C EFFLUENT CW TEMPERATURES ARE AS FOLLOWS'

$T C_{1}=71.49 \quad T C 2=44.03 \quad T C 3=31.06 \quad T C 4=35.93$

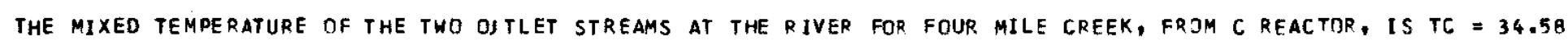
THE EVAPORATION IN FOUR MILE CREEK, FROM C REACTOR, IS EC $=0.009505$

THE K EFFLUENT CW TEMPERATURES ARE AS FOLLOWS.

$T K 1=54.84 \quad T K 2=48.50 \quad T K 3=29.40$

THE L EFFLUENT CW TEMPERATURES APE AS FOLLIJWS
$T L L=69.42$
$T L 2=52.86$
$T L 3=33.56$
$T L 4=38.27$

THE temperatures in STEEL CREek NEAP the River are as follows.

$T K L 1=31.56 \quad T K L 2=34.43 \quad T K L 3=33.89 \quad T K L=32.40$

THE TEMPERATURE OF STEEL CREEK OUTLET AT THE RIVER, FROM K AND L REACTORS, IS TKL $=32.40$

THE EVAPORATION IN PEN BRANCH ANO STEEL CPEEKS, FROM K AND L REACTORS, IS EKL $=0.013187$ 


\section{LIMN Printout 4}

\begin{tabular}{|c|c|c|c|c|c|c|}
\hline 0 & ${ }_{0}^{I P}$ & ${ }_{1}^{11}$ & ${ }_{1}^{I k}$ & ${ }_{1}^{\text {IC }}$ & & \\
\hline $\begin{array}{l}\text { PR } \\
D .\end{array}$ & PP & $\begin{array}{r}\mathrm{PL} \\
2100^{-}\end{array}$ & $\begin{array}{r}P K \\
2100^{\circ}\end{array}$ & $\begin{array}{r}P C \\
2250\end{array}$ & & \\
\hline $0.0^{F R}$ & $0.0^{F P}$ & $0 . n^{F}$ & 0.0 & FSEEP & $0.0^{\mathrm{FFF}}$ & \\
\hline $\begin{array}{c}F L \\
0.180000\end{array}$ & $\begin{array}{c}F K \\
0.180008\end{array}$ & 0.18 & & & & \\
\hline $\begin{array}{c}\text { TRIV } \\
27.80\end{array}$ & $0.0^{T 1}$ & $0.0^{\text {DTG }}$ & & & & \\
\hline $\begin{array}{c}\text { TA IR } \\
30.90\end{array}$ & $\begin{array}{r}\text { TWB } \\
25.60\end{array}$ & $\begin{array}{l}\text { PAIP } \\
21.780\end{array}$ & $\begin{array}{r}W \\
3.8\end{array}$ & $\begin{array}{r}H S \\
60.00\end{array}$ & $\begin{array}{r}R \\
0.0\end{array}$ & 1. Donon \\
\hline 0.0 & $0.0^{2}$ & 0.0 & $\because . n^{F F P}$ & $c . r^{F F A}$ & $0.5^{F F C}$ & \\
\hline
\end{tabular}

OUTPUT

LANGHAARS COOLING RATE CURVE FOR OPEN CONDITIONS"

$\begin{array}{lrrrrrrrrrr}\text { DEGREES C } & 95.00 & 85.30 & 75.00 & 65.00 & 55.00 & 45.00 & 35.00 & 25.00 & 15.39 & 5.00 \\ \text { HT } & 1521.51 & 1049.40 & 700.80 & 449.79 & 270.90 & 144.50 & 55.13 & -8.87 & -56.10 & -92.70 \\ \text { EM } & & 47.3114 & 34.7598 & 25.1008 & 17.8893 & 12.6392 & 8.9379 & 6.3992 & 4.7231 & 3.6607 \\ \text { B } & & -2973.08 & -1776.18 & -1181.77 & -713.01 & -424.26 & -257.70 & -168.84 & -126.94 & -111.91 \\ \text { TE } & & 64.1087 & 56.5649 & 49.4711 & 43.2110 & 38.3141 & 35.5453 & 35.7616 & 39.5805 & 46.7140\end{array}$


LANGHAARS COOL ING RATE CURVE FOR SWAMP CONDITIONS.

$\begin{array}{lrrrrrrrrrr}\text { OEGREES C } & 95.00 & 85.00 & 75.00 & 65.00 & 55.00 & 45.00 & 35.00 & 25.00 & 15.00 & 5.00 \\ \text { HTS } & 1113.13 & 768.65 & 515.11 & 331.57 & 260.28 & 107.04 & 40.62 & -7.40 & -43.23 & -71.46 \\ \text { EMS } & & 34.4489 & 25.3535 & 18.3542 & 13.1285 & 9.3241 & 6.6419 & 4.8023 & 3.5878 & 2.8179 \\ \text { BS } & -2159.51 & -1386.40 & -861.46 & -521.78 & -312.54 & -191.34 & -127.46 & -97.09 & -85.55 \\ \text { TES } & & 62.6873 & 54.6828 & 46.9351 & 39.7443 & 33.5197 & 28.8837 & 26.5407 & 27.2623 & 32.3577\end{array}$

THE C EFFLUENT CW TEMPERATLRES ARE AS FOLLOWS'

$T C_{1}=75.22 \quad T C 2=48.30 \quad T C 3=29.77 \quad T C 4=38.53$

THE MIXED TEMPERATURE OF THE TWO OUTLET STREAMS AT THE RIVER FOR FOUR MILE CREEK, FROYM C REACTJR, IS TE = 36.1I

THE EVAPORATION IN FOUR MILE CREEK, FROM C REACTOR, IS EC $=0.010464$

THE K EFFLUENT CW TEMPERATURES ARE AS FOLLOWS,

$T K 1=72.06 \quad T K 2=60.42 \quad T K 3=29.12$

THE L EFFLUENT CW TEMPERATURES ARE AS FOLLOWS.

$T L 1=72.06 \quad T L 2=56.91 \quad T L 3=35.62 \quad T L 4=40.72$

THE TEMPERATURES IN STEEL CREEK NEAR THE RIVER ARE AS FOLLCWS.

TKL1 $=32.59 \quad$ TKL2 $=36.13 \quad$ TKL3 $=35.58 \quad$ TKL $=33.50$

THE TEMPERATURE OF STEEL CREEK OUTLET AT THE RIVER, FROM K AND L REACTORS, IS TKL $=33.53$

THE EVAPORATION IN PEN ERANCH ANO STEEL CREEKS, FRJM K AND L REACTORS, IS EKL $=0.017415$ 


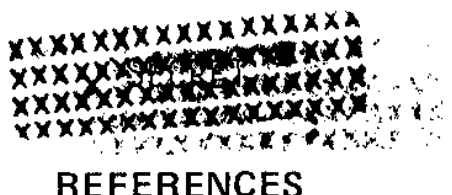

1. J. W. Langhaar. "Cooling Pond May Answer Your Water Cooling Problem." Chem. Eng. 60(8), 194 (1953).

2. C. F. Becker and J. S. Boyd. "Solar Radiation Availability on Surfaces in the United States as Affected by Season, Orientation, Latitude, Altitude, and Cloudiness." J. Solar Energy, Science Eng. 1(1), 13 (1957).

3. Water-Loss Investigations: Lake Hefner Studies, Technica? Report. U. S. Geological Survey Professional Paper 269, U. S. Government Printing Office, Washington, D. C. (1954).

4. R. R. Hood, Cooling Ponds. USAEC Report DP-233, E. I. du Pont de Nemours \& Co., Savannah River Laboratory, Aiken, S. C. (1957) (Confidential).

5. R. R. Hood. Large Cooling Ponds. USAEC Report DP-940, E. I. du Pont de Nemours \& Co., Savannah River Laboratory, Aiken, S. C. (1965)(Secret).

6. G. E. Harbeck, Jr., G. E. Koberg, and G. H. Hughes. The Effect of the Addition of Heat from a Power Plant on the Thermal Structure and Evaporation of Lake Colorado City, Texas. U. S. Geological Survey Professional Paper 272-B, U. S. Government Printing Office, Washington, D. C. (1959).

7. The Temperature Effects Upon the Savannah River of the Effluent Discharge From the Savannah River Plant of the Atomic Energy Commission. Supplement F, U. S. Geological Survey, U. S. Department of the Interior, U. S. Government Printing Office, Washington, D. C. (1965).

8. The Effects of High Temperature on Catfish. Academy of Natural Sciences of Philadelphia, Department of Limnology, Philadelphia, Pa. (1955) .

9. J. H. Kennan and F. G. Keyes. Thermodynamic Properties of Steam. John Wiley \& Sons, Inc., New York (1936).

10. Local Climatological Data, Augusta, Ga., Bush Field. U. S. Department of Commerce, National Climatic Center, Asheville, N. C.

11. J. W. Croach. Gravity Flow of a Stratified Fluid to a sink. USAEC Report DP-1255, E. I. du Pont de Nemours \& Co., Savannah River Laboratory, Aiken, S. C. (1971).

12. C. H. Mortimer. "Water Movements in Lakes During Summer Stratification; Evidence from the Distribution of Temperature in Windermere." Phil. Trans. Roy. Soc. London B236, 355 (1952).

$\mathrm{TL} / \mathrm{jh}$ $-105-$

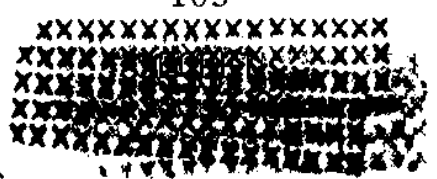

